MARIANA CALLIL VOOS

\title{
A INFLUÊNCIA DA IDADE E DA ESCOLARIDADE NA EXECUÇÃO E NO APRENDIZADO DE UMA TAREFA COGNITIVO-MOTORA
}

SÃO PAULO

2009 


\section{A INFLUÊNCIA DA IDADE E DA ESCOLARIDADE NA EXECUÇÃO E NO APRENDIZADO DE UMA TAREFA COGNITIVO-MOTORA}

Tese apresentada ao Instituto de Psicologia da Universidade de São Paulo para obtenção do título de Doutor em Neurociências e Comportamento Área de concentração: Neurociências e Comportamento Orientador: Prof. Dr. Luiz Eduardo Ribeiro do Valle

SÃO PAULO 
Biblioteca Dante Moreira Leite

Instituto de Psicologia da Universidade de São Paulo

Voos, Mariana Callil.

A influência da idade e da escolaridade na execução e no aprendizado de uma tarefa cognitivo-motora / Mariana Callil Voos; orientador Luiz Eduardo Ribeiro do Valle. -- São Paulo, 2009.

$131 \mathrm{p}$.

Tese (Doutorado - Programa de Pós-Graduação em Psicologia. Área de Concentração: Neurociências e Comportamento) - Instituto de Psicologia da Universidade de São Paulo.

1. Avaliação geriátrica 2. Avaliação neuropsicológica 3. Cognição 4. Envelhecimento 5. Locomoção 6. Percepção visual I. Título. 
Nome: VOOS, Mariana Callil

Título: A influência da idade e da escolaridade na execução e no aprendizado de uma tarefa cognitivo-motora

Tese apresentada ao Instituto de Psicologia da Universidade de São Paulo para obtenção do título de Doutor em Neurociências e Comportamento

Tese defendida e aprovada em:

Banca Examinadora

Prof. Dr. Instituição:

Julgamento: Assinatura:

Prof. Dr. Instituição:

Julgamento: Assinatura:

Prof. Dr. Instituição:

Julgamento: Assinatura:

Prof. Dr. Instituição:

Julgamento:

Assinatura:

Prof. Dr. Instituição:

Julgamento: Assinatura: 


\section{DEDICATÓRIA}

Dedico este trabalho ao meu amado marido, que me estimulou a espairecer nas horas vagas, o que foi fundamental para a preservação da minha função executiva para a realização deste trabalho. 


\section{AGRADECIMENTOS}

Ao Prof. Dr. Luiz Eduardo Ribeiro do Valle, que muito me ensinou e contribuiu para meu crescimento científico e intelectual.

Às Profas. Dras. Maria Elisa Pimentel Piemonte e Letícia Lessa Mansur, pelas valiosas sugestões e críticas realizadas no exame de qualificação.

Ao Prof. Dr. Jacob Pinheiro Goldberg pelas valiosas sugestões e pelo apoio durante a realização deste trabalho.

Às amigas e colegas de profissão e de pós-graduação Carolina de Oliveira Souza, Gisele Braga Pinheiro, Thaís Contenças, Érica Tardelli das Neves e Maria Clara Drummond Soares de Moura, pelo apoio e pelas sugestões e críticas.

Aos alunos do Curso Avançado de Fisioterapia em Neurologia Juliana Noda, Carolina Guerra, Luciana Cicca, Andréia Lázaro, Tiago Strufaldi, pela ajuda na coleta de parte dos dados deste trabalho e de outros projetos desenvolvidos de forma complementar e paralela. 
À educadora e bacharel em letras e ciências sociais Eliana Callil Voos, minha maior colaboradora e debatedora de idéias durante o desenvolvimento deste trabalho e por uma grande sorte minha, também minha mãe.

As invenções são o resultado de um trabalho teimoso. 


\section{RESUMO}

VOOS, M. C. A influência da idade e da escolaridade na execução e no aprendizado de uma tarefa cognitivo-motora. 2009. 99 p. Tese (Doutorado) Instituto de Psicologia, Universidade de São Paulo, São Paulo, 2009.

Função executiva é a habilidade necessária para planejar, iniciar, realizar e monitorar comportamentos intencionais, relacionados a um objetivo ou a demandas ambientais, com base na experiência prévia. Tanto indivíduos idosos, quanto indivíduos com escolaridade baixa apresentam dificuldade em tarefas que requerem função executiva, como o Trail Making Test (TMT), que consiste em traçar retas em uma folha de papel, conectando uma seqüência de números (parte $\mathrm{A}$, TMTA) e de números e letras, alternados (parte $\mathrm{B}$, TMTB), o mais rápido possível. $O$ presente estudo teve como objetivo geral desenvolver uma nova versão do TMT, o Teste de Deambulação Funcional (TDF), que poderia ser mais familiar a indivíduos com escolaridade baixa e favorecer sua compreensão e execução. Os objetivos específicos foram: testar se haveria diferenças de idade e/ou escolaridade (1) na execução das partes $A$ e $B$ do TDF (TDFA e TDFB) e das partes A e $B$ do TMT (TMTA e TMTB); (2) nos deltas cognitivos do TMT (dcTMT=TMTB-TMTA) e do TDF (dcTDF=TDFBTDFA); (3) nos deltas motores da parte $A(d m A=T D F A-T M T A)$ e da parte $B$ (dmB=TDFB-TMTB) e (4) no aprendizado do TDF. Participaram 70 voluntários, (24 jovens, 26 adultos maduros, e 20 idosos). Na primeira sessão os voluntários realizaram (I) o TDF, (II) o TMT, (III) sete repetições do TDFA, (IV) sete repetições do TDFB. Metade dos voluntários de cada faixa etária realizou a ordem (I) e (II) e metade, (II) e (I). Depois de uma semana, realizaram (V) quatro repetições do TDFA e (VI) quatro do TDFB. Foi adotado nível de significância de $p=0,05$. ANOVAs mostraram que (1) os idosos, principalmente 
aqueles com escolaridade baixa, foram mais lentos que os adultos jovens e maduros no TMT e no TDF, sobretudo na parte B e os idosos com escolaridade alta foram mais lentos no TDFB do que no TMTB; (2) os deltas cognitivos do TMT e do TDF foram mais altos para indivíduos com maior idade e menor escolaridade e o dcTMT foi maior que o dcTDF para idosos com escolaridade baixa; (3) o dmB de idosos com escolaridade baixa foi menor que o de idosos com escolaridade alta; (4) os idosos com escolaridade baixa foram mais lentos que aqueles com escolaridade alta na avaliação 1 da TDFA e em todas as avaliações da TDFB, mas não foram observadas diferenças de escolaridade no desempenho de adultos jovens e maduros. O TDF mostrou-se uma ferramenta complementar eficaz para avaliar indivíduos com diferentes idades e escolaridades. Indivíduos mais idosos e com escolaridade mais baixa apresentaram tempos mais altos, tanto no TMT, quanto no TDF. O dcTDF não parece ter sido equivalente ao dcTMT em indivíduos com escolaridade baixa, já que eles apresentaram menor dificuldade em resolver cognitivamente o TDF. Idosos com alta e baixa escolaridade apresentaram resultados antagônicos no dmB: idosos com escolaridade baixa apresentaram menor dificuldade no TDFB, com relação ao TMTB e o contrário ocorreu para idosos com escolaridade alta. A escolaridade baixa prejudicou o aprendizado da tarefa, principalmente em idosos. Idosos apresentaram estabilização mais lenta no desempenho do que adultos maduros, que por sua vez apresentaram estabilização mais lenta que jovens.

Palavras-chave: avaliação geriátrica; cognição; envelhecimento; locomoção; percepção visual. 


\section{ABSTRACT}

VOOS, M. C. The influence of age and educational status on the performance of a cognitive-motor task and on its learning. 2009. $99 \mathrm{p}$. Thesis (PhD) - Instituto de Psicologia, Universidade de São Paulo, São Paulo, 2009.

Executive function is the ability of planning, initiating, performing and monitoring intentional behaviors, related to an objective or environmental demands, based on previous experience. Older adults and individuals with a low educational status have difficulty in performing executive function tasks, such as the Trail Making Test (TMT), which consists on linking a sequence of numbers on a sheet of paper (part A, TMTA) and alternated numbers and letters (part B, TMTB) as fast as possible. The present study had as a general aim to develop a new version of the TMT, the Functional Gait Test (FGT), which could be more familiar to individuals with a low educational status and favor their comprehension and performance. The specific aims were: to investigate possible differences due to age and/or educational status (1) in the performance of parts $A$ and $B$ of FGT (FGTA e FGTB) and of parts $A$ and $B$ of TMT (TMTA and TMTB); (2) in the cognitive deltas of TMT (cdTMT=TMTB-TMTA) and of FGT (cdFGT=FGTB-FGTA); (3) in the motor deltas of part A (mdA=FGTATMTA) and part B (mdB=FGTB-TMTB) and (4) in the learning process of FGT. Seventy volunteers participated (24 young adults, 26 mature adults and 20 older adults). At the first session, volunteers performed (I) the FGT, (II) the TMT, (III) seven repetitions of the FGTA, (IV) seven repetitions of the FGTB. Half of the sample of each age group performed the order (I) and (II) and the other half, (II) and (I). After one week, they performed (V) four repetitions of the FGTA and (VI) four of the FGTB. Significance level was $p=0,05$. ANOVAs showed that (1) older adults, mainly the ones with a low educational status, were slower than young and mature adults on the TMT and on the FGT, principally on part $B$ and older adults with a high educational status were slower on the FGTB than on the TMTB; (2) the cognitive deltas of TMT and FGT were higher for individuals with higher age and lower level of education and the cdTMT was higher than cdFGT for older adults with a low educational status; 
(3) the mdB of older adults with a low educational level was lower that the $\mathrm{mdB}$ of older adults with more years of formal education; (4) older adults with a low educational status were slower than the ones with a high level of education on assessment 1 of the FGTA and in all assessments of the FGTB, but no educational status differences were observed in the performance of young and mature adults. The FGT is an useful complementary tool to evaluate individuals with different ages and educational levels. Older adults and individuals with a lower educational level showed higher times, both in the TMT and in the FGT. The cdFGT did not seem equivalent to the cdTMT in individuals with a low educational status, since they had less difficulty in solving the cognitive part of the FGT. Older adults with a high and a low educational level had antagonistic results on mdB: older adults with a low educational status had less difficulty on the FGTB, compared to the TMTB and the opposite occurred for the ones with a high educational status. The low educational level impaired the learning process, mainly for older adults. Older adults showed slower stabilization on performance than mature adults and mature adults showed slower stabilization than young adults.

Key-words: geriatric assessment; cognition; aging; locomotion; visual perception. 


\section{SUMÁRIO}

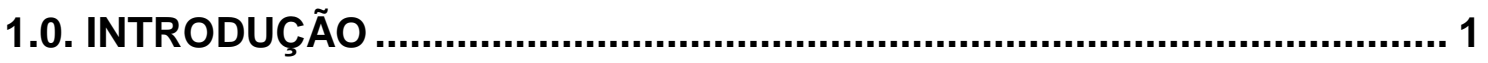

2.0. REVISÃO DE LITERATURA

2.1. A influência da idade em tarefas cognitivo-motoras .............................. 7

2.2. A influência da escolaridade em tarefas cognitivo-motoras ................... 10

2.3. Interação da idade com a escolaridade em tarefas cognitivo-motoras .. 16

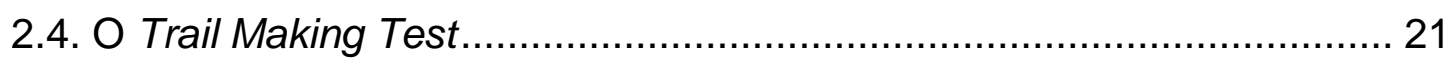

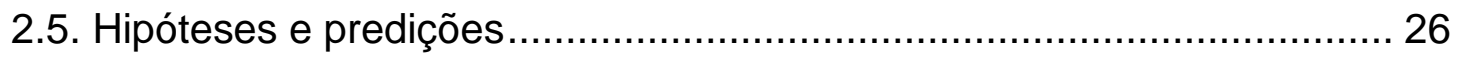

3.0. OBJETIVOS

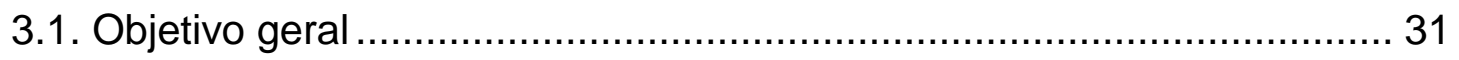

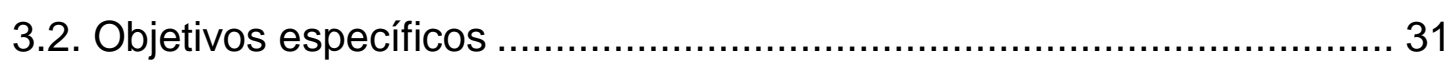

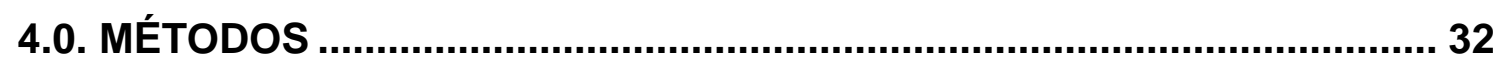

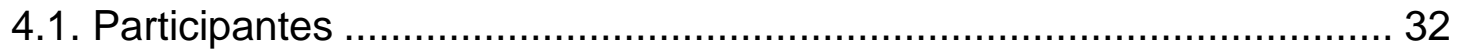

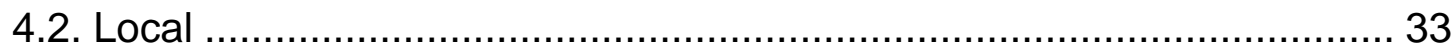

4.3. Materiais e procedimentos específicos de cada teste …....................... 34

4.3.1. Trail Making Test .................................................................. 34

4.3.2. Teste de Deambulação Funcional .............................................. 35

4.3.3. Ordem de realização dos testes .................................................. 36

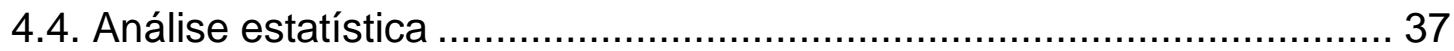

5.0. RESULTADOS

5.1. A influência da idade e da escolaridade no desempenho nas partes $A$ e $B$

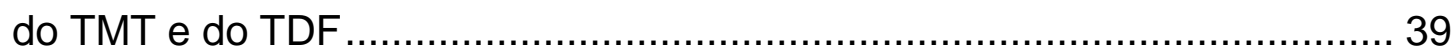

5.2. A influência da idade e da escolaridade no delta cognitivo do TMT e do TDF

5.3. A influência da idade e da escolaridade no delta motor do TMT e do TDF

5.4. A influência da idade e da escolaridade no aprendizado de cada uma das partes do TDF

5.4.1. Diferenças entre as avaliações .................................................. 51

5.4.2. Diferenças decorrentes da idade ................................................ 53 
6.0. DISCUSSÃO

6.1. Desempenho nas partes A e B do TMT e do TDF ................................. 58

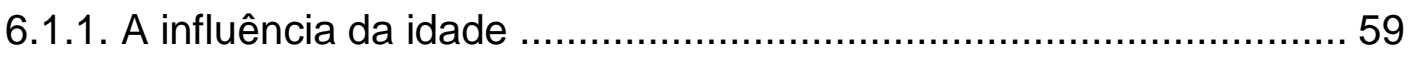

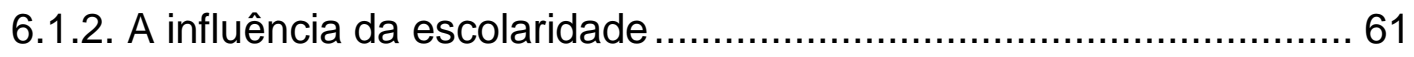

6.1.3. A influência da resposta motora do teste........................................ 66

6.2. A influência do delta cognitivo do TMT e do TDF................................. 67

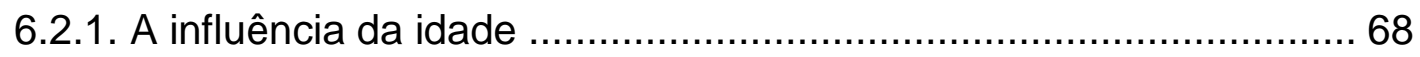

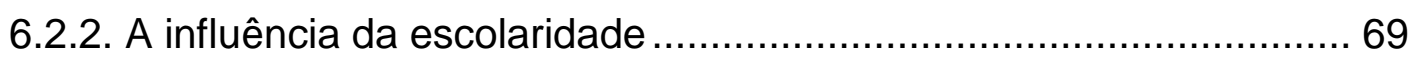

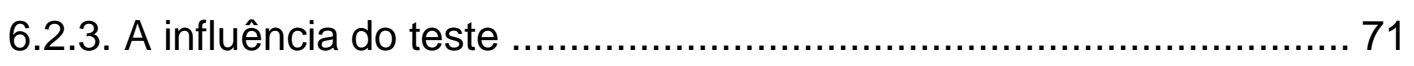

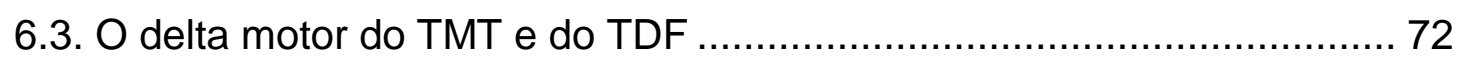

6.3.1. A influência da idade ................................................................. 72

6.3.2. A influência da escolaridade ..................................................... 73

6.3.3. A influência da parte do teste .................................................... 73

6.4. A influência da idade e da escolaridade no aprendizado de cada uma das

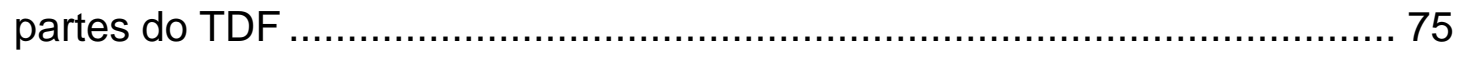

6.4.1. A influência da idade ........................................................... 75

6.4.2. A influência da escolaridade ..................................................... 77

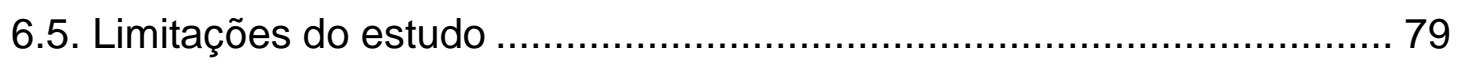

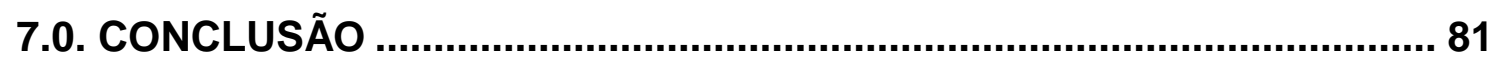

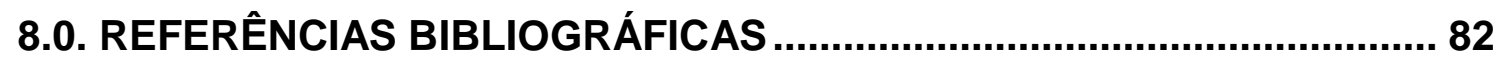




\section{LISTA DE ABREVIAÇÕES}

AJ - adultos jovens

$\mathrm{AM}$ - adultos maduros

ANOVA - análise de variância

dmA - delta motor da parte $A$

$\mathrm{dmB}$ - delta motor da parte B

dcTMT - delta cognitivo do Trail Making Test

dcTDF - delta cognitivo do Teste de Deambulação Funcional

dp - desvio-padrão

EA - escolaridade alta

EB - escolaridade baixa

EEB - Escala de Equilíbrio de Berg

MEEM - Mini Exame do Estado Mental

m - média

ID - idosos

TDFA - parte A do Teste de Deambulação Funcional

TDFB - parte B do Teste de Deambulação Funcional

TMT - Trail Making Test

TMTA - parte A do Trail Making Test

TMTB - parte B do Trail Making Test 


\section{LISTA DE FIGURAS}

Figura 1 - Tempo, em segundos (média \pm desvio-padrão) para realização do Trail Making Test e o Teste de Deambulação Funcional. pág. 43

Figura 2 - Deltas cognitivos do Trail Making Test e do Teste de Deambulação Funcional em função da idade e da escolaridade. pág. 46

Figura 3 - Deltas motores das partes A e B (TDFA - TMTA e TDFB - TMTB) (média \pm desvio-padrão) em função da idade e da escolaridade pág. 48

Figura 4 - Tempo, em segundos (média \pm desvio-padrão) para realização do Teste de Deambulação Funcional em função da escolaridade e da parte do teste no aprendizado ao longo das doze avaliações realizadas nos voluntários adultos jovens pág. 55

Figura 5 - Tempo, em segundos (média \pm desvio-padrão) para realização do Teste de Deambulação Funcional em função da escolaridade e da parte do teste no aprendizado ao longo das doze avaliações realizadas nos voluntários adultos maduros. pág. 56

Figura 6 - Tempo, em segundos (média \pm desvio-padrão) para realização do Teste de Deambulação Funcional em função da escolaridade e da parte do teste no aprendizado ao longo das doze avaliações realizadas nos voluntários idosos pág. 57 
Figura 7 - Exemplo do TMT, realizado pelo examinador (Parte A).......ANEXO A

Figura 8 - Versão do TMT realizada pelo paciente (Parte A)................ANEXO A

Figura 9 - Exemplo do TMT, realizado pelo examinador (Parte B).......ANEXO A

Figura 10 - Versão do TMT realizada pelo paciente (Parte B)..............ANEXO A

Figura 11 - Exemplo do TDF realizado pelo examinador (Parte A)......ANEXO B

Figura 12 - Versão do TDF realizada pelo paciente (Parte A)..............ANEXO B

Figura 13 - Exemplo realizado pelo examinador (Parte B)...................ANEXO B

Figura 14 - Versão do TDF realizada pelo paciente (Parte B)..............ANEXO B 


\section{LISTA DE TABELAS}

Tabela 1 - Pontuações nas partes A e B do Trail Making Test em estudos que investigaram a relação da idade com a escolaridade.

pág. 15

Tabela 2 - Características dos indivíduos que participaram do estudo (média \pm desvio-padrão). Uma análise de variância não constatou diferenças de idade entre os subgrupos com alta e baixa escolaridade. pág. 33

Tabela 3 - Tempos, em segundos (média \pm desvio-padrão) dos voluntários nas partes A e B do Trail Making Test (TMTA e TMTB) e do Teste de Deambulação Funcional (TDFA e TDFB) pág. 39

Tabela 4 - Valores de p obtidos no teste post hoc de Tukey para as comparações entre os tempos de realização de cada tarefa nas diferentes idades pág. 40

Tabela 5 - Valores de p obtidos no teste post hoc de Tukey para as comparações entre os tempos de realização da tarefa nas duas escolaridades .pág.41

Tabela 6 - Valores de p obtidos no teste post hoc de Tukey para comparações entre os tempos de realização da tarefa em cada um dos testes. pág. 42

Tabela 7 - Deltas cognitivos do Trail Making Test (TMTB - TMTA) e do Teste de Deambulação Funcional (TDFB - TDFA) (média \pm desvio-padrão).......pág. 44 
Tabela 8 - Valores de p obtidos no teste post hoc de Tukey para as comparações entre os deltas cognitivos do Trail Making Test (dcTMT) e do Teste de Deambulação Funcional (dcTDF) nas diferentes idades pág. 45

Tabela 9 - Deltas motores da parte A (TDFA - TMTA) e da parte B (TDFB TMTB) (média \pm desvio-padrão). pág. 47

Tabela 10 - Tempo (em segundos) nas doze avaliações da parte A do Teste de Deambulação Funcional. pág. 49

Tabela 11 - Tempo (em segundos) nas doze avaliações da parte B do Teste de Deambulação Funcional. pág. 50

Tabela 12 - Resultados do teste post hoc de Tukey, realizado após ter sido constatada a interação idade $X$ escolaridade $X$ avaliação $X$ parte do teste ANEXO D

Tabela 13 - Escolaridade Média nos estados do Brasil nos Anos 2001 e 2005 ANEXO E

Tabela 14 - Comparação das pontuações no TMT - A e TMT - B no presente estudo com resultados de outros estudos que também investigaram a relação da idade com a escolaridade ANEXO F 


\subsection{INTRODUÇÃO}

O envelhecimento da população é um fenômeno mundial, que tem repercussão direta nos sistemas de saúde e na economia de países desenvolvidos e de países em desenvolvimento. No Brasil, a população de idosos tem aumentado consideravelmente e representa um contingente de cerca de 15 milhões de pessoas com 60 anos ou mais de idade $(8,6 \%$ da população brasileira) (IBGE, 2009).

Está bem documentada na literatura a ocorrência de uma associação entre envelhecimento e decréscimo da função executiva, que poderia explicar, pelo menos em parte, o prejuízo que ocorre no desempenho de tarefas do cotidiano (HANNA-PLADDY, 2007; ALLEY et al., 2007; ZALONIS et al. 2007; COPPIN et al., 2006; BLE et al., 2005; TOMBAUGH, 2004).

Função executiva é a habilidade necessária para planejar, iniciar, realizar e monitorar comportamentos intencionais, relacionados a um objetivo ou a demandas ambientais, com base na experiência prévia. Envolve a capacidade de selecionar e manter um objetivo, organizar e monitorar informações internas e externas, suprimir comportamentos inadequados e formular planos alternativos, quando necessário (HANNA-PLADDY, 2007; COPPIN et al., 2006; BLE et al., 2005; LEZÀK, 2004).

Dentro do contexto de adaptação ambiental, a função executiva envolve uma ampla gama de funções, como resolução de problemas, inferência, alternância de tarefas, auto-monitorização, iniciativa, tomada de decisão, inibição, seleção de comportamentos, verificação e controle de ações, 
planejamento, seqüenciamento e flexibilidade cognitiva (HANNA-PLADDY, 2007; COPPIN et al., 2006; LEZÀK, 2004).

Tisserand et al. (2004) realizaram um estudo longitudinal que mediu a redução do volume cerebral decorrente do envelhecimento, por meio da morfometria. Os autores mostraram que os maiores decréscimos no volume da substância cinzenta, relacionados à idade, ocorreram no lobo frontal, que é a área mais solicitada em tarefas que exigem função executiva (HANNAPLADDY, 2007). Esse decréscimo de volume da substância cinzenta frontal, decorrente do envelhecimento, associa-se à redução da habilidade de planejar, organizar e executar estratégias cognitivo-motoras (ZIMMERMAN et al., 2006).

Outro estudo associou a integridade da substância branca à capacidade de processar informações rapidamente, ter bom desempenho de memória operacional e episódica, inibir respostas inapropriadas e mudar um padrão de resposta, quando necessário, em idosos. Esse mesmo estudo relatou a ocorrência de mudanças microestruturais da substância branca com 0 processo de envelhecimento (KENNEDY e RAZ, 2009).

Outro fenômeno bastante relevante, também com grande expressividade no Brasil e em diversos outros países em desenvolvimento, é a baixa escolaridade. No Brasil, a média de anos de estudo formal dos idosos é muito baixa (cerca de três anos) (IBGE, 2009). Apesar de haver uma quantidade tão expressiva de indivíduos com escolaridade baixa, principalmente idosos, estudos para compreender a saúde e as características sócio-demográficas desta parcela da população ainda são escassos (BRUCKI et al., 2003). 
Segundo Castro-Caldas et al. (1998), aprender a ler e a escrever durante a infância influencia na organização funcional do cérebro humano. Em um estudo com tomografia por emissão de pósitrons (PET), indivíduos alfabetizados apresentaram um melhor desempenho durante uma tarefa de repetição de palavras e, principalmente, de pseudopalavras do que indivíduos não-alfabetizados. Além disso, houve maior ativação cerebral dos indivíduos alfabetizados em regiões corticais do lobo frontal, além do putâmen, globo pálido, tálamo, ponte e vérmis do cerebelo.

O desempenho em diversos testes de avaliação neuropsicológica varia com a escolaridade (YASSUDA et al., 2009; BRUCKI e NITRINI, 2008; ALLEY et al., 2007; SEO et al., 2006; NITRINI et al., 2005; LEE et al., 2003; ARDILA et al., 2000; CASTRO-CALDAS et al., 1998). Na maioria das tarefas avaliadas, quanto mais anos de estudo o indivíduo apresenta, melhor tende a ser o seu desempenho. Dentre esses testes, estão os que medem função executiva, como, por exemplo, o Trail Making Test (TMT).

O TMT é um teste neuropsicológico de lápis e papel, formado por duas partes: A e B. A parte A requer a conexão seqüencial crescente por meio de traços, de números de 1 a 25, localizados dentro de círculos, distribuídos de forma randômica em uma folha de papel de tamanho A4. Na parte B, há maior demanda cognitiva, pois, ao invés de ligar apenas números, o indivíduo deve alternar, de forma crescente, uma seqüência de números e letras (1, A, 2, B, 3, C, etc.). Tanto na parte $A$ quanto na B há 25 círculos no total. $O$ trajeto deve ser realizado o mais rápido possível e sem tirar o lápis do papel.

Diversos estudos demonstraram que o desempenho no TMT é afetado tanto pela idade quanto pela escolaridade (HESTER et al., 2005; TOMBAUGH, 
2004; IVNIK et al., 1996). Acreditávamos que, criando-se uma nova resposta ao TMT, seria possível investigar novos efeitos e novas interações da idade e da escolaridade.

Por isso, além de solicitarmos ao voluntário que realizasse o teste da forma tradicional, ou seja, riscando o papel, ampliamos a superfície do teste e solicitamos que o voluntário o realizasse por meio da deambulação e pisasse com os dois pés sobre cada círculo antes de seguir para o próximo número. Com essa modificação, além de coordenação motora, passamos a exigir mudanças de direção, transferência de peso, equilíbrio estático e dinâmico.

A esta nova versão do teste, demos o nome de Teste de Deambulação Funcional (TDF). Com os dados de ambos os testes, foi possível o cálculo de um novo delta, ao qual nomeamos delta motor.

O delta motor consistiu em subtrair o resultado do teste que supúnhamos ter a resposta motora mais simples e, portanto, mais rápida (TMT), do resultado do teste com resposta motora possivelmente mais complexa e, portanto, mais lenta (TDF). O delta motor foi calculado para cada uma das partes do teste. Para a parte A, foi realizada a subtração do tempo na parte $\mathrm{A}$ do TMT (TMTA) do tempo na parte $\mathrm{A}$ do TDF (TDFA) (TDFA-TMTA= delta motor $\mathrm{A})$. O mesmo foi feito para a parte $\mathrm{B}($ TDFB-TMTB= delta motor $\mathrm{B})$.

Esperávamos que, quanto maior a idade, maior seria o tempo no TDF em relação ao TMT, portanto, o delta motor seria maior. Por outro lado, quanto menor a escolaridade, maior a dificuldade no TMT, em relação à dificuldade no TDF, portanto, o delta motor seria menor. Sendo assim, o envelhecimento e a escolaridade baixa poderiam ter efeitos antagônicos sobre o delta motor. 
Além do delta motor, elaboramos hipóteses a respeito dos deltas cognitivos do TDF (TDFB - TDFA) e do TMT (TMTB - TMTA). O delta cognitivo do TMT já foi bastante discutido na literatura (PERIÀÑEZ et al., 2007; HASHIMOTO et al., 2006; COPPIN et al., 2006; BLE et al., 2005; HESTER et al., 2005; STUSS et al., 2001; ARBUTHNOTT e FRANK, 2000; LEZÀK, 2004). O cálculo do delta cognitivo elimina o componente motor e ressalta a função executiva (BLE et al., 2005; STUSS et al., 2001; ARBUTHNOTT e FRANK, 2000; LEZÀK, 2004).

$\mathrm{Na}$ ausência de diferenças significativas entre os deltas cognitivos, seria comprovado que, de fato, a dificuldade cognitiva do TDF equivaleria à do TMT. Por outro lado, caso houvesse alguma diferença entre o delta cognitivo do TDF e o delta cognitivo do TMT, chegaríamos à conclusão de que a mudança de resposta do TMT para o TDF não teria consistido apenas numa modificação da demanda motora, mas numa modificação da demanda cognitiva.

Também tínhamos a premissa de que o envelhecimento e a escolaridade baixa prejudicariam o aprendizado de uma tarefa cognitivomotora, no caso, o TDF. Esperávamos que os piores desempenhos ocorressem para indivíduos idosos e para indivíduos com escolaridade baixa. Por outro lado, por partirem de um desempenho pior, esses indivíduos poderiam se beneficiar mais do treinamento.

A relevância do presente estudo sustenta-se no fato de não terem sido encontrados outros estudos que investigassem simultaneamente a influência da idade e da escolaridade em uma tarefa visuomotora familiar a todos os voluntários, já que tarefas de lápis e papel costumam favorecer indivíduos com 
escolaridade alta. Também é importante destacar o fato de termos modificado o mínimo possível os aspectos cognitivos do TMT quando criamos o TDF, o que acreditamos ter favorecido um número maior de comparações, ora com ênfase em aspectos motores, com o delta motor, ora com ênfase em aspectos cognitivos, com o delta cognitivo.

Com o uso desta tarefa, acreditamos que os nossos resultados possam contribuir para a prática clínica de diversos profissionais, já que se trata de um teste multidisciplinar, com técnicas de avaliação mais adequadas ao nível de escolaridade do indivíduo e também para o campo da neurociência, com informações importantes sobre como o tempo de escolaridade interfere na realização e no aprendizado de uma tarefa cognitivo-motora. 


\subsection{REVISÃo DE LITERATURA}

\subsection{A influência da idade em tarefas cognitivo-motoras}

O processo de envelhecimento resulta no decréscimo do desempenho nas tarefas do cotidiano que requerem sensibilidade vestibular (KOVACS, 2005), visual (LORD, 2006) e/ou proprioceptiva (CHAPMAN e HOLLANDS, 2006), divisão de atenção (OXLEY et al., 2005), habilidade perceptual (BALL e OWSLEY, 1993), planejamento e seleção de estratégias motoras (COPPIN et al., 2006; BLE et al., 2005), reação rápida frente a um estímulo (KENNEDY e RAZ, 2009; DIFABIO et al., 2005), retenção de informações a curto e/ou longo prazo (REBOK, CARLSON e LAUNGBAUM, 2007), aprendizado e/ou gerenciamento de duas ou mais tarefas simultâneas (TEIXEIRA et al., 2008) e função executiva (KENNEDY e RAZ, 2009; HANNA-PLADDY, 2007).

Diversas tarefas cognitivo-motoras dependem da função executiva para serem realizadas de forma satisfatória. Há tanto tarefas que envolvem predominantemente o ajuste compensatório, como manter o equilíbrio em situações de instabilidade, durante a realização de tarefas-duplas (MELZER et al., 2007; COPPIN et al., 2006; BRAUER, WOOLLACCOT e SHUMWAYCOOK, 2001), quanto tarefas que envolvem predominantemente o ajuste antecipatório, como saltar obstáculos (COPPIN et al., 2006; DIFABIO et al., 2005; BLE et al., 2005), dirigir (NOVACK et al., 2006; BALL e OWSLEY, 1993), ajustar a velocidade e o padrão de marcha (VAN IERSEL et al., 2007; COPPIN et al., 2006; BLE et al., 2005), orientar-se espacialmente e mudar de direção ao 
deambular em ambientes externos (OXLEY et al., 2005; BROMAN et al., 2004; TURANO et al., 2004).

Oxley et al. (2005) avaliaram a habilidade de indivíduos jovens e idosos de decidirem o melhor momento de atravessar a rua e de adequarem a velocidade da marcha, em relação a veículos que se aproximavam em diversas velocidades, em um simulador de tráfego. Os autores concluíram que pedestres idosos têm maior dificuldade que os jovens, tanto na tomada de decisão de quando devem ou não atravessar a rua, quanto na adequação da velocidade da marcha.

Segundo os autores, a associação do ato motor de atravessar a rua ao de olhar os carros que se aproximam dificulta a locomoção, devido a uma redução da capacidade de dividir a atenção, que normalmente surge com 0 envelhecimento. Além disso, os idosos são mais dependentes da visão quando andam e, por isso, olham mais freqüentemente para o chão durante a marcha. Isso prejudica o monitoramento simultâneo da distância do carro e da distância a ser percorrida e retarda a aceleração a marcha, nos casos em que ela é necessária. Por fim, a tomada de decisão é menos adequada em idosos, pelo decréscimo da função executiva.

Ble et al. (2005) avaliaram o desempenho de idosos em duas tarefas de marcha com diferentes graus de dificuldade: na mais simples, o idoso deveria andar por $4 \mathrm{~m}$ na velocidade usual (tarefa automática) e na mais complexa, o idoso deveria andar por $7 \mathrm{~m}$ o mais rápido possível e saltar dois obstáculos, de 6 e $30 \mathrm{~cm}$ de altura (tarefa que requer habilidade executiva). Os dados obtidos foram correlacionados com o delta do Trail Making Test, ou delta TMT (tempo da parte $B$ menos tempo da parte A). 
Os resultados de Ble et al. (2005) não indicaram associação entre o delta e a velocidade da marcha normal, contudo, houve uma associação forte entre o delta e a velocidade na tarefa de andar rápido saltando obstáculos, pelo fato desta ter requerido consideravelmente mais atenção. Os autores argumentaram que a função executiva teria um papel importante na execução de atividades complexas de membros inferiores em idosos, sendo muito menos necessárias em tarefas extensivamente treinadas, como andar na velocidade habitual sobre uma superfície plana e sem obstáculos.

Por outro lado, Hausdorff et al. (2005) e Sparrow et al. (2002) defenderam a idéia de que a marcha sempre apresentaria algum custo atencional. Por ter sido extensivamente treinada, encontrar-se-ia automatizada e, por isso, não inibiria a capacidade de realizar outras atividades ao mesmo tempo. Durante a marcha, aferências e objetivos seriam integrados ao longo dos níveis hierárquicos. Até o ato de andar sem outras atividades associadas poderia ser visto como uma tarefa-dupla, que necessitaria de recursos cognitivos, mesmo que em quantidade mínima.

Com o envelhecimento, o controle rítmico de passos passaria a requerer maior atenção, pois haveria diminuição da sensibilidade, percepção, velocidade e planejamento. Dessa forma, a atenção já estaria atuando de forma compensatória nestes sistemas e estaria menos disponível para ser alocada a tarefas cognitivas freqüentemente associadas à marcha.

Apesar de, em condições de teste, haver diferenças significativas entre jovens e idosos, estudos constataram aprendizado proporcional entre os dois grupos, ou até a diminuição da diferença entre jovens e idosos quando foi realizado algum tipo de treinamento. Bherer et al. (2006) realizaram uma tarefa 
de discriminação auditiva isolada e associada a uma tarefa de discriminação visual e verificaram aprendizado significativo, evidenciado pela diminuição dos tempos de reação nas tarefas isoladas e associadas, tanto para jovens, quanto para idosos. Em algumas ocasiões, a diferença entre jovens e idosos chegou a diminuir, ou seja, o treinamento minimizou as perdas de desempenho que haviam sido proporcionadas pelo envelhecimento.

O mesmo ocorreu nos trabalhos de Melzer et al. (2007) e de Melzer e Oddsson (2004), que propuseram uma tarefa de dar um passo para frente ou para o lado o mais rápido possível, após um estímulo tátil no tornozelo, em duas condições: tarefa isolada e tarefa-dupla, sendo que, na segunda condição, a tarefa motora foi associada ao teste de Stroop.

Nos dois trabalhos, os idosos foram mais lentos que os jovens na tarefa isolada e, principalmente, na tarefa-dupla, ao longo de todo o experimento. Porém, tanto os jovens, quanto os idosos apresentaram aprendizado significativo com as repetições realizadas. Em ambos os experimentos, principalmente no de Melzer e Oddsson (2004), a melhora dos idosos foi mais acentuada que a dos jovens, ou seja, embora os idosos ainda tenham terminado o experimento com tempo de reação maior que os jovens, a diferença entre jovens e idosos diminuiu.

\subsection{A influência da escolaridade em tarefas cognitivo-motoras}

Indivíduos com escolaridade baixa demonstram desempenho pior do que indivíduos com escolaridade alta em tarefas que requerem percepção visuoespacial (BRUCKI e NITRINI, 2008; REIS et al., 2006; NITRINI et al., 
2004), fluência verbal (BRUCKI e ROCHA, 2004; NITRINI, 2004), cálculo e representação monetária (ARDILA et al., 2000; DELOCHE et al., 1999), destreza e habilidade práxica (NEVES, 2008; DANSILIO e CHARAMELO, 2005; NITRINI et al., 2005; NITRINI et al., 2004; CAVALCANTE, 2004), memória de longa e curta duração (BARNES et al. 2004; NITRINI et al., 2004), memória operacional (LE CARRET et al., 2003), realização concomitante de duas tarefas (ANDRADE-MACHADO et al., 2009) e função executiva (TUN e LACHMAN, 2008; VAN DER ELST et al., 2006).

Indivíduos com poucos anos de estudo formal tendem a ser mais lentos e a apresentar maior número de erros ao identificarem representações bidimensionais esquemáticas de objetos comumente utilizados no dia-a-dia (NITRINI et al., 2004; PETERSSON et al., 2001; REIS et al., 2001). Contudo, essa diferença de desempenho diminui quando os objetos a serem identificados são apresentados em fotos e desaparece com a observação dos objetos reais (REIS et al., 2001).

Esses dados sugerem que o desempenho em tarefas de nomeação seja dependente da representação visual, da linguagem e da interação entre ambas. Em atividades escolares, o reconhecimento de imagens bidimensionais é extensivamente treinado, o que faz com que indivíduos de maior escolaridade tenham maior familiaridade em decodificar e interpretar informações em duas dimensões (REIS et al., 2001).

Brucki e Nitrini (2008) estudaram a influência da escolaridade em indivíduos da região amazônica. Compararam o desempenho de voluntários que nunca haviam freqüentado a escola com o de indivíduos com quatro anos 
de escolaridade em uma tarefa de cancelamento de figuras. Constataram que os indivíduos que nunca haviam freqüentado a escola apresentavam um maior tempo para concluir a tarefa e um maior número de erros dos que os indivíduos que haviam freqüentado a escola por quatro anos.

Pessoas com escolaridade baixa tendem a ter menor fluência verbal. Assim, quando são solicitados a enumerar o maior número de animais que consigam em um minuto, eles apresentam um desempenho inferior ao de indivíduos com escolaridade alta (BRUCKI e ROCHA, 2004; NITRINI, 2004; ARDILA et al., 2000).

Além da dificuldade em tarefas de linguagem, a escolaridade baixa associa-se à menor habilidade aritmética. Foi demonstrado que indivíduos com escolaridade baixa apresentam pior desempenho em testes de leitura de algarismos, cálculo e representação monetária (ARDILA et al., 2000; DELOCHE et al., 1999).

A escolaridade baixa resulta na diminuição da capacidade visuomotora, bem como em menor destreza e habilidade práxica (DANSILIO e CHARAMELO, 2005; NITRINI et al., 2005; NITRINI et al., 2004; SAHADEVAN et al., 1997).

Sahadevan et al. (1997) observaram um pior desempenho de indivíduos com escolaridade baixa na tarefa de organização visuoespacial da Escala de Inteligência Weschler para adultos, que envolve construir réplicas com cubos vermelhos e brancos a partir de figuras desenhadas.

Dansilio e Charamelo (2005) compararam o desempenho de indivíduos com escolaridade alta ao de indivíduos com escolaridade baixa por meio de 
testes de praxia construcional, nos quais algumas figuras deveriam ser copiadas. Em ambos os estudos, voluntários com escolaridade baixa apresentaram maior número de erros do que os com escolaridade alta. Nitrini et al. (2004) utilizaram a tarefa do desenho do relógio e obtiveram o mesmo resultado.

Nitrini et al. (2005) constataram um pior desempenho de indivíduos com escolaridade baixa em testes de movimentos manuais seqüenciais (Luria's fistedge-palm). Segundo os autores, indivíduos com escolaridade alta adotam estratégias diferentes dos com escolaridade baixa para execução e aprendizado de tarefas motoras seqüenciais.

Duas estratégias são normalmente usadas para ajudar na formulação de um movimento. A primeira é baseada na análise visual do movimento (estratégia sensorial), com transformação da informação visual em representação motora. A segunda é baseada na interpretação verbal do gesto (estratégia semântica) e ocorre quando, por exemplo, é dado um comando verbal para um movimento.

De acordo com Nitrini et al. (2005), indivíduos com escolaridade alta usam as duas estratégias para reproduzir e ajustar os movimentos quando solicitados a realizar uma seqüência de gestos. Porém, a estratégia verbal é menos elaborada nos indivíduos com escolaridade baixa, o que os torna dependentes, quase que exclusivamente, da estratégia visual e pode resultar em mais falhas e em pontuações mais baixas em diversos testes motores.

Cavalcante (2004) avaliou a habilidade de produzir e reconhecer gestos em idosos de diferentes escolaridades. Constatou que os idosos com 
escolaridade baixa apresentaram pior desempenho que os com escolaridade alta. Segundo a autora, o fato de ter freqüentado a escola por poucos anos está associado a uma maior dificuldade em produzir e reconhecer gestos nãocontextualizados e em demonstrar corretamente a posição da mão ao imitar um gesto demonstrado pelo examinador.

Um teste de memória bastante utilizado na literatura consiste na reprodução de palavras lidas por um examinador. Para a avaliação da memória imediata são apresentadas dez palavras consecutivas, que devem ser repetidas em seguida. Já para a avaliação da memória de longa duração, as dez palavras são apresentadas mais duas vezes e, depois disso, uma tarefa que distrai a atenção é realizada. As dez palavras devem, então, ser novamente repetidas (BERTOLUCCI et al., 2001). Por meio deste teste, Nitrini et al. (2004) e Sahadevan et al. (1997) demonstraram que pessoas menos escolarizadas apresentavam pior retenção imediata e a longo prazo do que pessoas mais escolarizadas.

Pessoas com escolaridade baixa tendem a apresentar maior dificuldade na realização de tarefas-duplas (ANDRADE-MACHADO et al., 2009). Em um experimento que associou uma tarefa visual de identificação e comparação de figuras a uma tarefa motora de alternância de passos do chão a uma plataforma, indivíduos com escolaridade baixa apresentaram maior dificuldade em cada uma das tarefas isoladamente e um aumento mais acentuado do número de erros na tarefa visual quando esta foi realizada simultaneamente à tarefa motora. 
Quanto às diferenças no aprendizado motor, decorrentes da escolaridade, Neves (2008) verificou que idosos com escolaridade baixa apresentaram maior dificuldade para aprender uma seqüência de oposição de dedos do que idosos com escolaridade alta. Os idosos com escolaridade baixa apresentaram mais erros e menor velocidade na seqüência treinada que os de maior escolaridade.

Além disso, os idosos com escolaridade baixa não conseguiram generalizar o aprendizado da tarefa treinada para uma tarefa controle, que não havia sido treinada, enquanto os de maior escolaridade conseguiram. Segundo a autora, o cérebro humano passa por modificações estruturais e funcionais na presença de educação formal e essas modificações interferem não só em processos cognitivos, mas também em processos motores (NEVES, 2008).

Segundo Ardila et al. (2000), o fato de indivíduos com escolaridade baixa ficarem mais tensos em situações de teste, além de reduzirem a velocidade devido ao maior medo de cometer erros, contribui com esses resultados. Além disso, o autor acredita que as piores condições de saúde e sócio-econômicas, comumente associadas à escolaridade baixa, somam-se às deficiências específicas da baixa educação formal.

No entanto, estudos que controlaram as condições sócio-econômicas e de saúde e compararam o desempenho de indivíduos com escolaridade alta ao de indivíduos com escolaridade baixa também encontraram diferenças significativas decorrentes do tempo de educação formal, o que sugere que, independentemente da situação sócio-econômica, a escolaridade tenha, de 
fato um papel muito importante no desempenho de tarefas cognitivo-motoras (TUN e LACHMAN, 2008; LEE et al., 2003).

\subsection{Interação entre idade e escolaridade em tarefas cognitivo- motoras}

Indivíduos com baixo nível de escolaridade apresentam sinais precoces de envelhecimento cognitivo (KULAIF, 2005). Por outro lado, há evidências de que um maior nível de escolaridade ocasiona maior ativação sináptica, com maior fluxo de sangue cerebral em regiões fronto-temporais (CHIU et al., 2004), o que poderia proporcionar melhor percepção, memória e raciocínio e retardar o aparecimento de quadros demenciais (LEE et al., 2003; STERN et al., 2005).

Em uma série de estudos conhecida como Nun Study (estudo das freiras), foram estudadas mulheres com diferentes escolaridades, mas que desde a juventude, ordenaram-se freiras e moraram no mesmo local, receberam a mesma alimentação e mantiveram hábitos de vida semelhantes. Ao longo do processo de envelhecimento, as freiras com maior escolaridade tenderam a manter por mais tempo uma boa coordenação e uma maior força de preensão manual, além de uma melhor acuidade visual e de menos alterações cognitivas (OSTWALD et al., 1989).

Além disso, outros estudos com este mesmo grupo de voluntárias demonstraram que as freiras com escolaridade alta tenderam a apresentar uma melhor capacidade de expressar idéias por escrito (SNOWDON et al., 1996) e mantiveram a habilidade de desempenhar atividades de vida diária sem precisar de auxílio por mais tempo (SNOWDON et al., 1989). 
Estudos que tiveram como objetivo verificar quais fatores poderiam contribuir para uma preservação da habilidade cognitiva durante o processo de envelhecimento e, conseqüentemente, uma manutenção da independência funcional por mais tempo, verificaram que o nível educacional está entre os fatores mais importantes para a determinação de um bom prognóstico (YAO et al., 2009; ALLEY, SUTHERS e CRIMMINS, 2007; JAGGER et al., 2007; ARDILA et al., 2000; SNOWDON et al., 1989).

De acordo com Paradise, Cooper e Livingston (2009), níveis mais altos de educação compensam a progressão da Doença de Alzheimer e atrasam suas manifestações clínicas. A teoria da reserva cognitiva propõe que a educação fornece uma reserva cognitiva e neurológica, por meio de mudanças neuronais ou aumento da eficiência de redes de processamento, o que faz com que os sintomas clínicos da neurodegeneração decorrente da Doença de Alzheimer surjam mais tardiamente (FRITSCH et al., 2001).

Então, dentre os indivíduos que evoluíram com demência, os que apresentavam níveis maior número de anos de estudo formal mostraram sintomas mais tardiamente do que aqueles com menor escolaridade (LEE et al., 2003; CHIU et al., 2004; STERN et al., 2005). Indivíduos com mais de oito anos de estudo formal são protegidos contra uma redução de suas capacidades para solucionar testes cognitivos (KULAIF, 2005).

Estes dados foram confirmados por estudos com ressonância magnética funcional (STERN et al., 1992) e por estudos post-mortem (BENNETT et al., 2003; ROE et al., 2007). Estes estudos demonstraram que, entre indivíduos com o mesmo comprometimento clínico, com a mesma classificação de 
gravidade da doença e de prejuízo cognitivo, aqueles com maior nível de escolaridade apresentavam um maior número de achados neuropatológicos.

A hipótese da compensação sugere que a educação formal e/ou a atividade intelectual podem diminuir o declínio cognitivo até um ponto no qual habilidades básicas começam a se deteriorar com o envelhecimento. Neste momento, indivíduos com maior escolaridade podem mostrar uma progressão mais rápida do declínio cognitivo (ALLEY, SUTHERS e CRIMMINS, 2007; TUN e LACHMAN, 2008).

Embora muitos estudos tenham associado a escolaridade baixa ao surgimento de maiores alterações cognitivas durante 0 processo de envelhecimento (YAO et al., 2009; ALLEY, SUTHERS e CRIMMINS, 2007; MANCKOUNDIA et al., 2006; ARDILA et al., 2000), poucos associaram o baixo número de anos de estudo formal a alterações motoras (NEVES, 2008; CAVALCANTE, 2004).

A cognição permite o controle adequado de ações, com base em regras e em representações de eventos. Ações ocorrem com planejamento e alvo definidos. O planejamento, por sua vez, é realizado de acordo com regras, que governam eventos ou tarefas (VON HOFSTEN, 2007). Por exemplo: a redução do equilíbrio funcional e o aumento do risco de quedas, que ocorrem com o envelhecimento, são agravados pela escolaridade baixa. Um estudo que visou investigar a relação entre a Escala de Equilíbrio de Berg e o número de anos de estudo formal verificou que, embora haja exceções, idosos com escolaridade baixa tendem a apresentar menor pontuação na escala de equilíbrio (VOOS, CUSTODIO e MALAQUIAS, 2009). 
Um estudo de Gitlin et al. (2008) visou investigar se diferenças de escolaridade em idosos poderiam resultar em ganhos distintos após a aplicação de um programa de orientações, realizado por um fisioterapeuta e um terapeuta ocupacional, que visou minimizar disparidades entre a capacidade física do idoso e as demandas ambientais.

O fisioterapeuta ensinou exercícios de equilíbrio e fortalecimento muscular, reações de proteção em casos de quedas e orientações sobre como levantar do chão de forma segura após uma eventual queda. $O$ terapeuta ocupacional propôs formas mais adequadas de uso de ferramentas, conservação de energia e modificações na residência para maior segurança. $O$ desempenho foi avaliado após seis e após doze meses de intervenção.

Após a intervenção, o grupo com escolaridade baixa apresentou melhora mais expressiva que o grupo com escolaridade alta nas áreas de atividades de vida diária, mobilidade, confiança em lidar com dificuldades funcionais e prevenção de quedas. Segundo os autores, uma possível explicação para este fato é a menor acessibilidade a esse tipo de informação, bem como a recursos de assistência à locomoção e menor conhecimento de estratégias compensatórias de indivíduos com escolaridade baixa.

Segundo Tun e Lachman (2008), níveis mais altos de escolaridade estão associados à melhor eficiência de função executiva. Em uma tarefa que envolvia controle inibitório e alternância de padrão de resposta verbal a estímulos sonoros, indivíduos com nível superior apresentaram desempenho equivalente ao de indivíduos menos escolarizados dez anos mais jovens. As autoras concluíram que níveis mais altos de educação formal poderiam diminuir 
a influência do envelhecimento em tarefas complexas que envolvessem velocidade de processamento cognitivo-motor e função executiva.

A função executiva, por sua vez, pode prevenir quedas em idosos, atuando de forma compensatória em relação à instabilidade postural, característica do envelhecimento. Um estudo de Liu-Ambrose et al. (2008) verificou que indivíduos com menor habilidade em tarefas de função executiva (Trail Making Test), de inibição (teste de Stroop) e de memória operacional (repetição de dígitos de trás para frente) tendem a apresentar maior risco de quedas e maior oscilação postural. Voos, Custódio e Malaquias (2009) constataram que indivíduos com maiores pontuações na Escala de Equilíbrio de Berg também apresentaram melhor desempenho no TMT.

Diversos autores estudaram a interação da idade com a escolaridade no desempenho do TMT, em populações de diferentes nacionalidades e com diferentes características sócio-culturais (TOMBAUGH, 2004; HESTER et al., 2005; SEO et al., 2006; HASHIMOTO et al., 2007; ZALONIS et al., 2007; ASHENDORF et al., 2008).

Tombaugh (2004) e Hester et al. (2005) estudaram indivíduos idosos saudáveis, divididos em quatro grupos por idade $(60$ a 69, 70 a 74, 75 a 79 e 84 a 84 anos) e em dois níveis de escolaridade ( $\leq 11$ e $>11$ anos de estudo formal). Ambos verificaram que a interferência da idade, bem como a da educação não foi igual nas partes $A$ e $B$ do teste. Na parte $A$, mais simples, o desempenho piorou com o aumento da idade, mas não sofreu interferência da educação. Na parte $\mathrm{B}$, mais complexa, os indivíduos sofreram tanto influência da idade, quanto da escolaridade. Portanto, para indivíduos com escolaridade 
baixa, houve declínio mais acentuado do desempenho a cada década de vida do que na comparação de indivíduos com escolaridade alta.

\subsection{O Trail Making Test (TMT)}

O Trail Making Test (TMT) foi desenvolvido por Partington em 1938, como uma ferramenta para avaliar atenção dividida. Passou a ser utilizado por psicólogos do exército americano e foi publicado pela primeira vez em 1944, na Bateria de Testes Individuais do Exército (Army Individual Test Battery) (LEZÀK, 2004). Depois disso, teve papel importante no estudo de Ralph Reitan, com indivíduos com traumatismo crânio-encefálico (REITAN, 1958) e, posteriormente, foi incorporado na Bateria Neuropsicológica Halstead-Reitan (DIKMEN et al., 1999). Atualmente, é um teste de domínio público e pode ser reproduzido sem necessitar de autorização (LEZÀK, 2004). Os coeficientes de confiabilidade variam de 0,70 até 0,90 na literatura. A maioria dos estudos relata um valor por volta de 0,80 (LEZÀK, 2004).

O TMT é um teste neuropsicológico de lápis e papel, que fornece informações sobre a capacidade de busca por escaneamento visual (TOMBAUGH, 2004; LEZÀK, 2004; CROWE, 1998), velocidade de processamento (PERIÀÑEZ et al., 2007; TOMBAUGH, 2004), flexibilidade cognitiva (TOMBAUGH, 2004; LEZÀK, 2004), capacidade de alternar tarefas (SHIBUYA-TAYOSHI et al., 2007; ARBUTHNOTT e FRANK, 2000), atenção dividida (LEZÀK, 2004), inibição (HANNA-PLADDY, 2007), agilidade motora (LEZÀK, 2004; CROWE, 1998), coordenação motora (CROWE, 1998). Como visto anteriormente, boa parte dessas funções pertence ao grupo das funções executivas (LEZÀK, 2004; HANNA-PLADDY, 2007). 
É formado por duas partes: A e B. A parte A requer a conexão seqüencial crescente por meio de traços, de números de 1 a 25 , localizados dentro de círculos, distribuídos de forma randômica em uma folha de papel de tamanho A4. Na parte B, há maior demanda cognitiva, pois, ao invés de ligar apenas números, o indivíduo deve alternar, de forma crescente, uma seqüência de números e letras (1, A, 2, B, 3, C, etc.). Tanto na parte $A$ quanto na $B$ há 25 círculos no total. O trajeto deve ser realizado o mais rápido possível e sem tirar o lápis do papel.

Ambas as partes testam a capacidade de escaneamento visual (CROWE, 1998). A parte A do teste fornece informações sobre a agilidade e coordenação motora (HASHIMOTO, 2006; CROWE, 1998). A parte B, além de mensurar as funções da parte $A$, também é útil para evidenciar a capacidade de alternância entre duas tarefas (SHIBUYA-TAYOSHI et al., 2007; HASHIMOTO, 2006; CROWE, 1998; REITAN, 1958), por isso, o tempo da parte B do TMT é comumente usado como um índice de função executiva (DIFABIO et al., 2005; HASHIMOTO, 2006; HANNA-PLADDY, 2007). Por solicitar a alternância entre duas seqüências, a parte B requer maior atenção (GAUDINO, et al., 1997) e memória operacional (CROWE, 1998).

É necessária ainda, para a parte $B$, maior habilidade em suprimir uma tarefa (neste caso, ir até a próxima letra da seqüência) para realizar outra (ir até o próximo número da seqüência) e depois retornar à tarefa inicial (HANNAPLADDY, 2007; KORTTE et al., 2002; ARBUTHNOTT e FRANK, 2000; OLIVEIRA-SOUZA et al., 2000; CROWE, 1998). Essa característica é comumente chamada de flexibilidade mental (TOMBAUGH, 2004; BELLMCGINTY, 2002; CROWE, 1998). O processamento eficiente consiste na 
capacidade de ativar a informação que é relevante para a tarefa realizada naquele momento e inibir simultaneamente a informação que não é relevante (MINER e FERRARO, 1998).

Segundo estipulado por Reitan (1958), quando o voluntário comete um erro durante a realização do teste, o examinador deve apontar o erro no momento de sua ocorrência e solicitar que o examinado volte para o círculo anterior e continue o teste. Dessa forma, os erros não são registrados, mas resultam em aumento no tempo total, já que o indivíduo deve retornar à etapa anterior antes de continuar (BOWIE e HARVEY, 2006; LEZÀK, 2004; STUSS et al., 2001). Segundo Bowie e Harvey (2006), quando o tempo gasto para completar uma parte do teste passa de 300 segundos, o teste pode ser interrompido e pode ser atribuída a pontuação máxima.

Os índices diretos do TMT são a pontuação na parte $A(A)$ e a pontuação na parte $B(B)$, que consistem no tempo necessário para completar cada parte (TOMBAUGH, 2004). Os índices derivados do TMT são o delta (B-A) e a razão (B/A). O delta é o mais utilizado e, segundo alguns autores, é uma medida mais fiel de função executiva do que a parte B do teste, uma vez que, quando o tempo da parte $A$ é subtraído do tempo na parte $B$, são minimizados os efeitos decorrentes do controle motor e da percepção visuoespacial e restam a capacidade de alternância entre duas tarefas, a habilidade em suprimir uma tarefa para realizar outra e a flexibilidade mental (VAN IERSEL et al., 2007; COPPIN et al., 2006; BLE et al., 2005; LEZÀK, 2004; ARBUTHNOTT e FRANK, 2000; STUSS et al., 2001). 
Há algumas controvérsias na literatura envolvendo a parte B do TMT. Em primeiro lugar, alguns estudos questionaram a equivalência motora das partes A e B (ROSSINI e KARL, 1994), já que o comprimento total médio do trajeto da parte B é maior que o da parte $A$, ou seja, o maior tempo do voluntário na parte B também se deve a um trajeto mais longo a ser realizado nesta parte (CROWE, 1998; GAUDINO et al., 1997). Em segundo lugar, o escaneamento visual parece ser mais difícil na parte B porque os círculos estão mais embaralhados (GAUDINO et al., 1997; CROWE, 1998).

Durante a execução da parte B do TMT foi verificada maior ativação do córtex pré-frontal do que durante a execução da parte $A$ em jovens universitários (SHIBUYA-TAYOSHI et al., 2007). Estudos que compararam pacientes com lesão no lobo frontal com pacientes com lesão em regiões nãofrontais e com sujeitos controle descreveram a relação entre lesão frontal e alterações no desempenho nas partes A (DEMAKIS et al., 2004) e B (STUSS et al., 2001) do TMT.

O TMT pode ser usado para estimar ou prever habilidades funcionais. Seu desempenho está correlacionado à capacidade de dirigir (NOVACK et al., 2006; BOWIE e HARVEY, 2006) e é um teste de triagem útil quando associado aos resultados de avaliações em simuladores de direção (NOVACK et al., 2006; UC et al., 2006). De acordo com o estudo de BELL-MCGINTY et al. (2002), idosos com dificuldade na parte B do TMT tendem a apresentar problemas em atividades complexas de vida diária. Além disso, quando a pontuação na parte A é muito menor que a da parte $B$, ou seja, quando o delta é grande, o indivíduo geralmente apresenta dificuldade em realizar tarefasduplas ou múltiplas (LEZÀK, 2004). 
A grande maioria dos estudos afirma que, quanto maior a idade, maior o tempo necessário para completar tanto a parte A quanto a parte B do TMT (PERIÀÑEZ et al., 2007; ZALONIS et al., 2007; HASHIMOTO et al., 2006; SEO et al., 2006; HESTER et al., 2005; TOMBAUGH, 2004). O delta e a razão aumentam quando aumenta a idade do voluntário (HASHIMOTO et al., 2007).

A escolaridade também afeta o tempo no TMT (HASHIMOTO et al., 2007; ZALONIS et al., 2007; SEO et al., 2006), mas alguns estudos só encontraram este efeito para a parte B (IVNIK et al., 1996; TOMBAUGH, 2004; HESTER et al., 2005). A escolaridade tem efeito oposto ao da idade: o delta e a razão aumentam quando diminui a escolaridade do voluntário (HESTER et al., 2005).

Estudos relatam algum efeito de aprendizagem no TMT quando o teste é reaplicado em menos de seis meses (DIKMEN et al., 1999; MCCAFFREY et al., 1993), mas este efeito desaparece quando o teste é reaplicado após esse intervalo de tempo (BASSO, 1999; GIOVAGNOLI et al., 1996). Um estudo recente não encontrou diferenças significativas no desempenho de idosos quando o TMT foi reaplicado após o intervalo de trinta dias (YAMAZAKI, 2009).

McCaffrey et al. (1993) aplicaram o TMT três vezes, espaçadas por uma semana e verificaram que a parte B apresentou efeito de prática significativo. Entretanto, na quarta aplicação, após três meses decorridos da terceira, este efeito de prática deixou de ser observado, pois o desempenho se estabilizou.

Os principais resultados do TMT, presentes na literatura, provenientes de estudos que avaliaram indivíduos idosos subdivididos por idade e por escolaridade, estão resumidos na tabela 1, a seguir. 
Tabela 1: Pontuações nas partes A e B do Trail Making Test em estudos que investigaram a relação da idade com a escolaridade.

\begin{tabular}{|c|c|c|c|c|c|c|c|}
\hline $\begin{array}{l}\text { Estudo } \\
\text { (autores) }\end{array}$ & $\begin{array}{c}\text { Adultos } \\
\text { maduros } \\
\text { (anos) }\end{array}$ & $\begin{array}{l}\text { Escolaridade } \\
\text { (anos) }\end{array}$ & $\begin{array}{c}\text { TMTA } \\
\text { (segundos) }\end{array}$ & $\begin{array}{c}\text { TMTB } \\
\text { (segundos) }\end{array}$ & $\begin{array}{l}\text { Idosos } \\
\text { (anos) }\end{array}$ & $\begin{array}{c}\text { TMTA } \\
\text { (segundos) }\end{array}$ & $\begin{array}{c}\text { TMTB } \\
\text { (segundos) }\end{array}$ \\
\hline $\begin{array}{c}\text { Tombaugh } \\
\text { (2004) }\end{array}$ & $60-69$ & $\begin{array}{l}<11 \\
\geq 11\end{array}$ & $\begin{array}{l}39,1 \\
33,8\end{array}$ & $\begin{array}{l}91,3 \\
67,1\end{array}$ & $70-74$ & $\begin{array}{l}42,5 \\
40,1\end{array}$ & $\begin{array}{c}109,9 \\
86,2\end{array}$ \\
\hline $\begin{array}{c}\text { Hester et al. } \\
\text { (2005) }\end{array}$ & $60-69$ & $\begin{array}{l}<11 \\
\geq 11\end{array}$ & $\begin{array}{l}43,6 \\
36,7\end{array}$ & $\begin{array}{c}103,4 \\
81,5\end{array}$ & $70-74$ & $\begin{array}{l}44,6 \\
42,9\end{array}$ & $\begin{array}{l}106,3 \\
101,7\end{array}$ \\
\hline $\begin{array}{c}\text { Seo et al. } \\
\text { (2006) }\end{array}$ & $60-69$ & $\begin{array}{c}8 \\
\geq 10\end{array}$ & $\begin{array}{l}68,3 \\
56,2\end{array}$ & $\begin{array}{l}185,1 \\
159,8\end{array}$ & $70-74$ & $\begin{array}{l}67,9 \\
58,0\end{array}$ & $\begin{array}{l}190,5 \\
163,8\end{array}$ \\
\hline $\begin{array}{l}\text { Hashimoto et } \\
\text { al. (2007) }\end{array}$ & $\begin{array}{c}\text { não } \\
\text { avaliado }\end{array}$ & $\begin{array}{l}<11 \\
\geq 11\end{array}$ & $\begin{array}{c}\text { não } \\
\text { avaliado }\end{array}$ & $\begin{array}{c}\text { não } \\
\text { avaliado }\end{array}$ & $70-74$ & $\begin{array}{l}63,4 \\
57,3\end{array}$ & $\begin{array}{l}190,6 \\
154,4\end{array}$ \\
\hline $\begin{array}{c}\text { Zalonis et al. } \\
\quad(2007)\end{array}$ & $45-65$ & $\begin{array}{l}<9 \\
>13\end{array}$ & $\begin{array}{l}59,2 \\
45,5\end{array}$ & $\begin{array}{c}146,1 \\
94,5\end{array}$ & $60-80$ & $\begin{array}{l}72,3 \\
59,8\end{array}$ & $\begin{array}{l}165,3 \\
140,3\end{array}$ \\
\hline $\begin{array}{l}\text { Ashendorf et } \\
\text { al. (2008) }\end{array}$ & $55-74$ & $\begin{array}{l}<16 \\
\geq 16\end{array}$ & $\begin{array}{l}33,5 \\
29,0\end{array}$ & $\begin{array}{l}79,0 \\
61,0\end{array}$ & $75-98$ & $\begin{array}{l}42,5 \\
38,5\end{array}$ & $\begin{array}{c}103,0 \\
88,0\end{array}$ \\
\hline
\end{tabular}

Legenda: TMTA: parte A do Trail Making Test; TMTB: parte B do Trail Making

Test.

\subsection{Hipóteses e predições}

Muitos estudos discutiram isoladamente o impacto do envelhecimento e da escolaridade baixa em tarefas cognitivo-motoras. No entanto, poucos estudos discutiram interações entre idade e escolaridade e, dentre os que o fizeram, praticamente todos enfatizaram os aspectos cognitivos, dando menor espaço para os aspectos motores.

O TMT é um teste de domínio público e requer diversas habilidades cognitivo-motoras, como atenção espacial, escaneamento visual, flexibilidade mental, memória operacional e coordenação motora. O TMT é considerado uma das melhores medidas de função executiva e seus aspectos cognitivos têm sido amplamente explorados. 
O componente motor do TMT, no entanto, ora é eliminado por meio do cálculo do delta (parte B - parte A), ora é deixado em segundo plano nas discussões dos trabalhos, uma vez que é dada maior ênfase para a parte B do teste, considerada uma medida mais fiel da função executiva. Acreditávamos que, modificando-se a resposta motora do teste, poderíamos evidenciar outras diferenças e interações entre idade e escolaridade.

Por essa razão, optamos por ampliar o TMT catorze vezes e confeccioná-lo sobre um material antiderrapante, para solicitarmos que os voluntários deambulassem sobre a área do teste e pisassem com os dois pés sobre cada círculo antes de seguirem para o próximo número. Ao exigirmos mudanças de direção, transferência de peso, equilíbrio estático e dinâmico, modificamos o componente motor do teste, que originalmente consiste em riscar traços sobre uma folha de papel, com o membro dominante.

A esta nova versão do TMT com nova resposta motora, demos o nome de Teste de Deambulação Funcional (TDF). Com os dados do TMT e do TDF, seria possível o cálculo de um novo delta, ao qual nomeamos delta motor.

O delta motor consistiria em subtrair o resultado do teste que supúnhamos ter a resposta motora mais simples e, portanto, mais rápida (TMT), do resultado do teste com resposta motora possivelmente mais complexa e, portanto, mais lenta (TDF). O delta motor seria calculado para cada uma das partes do teste: para a parte A: TDFA - TMTA = delta motor A e para a parte B: TDFB - TMTB $=$ delta motor B.

Esperávamos que, quanto maior a idade, maior seria o tempo no TDF em relação ao TMT. Se o TDF fosse concluído em mais tempo, o delta motor 
seria maior. Essa suposição foi feita sabendo-se que o processo de envelhecimento resulta no decréscimo do desempenho de tarefas motoras que requerem sensibilidade vestibular (KOVACS, 2005), sensibilidade proprioceptiva (CHAPMAN e HOLLANDS, 2006), equilíbrio (MELZER et al., 2007; COPPIN et al., 2006; BRAUER, WOOLLACCOT e SHUMWAY-COOK, 2001), mudança de direção (OXLEY et al., 2005; BROMAN et al., 2004; TURANO et al., 2004), transferência de peso (MELZER et al., 2007; MELZER e ODDSSON, 2004), planejamento e seleção de respostas (COPPIN et al., 2006; BLE et al., 2005), adequação da velocidade da marcha (VAN IERSEL et al., 2007; COPPIN et al., 2006; BLE et al., 2005), habilidades que acreditávamos que seriam mais solicitadas pelo TDF do que pelo TMT.

Esperávamos que, quanto menor a escolaridade, maior seria o tempo no TMT, com relação ao TDF. Acreditávamos que a parte motora do TDF, que consistia em deambular de um local a outro e manter o equilíbrio momentaneamente com uma base de apoio reduzida consistiria numa resposta igualmente familiar para indivíduos com escolaridade alta e com escolaridade baixa. Porém, a parte cognitiva de ambos os testes seria mais difícil para indivíduos com escolaridade baixa do que para indivíduos com escolaridade alta. Além disso, a parte cognitiva do TMT seria relativamente mais complexa para indivíduos com escolaridade baixa, por exigir domínio de representações bidimensionais e verbais, que tende a ser menos eficiente nesses indivíduos (NITRINI et al., 2004; REIS et al., 2001; PETERSSON et al., 2001).

Logo, o envelhecimento e a escolaridade baixa teriam efeitos antagônicos sobre o delta motor. Quanto maior a idade, maior seria o tempo no TDF com relação ao tempo no TMT e maior seria o delta motor. Por outro lado, 
quanto menor a escolaridade, maior seria o tempo no TMT com relação ao TDF e menor seria o delta motor.

Sendo assim, acreditávamos que seria particularmente interessante estudar o delta motor de indivíduos idosos e com escolaridade baixa, pois se 0 prejuízo da idade prevalecesse, o delta motor seria alto e se o prejuízo da escolaridade prevalecesse, o delta motor seria baixo. O fenômeno inverso poderia ocorrer para indivíduos jovens com escolaridade alta. Se o benefício da idade prevalecesse, o tempo do TDF tenderia a diminuir com relação ao do TMT e o delta seria baixo. Se o benefício da escolaridade prevalecesse, o tempo do TMT tenderia a diminuir com relação ao TDF e o delta seria alto.

Além do delta motor, tínhamos a intenção de testar hipóteses a respeito dos deltas cognitivos do TDF e do TMT. O delta do TMT tem sido calculado em diversos estudos e tem sido considerado por alguns autores como a principal medida de função executiva do TMT (VAN IERSEL et al., 2007; COPPIN et al., 2006; BLE et al., 2005; LEZÀK, 2004; STUSS et al., 2001; ARBUTHNOTT e FRANK, 2000). Caso não houvesse diferenças significativas entre os deltas cognitivos, calculados por meio da subtração da parte $A$ da parte $B$ de cada teste (TMTB - TMTA e TDFB - TDFA), seria comprovado que, de fato, a dificuldade cognitiva do TDF equivaleria à do TMT.

Por outro lado, caso houvesse alguma diferença entre o delta cognitivo do TDF e o delta cognitivo do TMT, chegaríamos à conclusão de que a mudança de resposta do TMT para o TDF não teria consistido apenas numa modificação da demanda motora, mas numa modificação da demanda cognitiva. Neste caso, se o delta do TMT fosse maior que o do TDF, a 
demanda cognitiva do TMT seria maior que a do TDF; se o delta do TMT fosse menor que o do TDF, a demanda cognitiva do TMT seria menor que a do TDF.

Além disso, acreditávamos que o envelhecimento e a escolaridade baixa prejudicariam o aprendizado de uma tarefa cognitivo-motora, no caso, o TDF. Esperávamos que os piores desempenhos ocorressem para indivíduos idosos. Porém, esperávamos que, com as repetições, as diferenças decorrentes da idade diminuíssem, de acordo com estudos prévios a este respeito (BHERER et al., 2006; MELZER e ODDSSON, 2004). Quanto à escolaridade, baseamonos nos resultados de Neves (2008) e consideramos que, com as repetições, o desempenho poderia apresentar uma melhora menos expressiva para indivíduos com escolaridade baixa. 


\subsection{OBJETIVOS}

\subsection{Objetivo geral}

O presente estudo visou primeiramente desenvolver uma nova versão do Trail Making Test (TMT), à qual demos o nome de Teste de Deambulação Funcional (TDF), que poderia evidenciar alterações cognitivas e motoras relacionadas à idade e escolaridade e interações idade-escolaridade.

\subsection{Objetivos específicos}

Em seguida, tivemos como objetivos testar se haveria diferenças decorrentes da idade e da escolaridade:

(1) na execução das partes A e B do TDF e das partes A e B do TMT;

(2) nos deltas cognitivos do TMT (TMTB - TMTA) e do TDF (TDFB TDFA);

(3) nos deltas motores da parte A (TDFA - TMTA) e da parte B (TDFB - TMTB), dos dois testes conjuntamente;

(4) no aprendizado (aquisição, estabilização e retenção do desempenho) do TDF. 


\subsection{MÉTODOS}

\subsection{Participantes}

Participaram deste estudo 70 voluntários, sendo 24 adultos jovens, entre 20 e 34 anos, 26 adultos maduros, entre 50 e 64 anos e 20 idosos, com idade entre 65 e 79 anos (tabela 2).

A amostra foi constituída por acompanhantes de pacientes dos ambulatórios do Departamento de Fisioterapia, Fonoaudiologia e Terapia Ocupacional da FMUSP, professores e alunos do departamento, integrantes da comunidade USP em geral. Os voluntários foram convidados por meio de cartazes, de um anúncio no jornal da USP e de palestras realizadas em ambulatórios e cursos para a terceira idade, que são oferecidos pela universidade.

Os critérios de inclusão foram escolaridade maior ou igual a seis anos, visão normal ou corrigida por lentes, testada pela tabela de Snellen, para acuidade visual para longe e pela tabela de Jaeger, para acuidade visual para perto (DUARTE et al., 2003).

Os critérios de exclusão foram (1) pontuação abaixo de 26 na versão em português do Mini Exame do Estado Mental (BRUCKI et al., 2003), (2) pontuação abaixo de 50 na Escala de Equilíbrio de Berg (MIYAMOTO et al., 2004), (3) indivíduos com alguma doença cárdio-vascular, respiratória, neurológica, ortopédica, reumatológica ou metabólica (auto-referida), (4) indivíduos que estudaram em supletivo (auto-referido), (5) indivíduos que faltaram à segunda sessão. 
Tabela 2: Características dos indivíduos que participaram do estudo (média \pm desvio-padrão). Uma análise de variância não constatou diferenças de idade entre os subgrupos com alta e baixa escolaridade.

\begin{tabular}{|c|c|c|c|c|c|c|c|}
\hline Grupo & Idade & $\begin{array}{l}\text { Média } \\
\text { de idade }\end{array}$ & Escolaridade & $\begin{array}{l}\text { Média de } \\
\text { escolaridade }\end{array}$ & Sexo & $\begin{array}{l}\text { Média no } \\
\text { MEEM }\end{array}$ & $\begin{array}{l}\text { Média na } \\
\text { EEBB }\end{array}$ \\
\hline \multirow{2}{*}{$\begin{array}{l}\text { Adultos } \\
\text { jovens }\end{array}$} & $20-34$ & $24,6 \pm 3,9$ & Alta & $17,0 \pm 1,4$ & $9+$ e $5 \hat{~}$ & $29,7 \pm 0,5$ & $55,9 \pm 0,5$ \\
\hline & $20-34$ & $25,6 \pm 4,1$ & Baixa & $10,6 \pm 1,0$ & 4 + e 6 ○े & $28,8 \pm 1,3$ & $55,5 \pm 0,5$ \\
\hline \multirow{2}{*}{$\begin{array}{l}\text { Adultos } \\
\text { maduros }\end{array}$} & $50-64$ & $56,6 \pm 5,2$ & Alta & $17,2 \pm 2,2$ & 8 + e $6 \hat{\sigma}$ & $28,4 \pm 1,1$ & $55,7 \pm 0,7$ \\
\hline & $50-64$ & $55,7 \pm 4,8$ & Baixa & $9,3 \pm 1,4$ & 8 + e $4 \hat{\jmath}$ & $27,8 \pm 1,1$ & $55,5 \pm 1,9$ \\
\hline \multirow[t]{2}{*}{ Idosos } & $65-79$ & $71,1 \pm 4,4$ & Alta & $16,6 \pm 2,4$ & 4 ㅇ e $6 \hat{\jmath}$ & $27,9 \pm 0,7$ & $53,9 \pm 2,3$ \\
\hline & $65-79$ & $74,3 \pm 5,8$ & Baixa & $8,1 \pm 1,9$ & 7 e $3 \hat{0}$ & $26,7 \pm 0,7$ & $52,8 \pm 2,2$ \\
\hline
\end{tabular}

Legenda: MEEM: Mini Exame do Estado Mental; EEB: Escala de Equilíbrio de Berg.

O presente estudo foi aprovado pela Comissão de Ética para Análise de Projetos de Pesquisa (CAPPesq) da diretoria clínica do Hospital das Clínicas e da Faculdade de Medicina da Universidade de São Paulo (protocolo 254/08).

\subsection{Local}

A pesquisa foi realizada no Ambulatório de Fisioterapia do Departamento de Fisioterapia, Fonoaudiologia e Terapia Ocupacional da Faculdade de Medicina da Universidade de São Paulo. 


\subsection{Materiais e procedimentos específicos de cada teste}

\subsubsection{Trail Making Test (TMT)}

Foram utilizados mesa, cadeira, lápis e quatro folhas de papel sulfite de tamanho A4 para cada voluntário, com a explicação para a parte A (modelo preenchido pelo examinador), aplicação da parte $A$, explicação da parte $B$ (modelo preenchido pelo examinador) e aplicação da parte B.

Em cada folha de modelo, usada para explicações do examinador ao voluntário sobre a parte $A$ e sobre a parte $B$, havia um retângulo, de $12 \times 7 \mathrm{~cm}$, com oito círculos em seu interior. Os círculos tinham 1,4 cm de diâmetro. $\mathrm{Na}$ parte $A$, os círculos continham um número (de 1 a 8 ) em seu interior. Na parte $\mathrm{B}$, quatro círculos continham números (de 1 a 4) e quatro continham letras (de A a D). Tantos os números quanto as letras tinham $0,7 \mathrm{~cm}$ de altura (Anexo A).

Na parte A do TMT, havia um retângulo de $18 \times 14 \mathrm{~cm}$, com 25 círculos em seu interior. Cada círculo tinha $1,1 \mathrm{~cm}$ de diâmetro. Dentro de cada círculo, havia um número (de 1 a 25), medindo $0,5 \mathrm{~cm}$. Na parte $B$, também havia um retângulo de $18 \times 14 \mathrm{~cm}$. Ao invés de 25, havia 24 círculos em seu interior. Cada círculo tinha $1,1 \mathrm{~cm}$ de diâmetro. Dentro de cada círculo, havia um número (de 1 a 13) ou uma letra (de $A$ a $M$ ), medindo $0,5 \mathrm{~cm}$.

Na parte A foram colocados 25 círculos e na parte B, 24, para minimizar a diferença no comprimento total do trajeto, descrita por Rossini e Karl (1994). Assim como em outro trabalho desenvolvido no Brasil com o TMT, de OliveiraSouza et al. (2000), a letra K foi o elemento eliminado, por não ser muito usada pelos brasileiros. 
O TMT foi aplicado de acordo com as recomendações de Bowie e Harvey (2006). Cada voluntário recebeu a instrução de completar cada parte do TMT o mais rápido possível e procurando não errar. Toda vez que ocorria um erro, o participante era orientado a retornar ao círculo no qual o erro havia se originado e a continuar o teste. O tempo de cada parte foi registrado.

\subsubsection{Teste de Deambulação Funcional (TDF)}

O Teste de Deambulação Funcional também consistiu de duas partes para explicações (modelo das partes A e B) e duas partes para a execução do teste (partes A e B). Ao invés de riscar com o lápis sobre a folha de papel, o trajeto foi realizado com o voluntário deambulando sobre um tatame.

Tanto na parte A, quanto na $B$, foi usado um tatame preto de EVA de 1,96 X 2,52 metros. No tatame havia círculos de cor cinza clara, de $20 \mathrm{~cm}$ de diâmetro. Na parte A, havia 25 números pretos (de 1 a 25), cada um com 10 $\mathrm{cm}$ de altura, sendo um no interior de cada círculo. Na parte B, havia 13 números pretos (de 1 a 13) e 11 letras pretas (de A a M, sem a letra K), com o mesmo tamanho da parte $\mathrm{A}$, sendo um número ou uma letra no interior de cada círculo (Anexo B).

O TDF foi montado com medidas catorze vezes maiores que as utilizadas no TMT, para possibilitar a deambulação entre os círculos. Foram mantidas as posições dos círculos e demais medidas, de forma proporcional.

O tempo foi mensurado com um cronômetro e registrado em segundos. Os erros (pisar no número errado ou ir pela direção errada) foram anotados sob a forma de observações, mas não foram analisados diretamente, já que foram 
penalizados com o tempo, pois, sempre que o voluntário cometia um erro, o examinador avisava e solicitava o retorno ao círculo anterior para continuação do teste (ver Anexo A para maiores detalhes sobre as instruções dadas ao voluntário). Os voluntários podiam optar por usar tênis ou ficar descalços para a realização do teste.

\subsubsection{Ordem de realização dos testes}

Os participantes compareceram duas vezes ao Departamento de Fisioterapia, Fonoaudiologia e Terapia Ocupacional, com intervalo de uma semana. Na primeira sessão, o voluntário preencheu um cadastro com seus dados pessoais, recebeu a explicação sobre a pesquisa e assinou o Termo de Consentimento Livre e Esclarecido, foi submetido aos testes de inclusão. Em seguida, (1) realizou o TDF; (2) realizou o TMT; (3) realizou sete repetições da parte A do TDF; e (4) sete repetições da parte B do TDF. Metade dos voluntários de cada faixa etária realizou a ordem (1) e (2) e metade, (2) e (1). Os itens (3) e (4) foram realizados na mesma ordem por todos os participantes.

Na segunda sessão, os voluntários realizaram (5) mais quatro repetições da parte A e depois (6) quatro repetições da parte B do TDF. Após todos os dados terem sido coletados, foram calculados o delta cognitivo do TMT e do TDF e o delta motor A e B.

O cálculo do delta cognitivo do TMT foi realizado de acordo com estudos prévios (VAN IERSEL et al., 2007; COPPIN et al., 2006; BLE et al., 2005; LEZÀK, 2004; STUSS et al., 2001; ARBUTHNOTT e FRANK, 2000). Esse cálculo visou eliminar o componente motor (tempo necessário para riscar o 
trajeto no papel), que é comum entre as partes $\mathrm{A}$ e $\mathrm{B}$ e manter exclusivamente o componente cognitivo, que reflete a flexibilidade mental do indivíduo, ou seja, o quanto o indivíduo seria capaz de alternar uma seqüência de números e uma de letras.

O delta cognitivo foi calculado subtraindo-se do tempo na parte B o tempo na parte A (TMTB - TMTA). O mesmo cálculo foi feito para o TDF (TDFB TDFA), eliminando-se o componente motor (tempo necessário para deambular de um círculo ao outro, até terminar a seqüência) e evidenciando-se o componente cognitivo.

O delta motor A foi calculado subtraindo-se do tempo na parte A do TDF o tempo na parte A do TMT (TDFA - TMTA). O delta motor B foi calculado subtraindo-se do tempo na parte B do TDF o tempo na parte B do TMT (TDFB - TMTB). O delta motor seria uma medida indireta do quanto o TDF seria mais difícil do que o TMT do ponto de vista motor.

\subsection{Análise estatística}

(1) Para testar a influência da idade e da escolaridade no desempenho nas partes $A$ e $B$ do TMT e do TDF, foi feita uma ANOVA ( $3 \times 2 \times 4)$ que teve como fatores a idade (adulto jovem, adulto maduro e idoso), a escolaridade (alta e baixa) e o tipo de teste (TMTA, TMTB, TDFA e TDFB).

(2) Para testar a influência de idade e de escolaridade no delta cognitivo do TMT e no delta cognitivo do TDF, foi feita uma ANOVA $(3 \times 2 \times 2)$ que 
teve como fatores a idade (adulto jovem, adulto maduro e idoso), a escolaridade (alta e baixa) e o tipo de delta cognitivo (dcTMT e dcTDF).

(3) Para testar a influência de idade e de escolaridade no delta motor do TMT e do TDF foi feita uma ANOVA ( $3 \times 2 \times 2)$ que teve como fatores a idade (adulto jovem, adulto maduro e idoso), a escolaridade (alta e baixa) e o tipo de delta motor ( $d m A$ e dmB).

(4) Para testar o aprendizado no TDF, foi feita uma ANOVA que teve como fatores a idade (adulto jovem, adulto maduro e idoso), a escolaridade e a parte do teste ( $\mathrm{A}$ e B) e como medidas repetidas as doze avaliações do TDF. 


\subsection{RESULTADOS}

\subsection{Influência da idade e da escolaridade no desempenho nas partes A e B do TMT e do TDF}

Os tempos nas partes A e B do TMT e do TDF estão representados na tabela 3 e na figura 1.

Tabela 3: Tempos, em segundos (média \pm desvio-padrão) dos voluntários nas partes A e B do Trail Making Test (TMTA e TMTB) e do Teste de Deambulação Funcional (TDFA e TDFB).

\begin{tabular}{cccccc}
\hline Grupo & Escolaridade & TMTA & TDFA & TMTB & TDFB \\
\hline \multirow{2}{*}{ Adultos jovens } & Alta & $22,5 \pm 3,7$ & $32,8 \pm 5,9$ & $40,7 \pm 8,3$ & $51,4 \pm 12,7$ \\
& Baixa & $30,3 \pm 6,3$ & $42,8 \pm 12,1$ & $59,1 \pm 14,5$ & $68,1 \pm 22,5$ \\
\multirow{3}{*}{ Adultos maduros } & Alta & $33,4 \pm 6,3$ & $48,2 \pm 8,0$ & $65,1 \pm 13,3$ & $77,9 \pm 21,0$ \\
& Baixa & $39,3 \pm 11,8$ & $56,3 \pm 13,0$ & $80,8 \pm 19,0$ & $89,3 \pm 20,9$ \\
\cline { 3 - 5 } Idosos & Alta & $38,8 \pm 4,1$ & $54,8 \pm 10,2$ & $87,1 \pm 10,3$ & $113,4 \pm 17,8$ \\
& Baixa & $71,9 \pm 23,7$ & $93,1 \pm 16,3$ & $173,0 \pm 79,9$ & $171,3 \pm 49,9$ \\
& & & & & \\
\hline
\end{tabular}

Test; TDFA: parte A do Teste de Deambulação Funcional; TDFB: parte B do Teste de Deambulação Funcional.

$\mathrm{Na}$ análise de variância $(3 \times 2 \times 4)$ que teve como fatores a idade (adultos jovens, adultos maduros e idosos), a escolaridade (alta e baixa) e os quatro testes, houve efeito de idade $\left[F_{2,64}=60,26, p<0,001\right]$, de escolaridade $\left[F_{1,64}=37,91, p<0,001\right]$ e de teste $\left[F_{3,192}=147,29, p<0,001\right]$. Houve interação 
idade $X$ escolaridade $\left[F_{2,64}=10,58, p<0,001\right]$, idade $X$ teste $\left[F_{6,192}=17,81\right.$, $p<0,001]$, escolaridade $X$ teste $\left[F_{3,192}=7,90, p<0,001\right]$ e idade $X$ escolaridade $X$ teste $\left[F_{6,192}=2,58, \quad p=0,020\right]$. Após constatação da interação idade $X$ escolaridade $\mathrm{X}$ teste, foi feito o teste post hoc de Tukey (cujos resultados estão representados nas tabelas 4,5 e 6 ).

Tabela 4: Valores de $\mathrm{p}$ obtidos no teste post hoc de Tukey para as comparações entre os tempos de realização de cada tarefa nas diferentes idades. Resultados significativos estão indicados com um asterisco.

\begin{tabular}{|c|c|c|c|c|c|c|c|c|}
\hline & \multicolumn{2}{|c|}{$\begin{array}{c}\text { Parte A do TMT } \\
\text { (TMTA) }\end{array}$} & \multicolumn{2}{|c|}{$\begin{array}{c}\text { Parte A do TDF } \\
\text { (TDFA) }\end{array}$} & \multicolumn{2}{|c|}{$\begin{array}{c}\text { Parte B do TMT } \\
\text { (TMTB) }\end{array}$} & \multicolumn{2}{|c|}{$\begin{array}{l}\text { Parte } \mathrm{B} \text { do TDF } \\
\text { (TDFB) }\end{array}$} \\
\hline & EA & EB & EA & EB & EA & EB & EA & EB \\
\hline AJ X AM & 0,999 & 0,999 & 0,980 & 0,999 & 0,367 & 0,828 & 0,209 & 0,858 \\
\hline AJ X ID & 0,987 & $0,007^{*}$ & 0,759 & $0,001^{*}$ & $0,001^{*}$ & $0,001^{*}$ & $0,001^{*}$ & $0,001^{*}$ \\
\hline AM X ID & 0,999 & 0,098 & 0,999 & $0,023^{*}$ & 0,758 & $0,001^{*}$ & $0,024^{*}$ & $0,001^{*}$ \\
\hline
\end{tabular}

Legenda: TMT: Trail Making Test, TDF: Teste de Deambulação Funcional; AJ: adultos jovens; AM: adultos maduros; ID: idosos; EA: escolaridade alta; EB: escolaridade baixa.

Não houve diferenças de desempenho na parte A do TMT decorrentes da idade entre os indivíduos com escolaridade alta. Entre os indivíduos com escolaridade baixa, os idosos foram mais lentos que os jovens na parte $A$ do TMT $(p=0,007)$.

Na parte B do TMT, entre os indivíduos com escolaridade alta, os idosos foram mais lentos que os jovens $(p=0,001)$. Entre os indivíduos com 
escolaridade baixa, os idosos foram mais lentos que os adultos jovens e maduros ( $p=0,001$ para ambas as comparações).

$\mathrm{Na}$ parte $\mathrm{A}$ do TDF, não houve diferença de desempenho entre indivíduos com escolaridade alta. Entre indivíduos com escolaridade baixa, os idosos foram mais lentos que os adultos jovens $(p=0,001)$ e maduros $(p=0,023)$.

Na parte B do TDF, entre indivíduos com escolaridade alta, os idosos foram mais lentos que os adultos jovens $(p=0,001)$ e maduros $(p=0,024)$. Entre indivíduos com escolaridade baixa, os idosos também foram mais lentos que os adultos jovens $(p=0,001)$ e maduros $(p=0,001)$.

Tabela 5: Valores de $\mathrm{p}$ obtidos no teste post hoc de Tukey para as comparações entre os tempos de realização da tarefa nas duas escolaridades. Resultados significativos estão indicados com um asterisco.

\begin{tabular}{|c|c|c|c|c|}
\hline Griunn & $\begin{array}{c}\text { Parte A do TMT } \\
\text { (TMTA) }\end{array}$ & $\begin{array}{c}\text { Parte A do TDF } \\
\text { (TDFA) }\end{array}$ & $\begin{array}{c}\text { Parte B do TMT } \\
\text { (TMTB) }\end{array}$ & $\begin{array}{c}\text { Parte B do TDF } \\
\text { (TDFB) }\end{array}$ \\
\hline & $\mathrm{EA} \times \mathrm{EB}$ & $\mathrm{EA} \times \mathrm{EB}$ & EA X EB & $\mathrm{EA} \times \mathrm{EB}$ \\
\hline Adultos Jovens & 0,999 & 0,999 & 0,949 & 0,983 \\
\hline Adultos Maduros & 0,999 & 0,999 & 0,984 & 0,999 \\
\hline Idosos & 0,131 & $0,024^{*}$ & $0,001^{*}$ & $0,001^{*}$ \\
\hline
\end{tabular}

Legenda: TMT: Trail Making Test; TDF: Teste de Deambulação Funcional; EA: escolaridade alta; EB: escolaridade baixa. 
Com relação às diferenças de escolaridade, idosos com escolaridade baixa foram mais lentos que idosos com escolaridade alta no TDFA, TDFB e TMTB $(p=0,024$ para TDFA e $p=0,001$ para TDFB e TMTB).

Tabela 6: Valores de $\mathrm{p}$ obtidos no teste post hoc de Tukey para comparações entre os tempos de realização da tarefa em cada um dos testes. Resultados significativos estão indicados com um asterisco.

\begin{tabular}{lcccccc}
\hline & \multicolumn{2}{c}{ Adultos Jovens } & \multicolumn{2}{c}{ Adultos maduros } & \multicolumn{2}{c}{ Idosos } \\
\cline { 2 - 7 } & EA & EB & EA & EB & EA & EB \\
TMTA X TDFA & 0,993 & 0,990 & 0,739 & 0,610 & 0,867 & 0,343 \\
TMTB X TDFB & 0,989 & 0,999 & 0,915 & 0,999 & $\mathbf{0 , 0 5 0 *}$ & 0,999 \\
\hline Legenda: TMTA: & \multicolumn{3}{c}{ parte A do Trail Making Test, TMTB: parte B do Trail Making }
\end{tabular}

Test, TDFA: parte A do Teste de Deambulação Funcional, TDFB: parte B do Teste de Deambulação Funcional, EA: escolaridade alta, EB: escolaridade baixa.

Com relação às diferenças do teste, os idosos com escolaridade alta foram mais lentos no TDFB do que no TMTB $(p=0,050)$.

Todos estes resultados estão representados na figura 1, a seguir. 
Variações decorrentes da idade e da escolaridade no desempenho no Teste de Deambulação Funcional e no Trail Making Test
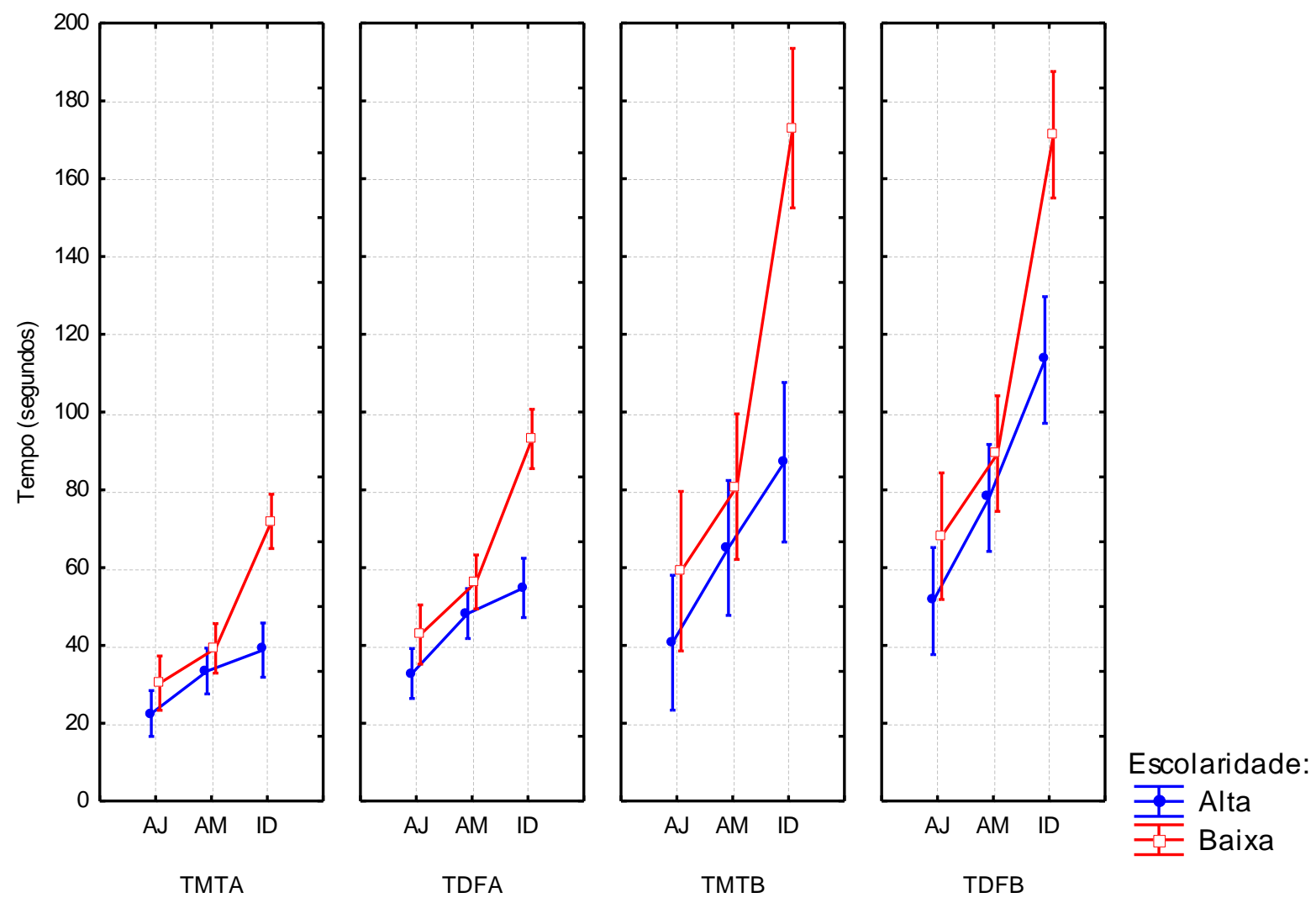

Figura 1: Tempo, em segundos (média \pm desvio-padrão) para realização do Trail Making Test e o Teste de Deambulação Funcional. Legenda: TMTA: parte A do Trail Making Test; TMTB: parte B do Trail Making Test; TDFA: parte A do Teste de Deambulação Funcional; TDFB: parte B do Teste de Deambulação Funcional; AJ: adultos jovens; AM: adultos maduros; ID: idosos. Os idosos com escolaridade alta apresentaram tempo significativamente mais alto no TDFB em relação ao TMTB. Essa diferença não foi evidente para idosos com escolaridade baixa. A piora do desempenho dos idosos com relação aos adultos maduros é mais acentuada para indivíduos com escolaridade baixa, sobretudo na parte B do TMT e do TDF. 


\subsection{Influência da idade e da escolaridade no delta cognitivo do TMT e do TDF}

O delta cognitivo do TMT foi calculado subtraindo-se do tempo na parte B o tempo na parte A (TMTB - TMTA). O mesmo foi feito para calcular o delta cognitivo do TDF (TDFB - TDFA). Na tabela 7 estão apresentados os resultados dos deltas cognitivos do TMT e do TDF.

Tabela 7: Deltas cognitivos do Trail Making Test (TMTB - TMTA) e do Teste de Deambulação Funcional (TDFB - TDFA) (média \pm desvio-padrão).

\begin{tabular}{cccc}
\hline Grupo & Escolaridade & Delta Cognitivo TMT & Delta Cognitivo TDF \\
\hline Adultos jovens & Alta & $18,2 \pm 7,0$ & $18,6 \pm 11,3$ \\
& Baixa & $28,8 \pm 10,2$ & $25,3 \pm 18,7$ \\
\multirow{2}{*}{ Adultos maduros } & Alta & $31,6 \pm 11,2$ & $29,7 \pm 20,3$ \\
& Baixa & $41,6 \pm 13,3$ & $33,0 \pm 14,3$ \\
\multirow{2}{*}{ Idosos } & Alta & $48,3 \pm 12,6$ & $58,6 \pm 23,8$ \\
& Baixa & $101,1 \pm 59,0$ & $78,2 \pm 48,9$ \\
\hline
\end{tabular}

Cognitivo TDF: Delta Cognitivo do Teste de Deambulação Funcional.

$\mathrm{Na}$ análise de variância $(3 \times 2 \times 2)$, que teve como fatores a idade (adultos jovens, adultos maduros e idosos), a escolaridade (alta e baixa) e os deltas cognitivos do TMT e do TDF (dcTMT e dcTDF), houve efeito de idade $\left[F_{2,64}=26,43, \quad p<0,001\right]$, de escolaridade $\left[F_{1,64}=9,58, \quad p=0,003\right]$ e de delta $\left[F_{1,64}=4,20, p=0,044\right]$. Não houve interação idade $X$ escolaridade $\left[F_{2,64}=2,79\right.$, 
$p=0,069]$, nem interação idade $X$ delta $\left[F_{2,64}=0,45, p=0,636\right]$, mas houve interação escolaridade $X$ delta $\left[F_{1,64}=11,75, p=0,001\right]$. Houve interação idade $X$ escolaridade $X$ delta $\left[F_{2,64}=4,48, p=0,015\right]$. Após constatação da interação idade $\mathrm{X}$ escolaridade $\mathrm{X}$ delta, foi feito o teste post hoc de Tukey.

Não houve diferença significativa entre o dcTMT de adultos jovens, adultos maduros e idosos com escolaridade alta. O dcTMT de idosos com escolaridade baixa foi maior que o dcTMT de adultos jovens $(p=0,001)$ e de adultos maduros de mesma escolaridade $(p=0,001)$.

O dcTDF dos idosos com escolaridade alta foi maior que o dcTDF dos jovens de mesma escolaridade $(p=0,009)$. O dcTDF de idosos com escolaridade baixa foi maior que o dcTDF de adultos jovens $(p<0,001)$ e de adultos maduros de mesma escolaridade $(p=0,003)$ (tabela 8$)$.

Tabela 8: Valores de $\mathrm{p}$ obtidos no teste post hoc de Tukey para as comparações entre os deltas cognitivos do Trail Making Test (dcTMT) e do Teste de Deambulação Funcional (dcTDF) nas diferentes idades.

\begin{tabular}{rcc|cccc}
\hline & \multicolumn{2}{c}{ AJ X AM } & \multicolumn{2}{c}{ AJ X ID } & \multicolumn{2}{c}{ AM X ID } \\
\cline { 2 - 7 } & EA & EB & EA & EB & EA & EB \\
dcTMT & 0,949 & 0,986 & 0,139 & $\mathbf{0 , 0 0 1 ^ { * }}$ & 0,889 & $\mathbf{0 , 0 0 1 ^ { * }}$ \\
dcTDF & 0,988 & 0,999 & $\mathbf{0 , 0 0 9 ^ { * }}$ & $\mathbf{0 , 0 0 1 ^ { * }}$ & 0,182 & $\mathbf{0 , 0 0 3 ^ { * }}$ \\
\hline
\end{tabular}

Legenda: AJ: adultos jovens; AM: adultos maduros; ID: idosos; dcTMT: delta cognitivo do Trail Making Test; dcTDF: delta cognitivo do Teste de Deambulação Funcional. 
O dcTMT de idosos com escolaridade baixa foi maior que o dcTMT de idosos com escolaridade alta $(p<0,001)$. Essa diferença não foi verificada para o dcTDF. O dcTMT foi maior que o dcTDF para os idosos com escolaridade baixa $(p=0,006)$. Todos esses resultados estão representados na figura 2 .

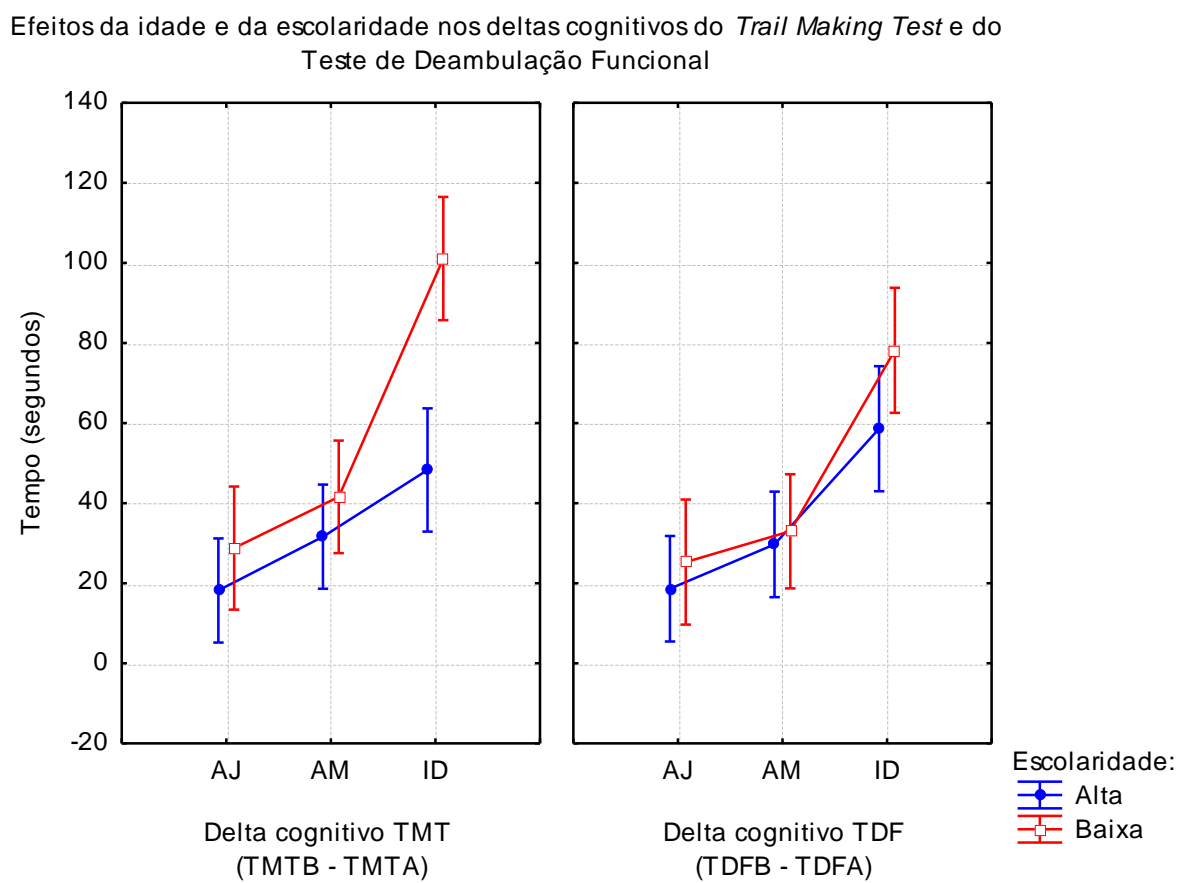

Figura 2: Deltas cognitivos do Trail Making Test e do Teste de Deambulação Funcional em função da idade e da escolaridade. Legenda: TMTA: parte A do Trail Making Test; TMTB: parte B do Trail Making Test; TDFA: parte A do Teste de Deambulação Funcional; TDFB: parte B do Teste de Deambulação Funcional; AJ: adultos jovens; AM: adultos maduros; ID: idosos. Os deltas cognitivos do TMT e do TDF de idosos com escolaridade baixa foram maiores que os deltas cognitivos do TMT e do TDF de adultos jovens e maduros de mesma escolaridade. O dcTDF dos idosos com escolaridade alta foi maior que o dcTDF de jovens de mesma escolaridade. O dcTMT de idosos com escolaridade baixa foi maior que o dcTMT de idosos com escolaridade alta. $O$ dcTMT foi maior que o dcTDF para os idosos com escolaridade baixa. 


\subsection{Influência da idade e da escolaridade no delta motor do TMT e do TDF}

O delta motor foi calculado subtraindo-se do tempo na parte A do TDF o tempo na parte A do TMT (TDFA - TMTA). O mesmo foi realizado para a parte B (TDFB - TMTB). Os valores obtidos estão apresentados na tabela 9.

Tabela 9: Deltas motores da parte A (TDFA - TMTA) e da parte B (TDFB TMTB) (média \pm desvio-padrão).

\begin{tabular}{cccc}
\hline Grupo & Escolaridade & Delta Motor A & Delta Motor B \\
\hline Adultos jovens & Alta & $10,3 \pm 5,4$ & $10,7 \pm 12,5$ \\
& Baixa & $12,5 \pm 7,5$ & $9,0 \pm 18,5$ \\
Adultos maduros & Alta & $14,8 \pm 8,3$ & $12,8 \pm 14,1$ \\
& Baixa & $17,1 \pm 7,7$ & $8,5 \pm 14,5$ \\
\hline \multirow{2}{*}{ Idosos } & Alta & $16,0 \pm 7,7$ & $26,3 \pm 14,5$ \\
& Baixa & $21,2 \pm 22,3$ & $-1,7 \pm 37,5$ \\
\hline
\end{tabular}

$\mathrm{Na}$ análise de variância $(3 \times 2 \times 2)$, que teve como fatores a idade (adultos jovens, adultos maduros e idosos), a escolaridade (alta e baixa) e os dois deltas motores (dmA e dmB), não houve efeito de idade $\left[F_{2,64}=0,73\right.$, $p=0,483]$, nem de escolaridade $\left[F_{1,64}=1,63, p=0,206\right]$, mas houve efeito de delta $\left[F_{1,64}=4,20, p=0,044\right]$. Não houve interação idade $X$ escolaridade $\left[F_{2,64}=1,25\right.$, $p=0,292]$, nem interação idade $X$ delta $\left[F_{2,64}=0,45, p=0,636\right]$, mas houve interação escolaridade $X$ delta $\left[F_{1,64}=11,78, p=0,001\right]$. Houve interação idade $X$ 


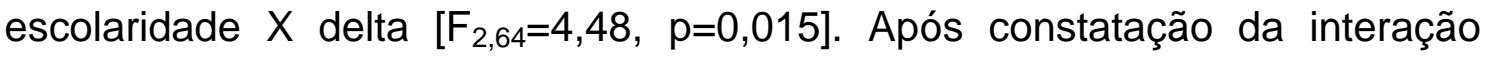
idade $\mathrm{X}$ escolaridade $\mathrm{X}$ delta, foi feito o teste post hoc de Tukey.

Não houve nenhum resultado significativo com relação às comparações de idade. $\mathrm{O}$ delta motor $\mathrm{B}$ de idosos com escolaridade baixa foi menor que $\mathrm{O}$ delta motor $B$ de idosos com escolaridade alta $(p=0,007)$. O delta motor $B$ foi menor que $o$ delta motor $A$ para idosos com escolaridade baixa $(p=0,006)$. Todos esses resultados estão representados na figura 3, a seguir.

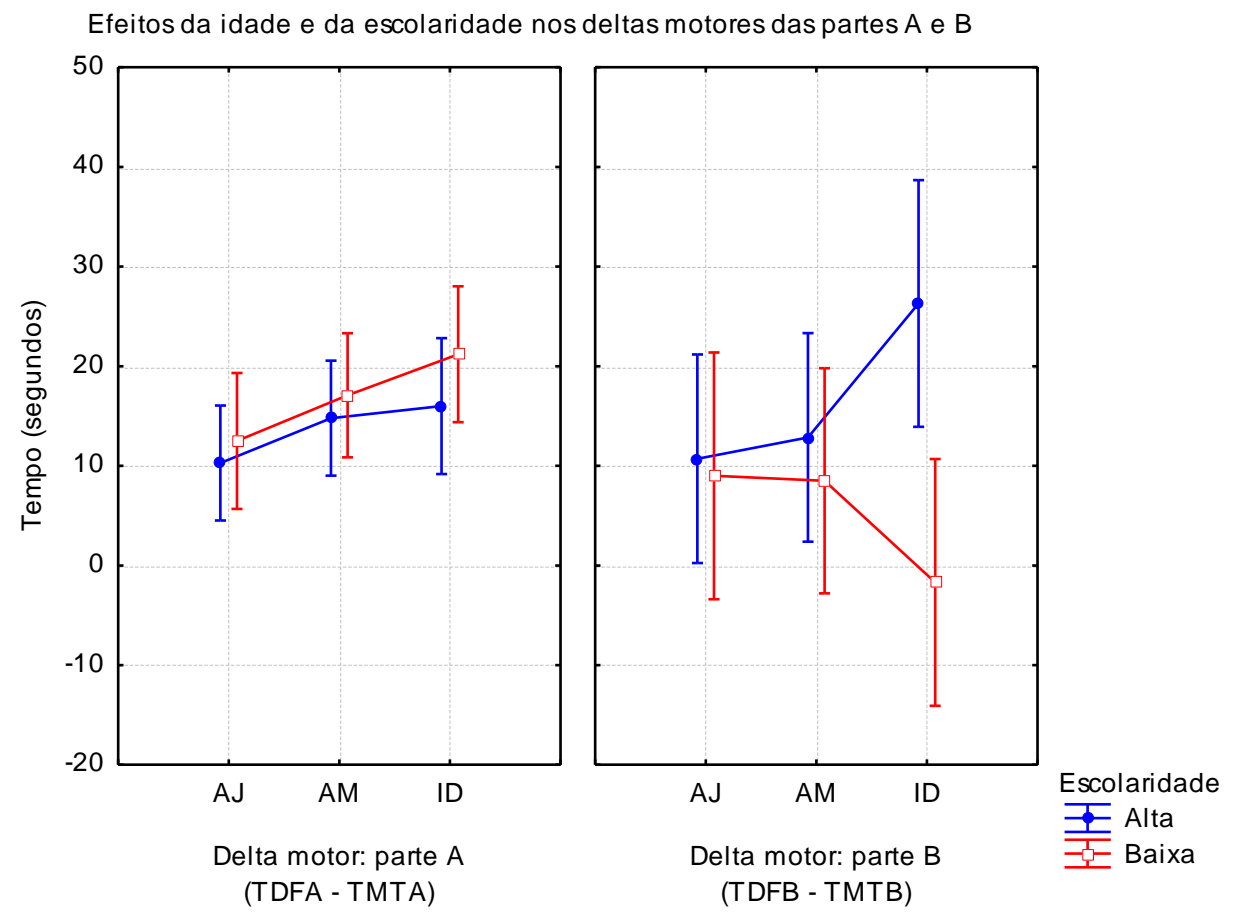

Figura 3: Deltas motores das partes A e B (TDFA - TMTA e TDFB - TMTB) (média \pm desvio-padrão) em função da idade e da escolaridade. Legenda: TMTA: parte A do Trail Making Test; TMTB: parte B do Trail Making Test; TDFA: parte A do Teste de Deambulação Funcional; TDFB: parte B do Teste de Deambulação Funcional; AJ: adultos jovens; AM: adultos maduros; ID: idosos. O delta motor $\mathrm{B}$ de idosos com escolaridade baixa foi menor que $\mathrm{O}$ 
delta motor $\mathrm{B}$ de idosos com escolaridade alta. $\mathrm{O}$ delta motor $\mathrm{B}$ foi menor que $\mathrm{O}$ delta motor A para idosos com escolaridade baixa.

\subsection{Influência da idade e da escolaridade no aprendizado de cada uma das partes do TDF}

Os resultados das doze avaliações estão representados na tabelas 10 (parte A do TDF) e 11 (parte B do TDF).

Tabela 10: Tempo (em segundos) nas doze avaliações da parte A do TDF.

\begin{tabular}{|c|c|c|c|c|c|c|c|c|c|c|c|c|c|}
\hline \multicolumn{2}{|c|}{ Avaliação } & 1 & 2 & 3 & 4 & 5 & 6 & 7 & 8 & 9 & 10 & 11 & 12 \\
\hline \multirow[t]{2}{*}{$\mathrm{AJ}(\mathrm{A})$} & $\mathbf{m}$ & 32,8 & 28,2 & 25,8 & 24,1 & 23,5 & 22,2 & 21,3 & 20,7 & 23,9 & 21,9 & 21,3 & 20,4 \\
\hline & $d p$ & 5,9 & 4,2 & 4,3 & 3,9 & 3,8 & 3,1 & 3,0 & 3,1 & 2,6 & 2,3 & 3,8 & 2,6 \\
\hline \multirow[t]{2}{*}{$\mathrm{AJ}(\mathrm{B})$} & $\mathbf{m}$ & 42,8 & 36,8 & 32,4 & 29,9 & 28,9 & 27,1 & 26,2 & 25,4 & 27,1 & 24,7 & 24,0 & 24,0 \\
\hline & dp & 12,1 & 8,0 & 6,4 & 5,3 & 5,6 & 6,0 & 4,4 & 4,6 & 6,8 & 5,5 & 6,0 & 5,6 \\
\hline \multirow[t]{2}{*}{$\mathrm{AM}(\mathrm{A})$} & $\mathbf{m}$ & 48,2 & 37,9 & 34,5 & 34,0 & 31,9 & 31,8 & 30,9 & 30,6 & 34,9 & 30,9 & 30,6 & 29,9 \\
\hline & $d p$ & 8,0 & 6,3 & 5,8 & 6,9 & 6,4 & 7,4 & 5,7 & 5,4 & 7,7 & 6,2 & 5,3 & 5,1 \\
\hline \multirow[t]{2}{*}{ AM(B) } & $\mathbf{m}$ & 56,3 & 42,3 & 38,2 & 34,5 & 33,4 & 32,6 & 30,3 & 29,7 & 31,8 & 30,6 & 29,5 & 29,7 \\
\hline & $d p$ & 13,0 & 11,4 & 9,1 & 9,5 & 8,1 & 8,6 & 7,0 & 6,2 & 6,9 & 6,2 & 5,3 & 6,2 \\
\hline \multirow[t]{2}{*}{$\operatorname{ID}(A)$} & $\mathbf{m}$ & 54,8 & 45,6 & 46,3 & 41,9 & 38,6 & 39,9 & 38,5 & 37,2 & 42,2 & 37,1 & 35,0 & 34,8 \\
\hline & $d p$ & 10,2 & 13,2 & 9,4 & 7,0 & 8,6 & 8,6 & 7,5 & 6,8 & 6,7 & 5,7 & 5,8 & 4,8 \\
\hline \multirow[t]{2}{*}{ ID(B) } & $\mathbf{m}$ & 93,1 & 71,0 & 61,6 & 56,8 & 54,4 & 55,2 & 50,2 & 50,0 & 57,8 & 51,3 & 47,9 & 46,4 \\
\hline & dp & 16,3 & 18,5 & 21,4 & 19,0 & 12,3 & 17,2 & 15,4 & 14,0 & 14,9 & 12,3 & 13,9 & 13,7 \\
\hline
\end{tabular}

Legenda: $A J(A)$ : adultos jovens com escolaridade alta; $A J(B)$ : adultos jovens com escolaridade baixa; $\operatorname{AM}(A)$ : adultos maduros com escolaridade alta; $A M(B)$ : adultos maduros com escolaridade baixa; $I D(A)$ : idosos com escolaridade alta; $I D(B)$ : idosos com escolaridade baixa; m: média; dp: desviopadrão. 
Tabela 11: Tempo (em segundos) nas doze avaliações da parte B do TDF.

\begin{tabular}{|c|c|c|c|c|c|c|c|c|c|c|c|c|c|}
\hline \multicolumn{2}{|c|}{ Avaliação } & 1 & 2 & 3 & 4 & 5 & 6 & 7 & 8 & 9 & 10 & 11 & 12 \\
\hline \multirow[t]{2}{*}{$\mathrm{AJ}(\mathrm{A})$} & $\mathbf{m}$ & 51,4 & 39,1 & 35,9 & 33,4 & 30,9 & 26,8 & 25,9 & 25,0 & 31,8 & 25,5 & 23,5 & 23,5 \\
\hline & dp & 12,7 & 9,6 & 7,3 & 7,7 & 5,0 & 4,7 & 4,0 & 4,2 & 7,6 & 4,9 & 3,5 & 4,2 \\
\hline \multirow[t]{2}{*}{$\mathrm{AJ}(\mathrm{B})$} & m & 68,1 & 61,9 & 53,6 & 47,4 & 42,0 & 37,5 & 34,7 & 34,6 & 37,1 & 31,1 & 29,7 & 28,7 \\
\hline & $d p$ & 22,5 & 28,3 & 22,6 & 19,8 & 18,9 & 14,3 & 9,3 & 13,0 & 11,5 & 9,5 & 9,1 & 8,2 \\
\hline \multirow[t]{2}{*}{$\mathrm{AM}(\mathrm{A})$} & m & 77,9 & 66,1 & 56,8 & 53,5 & 50,1 & 48,0 & 47,9 & 45,7 & 51,9 & 44,7 & 43,1 & 42,0 \\
\hline & $d p$ & 21,0 & 20,2 & 17,7 & 14,1 & 13,3 & 13,0 & 14,3 & 12,5 & 14,3 & 9,5 & 12,6 & 10,6 \\
\hline \multirow[t]{2}{*}{ AM(B) } & m & 89,3 & 75,8 & 64,9 & 63,2 & 53,4 & 50,3 & 44,8 & 43,1 & 51,8 & 42,2 & 37,0 & 38,0 \\
\hline & $d p$ & 20,9 & 17,2 & 15,5 & 22,9 & 16,0 & 16,3 & 11,6 & 14,0 & 13,7 & 8,1 & 8,4 & 8,1 \\
\hline \multirow[t]{2}{*}{$\mathrm{ID}(\mathbf{A})$} & m & 113,4 & 89,1 & 74,2 & 62,7 & 59,6 & 50,0 & 52,3 & 51,1 & 65,1 & 50,5 & 50,4 & 50,8 \\
\hline & $d p$ & 17,8 & 15,7 & 15,2 & 13,3 & 15,3 & 8,4 & 9,8 & 11,6 & 15,9 & 8,9 & 12,6 & 12,6 \\
\hline \multirow[t]{2}{*}{ ID(B) } & $\mathbf{m}$ & 171,3 & 156,2 & 138,4 & 135,1 & 121,9 & 111,7 & 109,5 & 92,6 & 134,1 & 105,5 & 97,3 & 89,5 \\
\hline & $d p$ & 49,9 & 47,1 & 41,2 & 40,2 & 29,8 & 36,4 & 40,8 & 30,4 & 36,1 & 30,0 & 27,6 & 31,4 \\
\hline
\end{tabular}

Legenda: $A J(A)$ : adultos jovens com escolaridade alta; $A J(B)$ : adultos jovens com escolaridade baixa; $\operatorname{AM}(A)$ : adultos maduros com escolaridade alta; $A M(B)$ : adultos maduros com escolaridade baixa; ID $(A)$ : idosos com escolaridade alta; $I D(B)$ : idosos com escolaridade baixa; m: média; dp: desviopadrão.

$\mathrm{Na}$ análise de variância ( $3 \times 2 \times 2 \times 12)$, que teve como fatores a idade (adultos jovens, adultos maduros e idosos), a escolaridade (alta e baixa) e a parte do TDF (parte A e parte B) e como medidas repetidas as doze repetições do TDF, houve efeito de idade $\left[F_{2,64}=91,31 ; p<0,001\right]$, de escolaridade 
$\left[F_{1,64}=44,11 ; \quad p<0,001\right]$, de teste $\left[F_{1,64}=186,84 ; \quad p<0,001\right]$, de avaliação $\left[F_{11,704}=207,15 ; p<0,001\right]$.

Houve interação idade $X$ escolaridade $\left[F_{2,64}=20,42 ; p<0,001\right]$, idade $X$ parte do teste $\left[F_{2,64}=29,48 ; \quad p<0,001\right]$, escolaridade $X$ parte do teste [ $\left.F_{1,64}=20,18 ; p<0,001\right]$, idade $X$ avaliação $\left[F_{22,704}=10,12 ; p<0,001\right]$, escolaridade $X$ avaliação $\left[F_{11,704}=10,26 ; p<0,001\right]$, parte do teste $X$ avaliação $\left[F_{11,704}=41,66\right.$; $p<0,001]$.

Houve interação idade $X$ escolaridade $X$ parte do teste $\left[F_{2,64}=11,77\right.$; $p<0,001]$, escolaridade $X$ avaliação $X$ parte do teste $\left[F_{11,704}=3,78 ; p<0,001\right]$, idade $X$ avaliação $X$ parte do teste $\left[F_{22,704}=3,30 ; p<0,001\right]$. Não houve interação idade $X$ escolaridade $X$ avaliação $\left[F_{22,704}=1,17 ; p=0,271\right]$.

Houve interação idade $X$ escolaridade $X$ avaliação $X$ parte do teste $\left[\mathrm{F}_{22,704}=1,64 ; \mathrm{p}=0,033\right]$. Os resultados do teste post hoc de Tukey estão na tabela 12 (Anexo D).

\subsubsection{Diferenças entre as avaliações}

Para adultos jovens com escolaridade alta, não houve diferenças significativas entre as avaliações 1 a 12 no desempenho da parte A do TDF. Na parte $B$, os tempos nas avaliações 3 a 12 foram menores que os tempos na avaliação 1 e os tempos nas avaliações 8, 10, 11 e 12 foram menores do que 0 tempo na avaliação 2.

Para adultos jovens com escolaridade baixa, as avaliações $6,7,8,10$, 11 e 12 apresentaram tempos menores do que a avaliação 1 no desempenho 
da parte $A$ do TDF. Na parte $B$, os tempos nas avaliações 4 a 12 foram menores do que na avaliação 1, os tempos nas avaliações 5 a 12 foram menores do que na avaliação 2, os tempos nas avaliações 6 a 12 foram menores do que na avaliação 3 e os tempos nas avaliações 10 a 12 foram menores do que na avaliação 4 .

Para adultos maduros com escolaridade alta, os tempos nas avaliações 3 a 12 foram menores do que o tempo na avaliação 1 na parte $\mathrm{A}$ do TDF. Na parte $B$, os tempos nas avaliações 3 a 12 foram menores do que na avaliação 1, os tempos nas avaliações 5 a 12 foram menores do que na avaliação 2 e os tempos nas avaliações 11 e 12 foram menores do que na avaliação 3.

Para adultos maduros com escolaridade baixa, os tempos nas avaliações 3 a 12 foram menores do que o tempo na avaliação 1 na parte A do TDF. Na parte B, os tempos nas avaliações 3 a 12 foram menores do que na avaliação 1, os tempos nas avaliações 5 a 12 foram menores do que na avaliação 2, os tempos nas avaliações $6,7,8,10,11$ e 12 foram menores do que na avaliação 3, os tempos nas avaliações 7, 8, 10, 11 e 12 foram menores do que na avaliação 4, os tempos nas avaliações 11 e 12 foram menores do que na avaliação 5 e o tempo na avaliação 11 foi menor do que na avaliação 9.

Para idosos com escolaridade alta, os tempos nas avaliações 5, 7, 8, 10, 11 e 12 foram menores do que na avaliação 1 na parte A do TDF. Na parte B, os tempos nas avaliações 2 a 12 foram menores que na avaliação 1, os tempos nas avaliações 4 a 12 foram menores do que na avaliação 2 e os tempos nas avaliações $6,7,8,10,11$ e 12 foram menores do que na avaliação 3. 
Para idosos com escolaridade baixa, os tempos nas avaliações 2 a 12 foram menores do que o tempo na avaliação 1 e os tempos nas avaliações 5 , $6,7,8,10,11$ e 12 foram menores do que o tempo na avaliação 2, na parte $A$ do TDF. Na parte B, os tempos nas avaliações 3 a 12 foram menores do que nas avaliações 1 e 2, os tempos nas avaliações $6,7,8,10,11$ e 12 foram menores do que nas avaliações 3 e 4, os tempos nas avaliações 8, 10, 11 e 12 foram menores do que na avaliação 5 , os tempos nas avaliações 8 e 12 foram menores do que na avaliação 6, os tempos nas avaliações 6, 8, 10, 11 e 12 foram menores do que o tempo na avaliação 9 e o tempo na avaliação 12 foi menor do que o tempo na avaliação 10 .

Esses resultados estão representados nas figuras 4, 5 e 6 .

\subsubsection{Diferenças decorrentes da idade}

Não houve diferença entre o desempenho de adultos jovens e adultos maduros com escolaridade alta nas partes A e B do TDF. Embora também não tenha havido diferença entre adultos jovens e idosos com escolaridade alta na parte $A$, os idosos foram mais lentos do que os adultos jovens nas avaliações 1, 2, 3 e 9 da parte B do TDF. Comparando-se adultos maduros e idosos com escolaridade alta, não houve diferença no desempenho na parte A do TDF e os idosos foram mais lentos que os adultos maduros na avaliação 1 da parte B.

Não houve diferença entre o desempenho de adultos jovens e adultos maduros com escolaridade baixa nas partes A e B do TDF. Os idosos foram mais lentos que os adultos jovens com escolaridade baixa nas avaliações 1 e 2 na parte $\mathrm{A}$ e em todas as avaliações na parte B. Os idosos foram mais lentos 
que os adultos maduros com escolaridade baixa na avaliação 1 da parte A do TDF e em todas as avaliações da parte B.

Esses resultados estão representados nas figuras 4, 5 e 6 .

\subsubsection{Diferenças decorrentes da escolaridade}

Os adultos jovens com escolaridade baixa não diferiram dos com escolaridade alta nem na parte A, nem na parte B do TDF. O mesmo ocorreu para os adultos maduros. Os idosos com escolaridade baixa foram mais lentos que os com escolaridade alta na avaliação 1 da parte A do TDF e em todas as avaliações da parte B do TDF.

Esses resultados estão representados nas figuras 4,5 e 6 . 

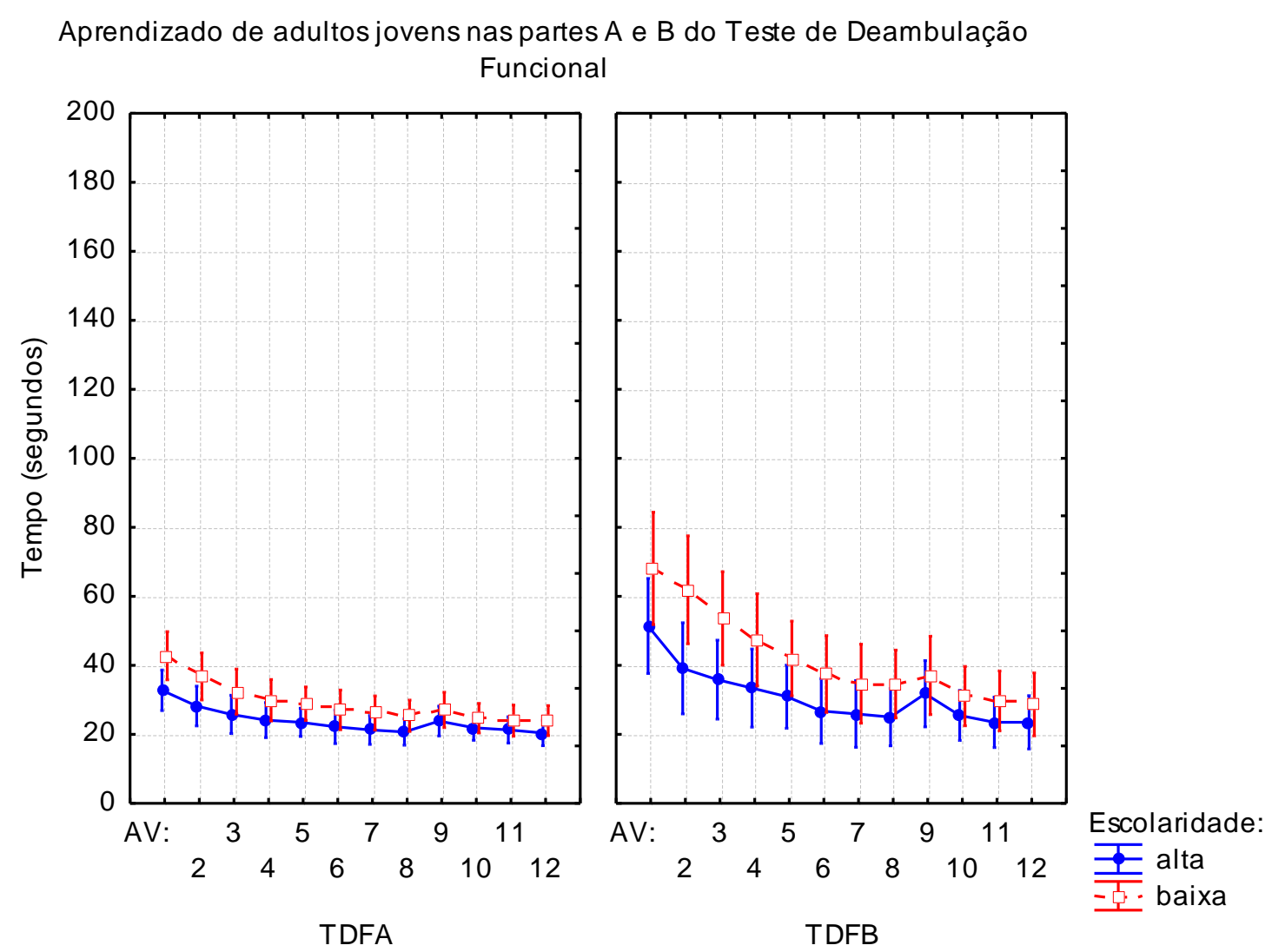

Figura 4: Tempo, em segundos (média \pm desvio-padrão) para realização do Teste de Deambulação Funcional em função da escolaridade e da parte do teste no aprendizado ao longo das 12 avaliações realizadas nos voluntários adultos jovens. Houve interação idade $X$ escolaridade $X$ avaliação $X$ parte do teste $\left[F_{22,704}=1,64 ; p=0,033\right]$. Os adultos jovens com escolaridade baixa não diferiram dos com escolaridade alta nem na parte A, nem na parte B do TDF. Legenda: TDFA: parte A do Teste de Deambulação Funcional; TDFB: parte B do Teste de Deambulação Funcional. 

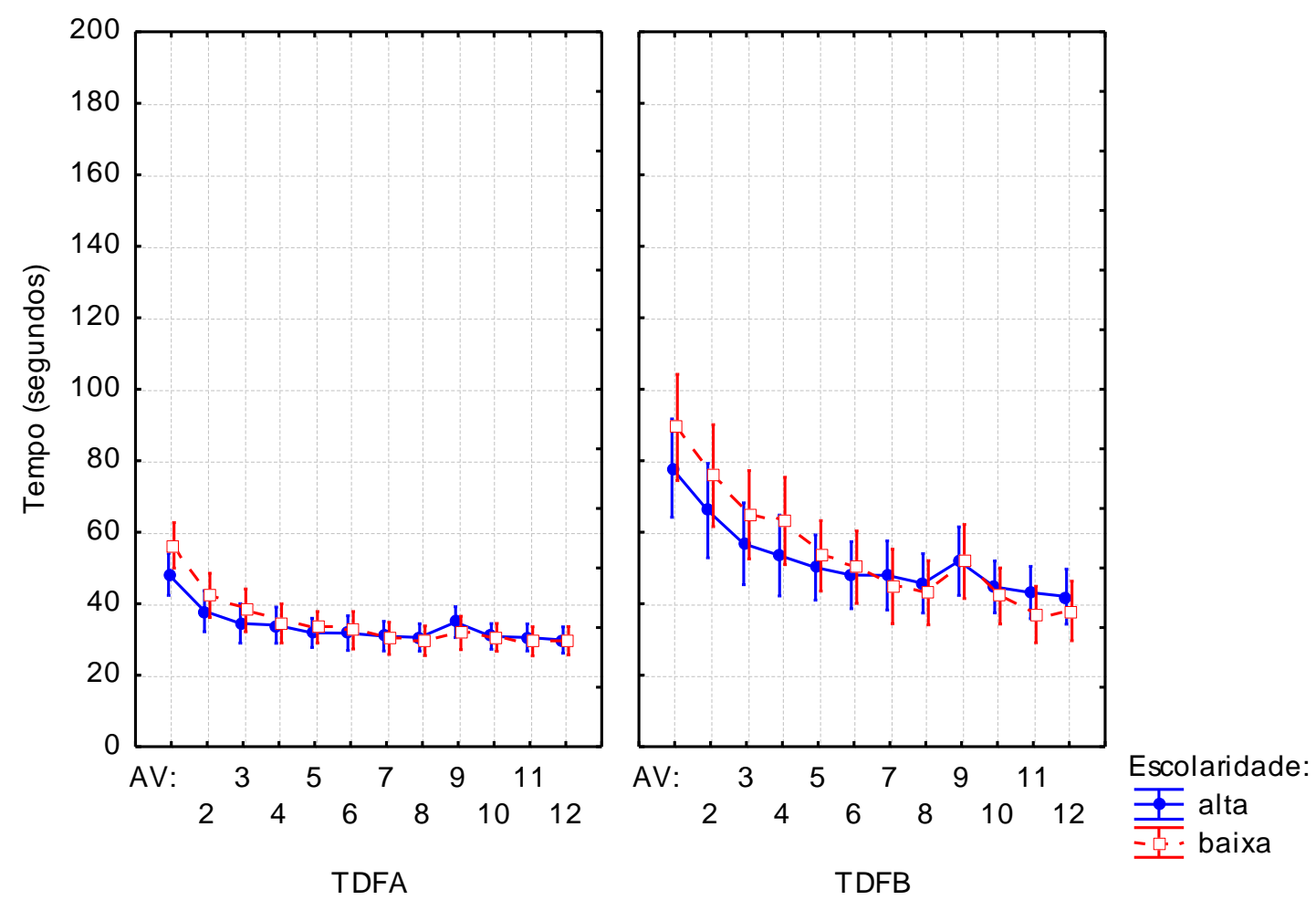

Figura 5: Tempo, em segundos (média \pm desvio-padrão) para realização do Teste de Deambulação Funcional em função da escolaridade e da parte do teste no aprendizado ao longo das 12 avaliações realizadas nos voluntários adultos maduros. Houve interação idade $X$ escolaridade $X$ avaliação $X$ parte do teste $\left[F_{22,704}=1,64 ; p=0,033\right]$. Os adultos maduros com escolaridade baixa não diferiram dos com escolaridade alta nem na parte A, nem na parte B do TDF. Legenda: TDFA: parte A do Teste de Deambulação Funcional; TDFB: parte B do Teste de Deambulação Funcional. 

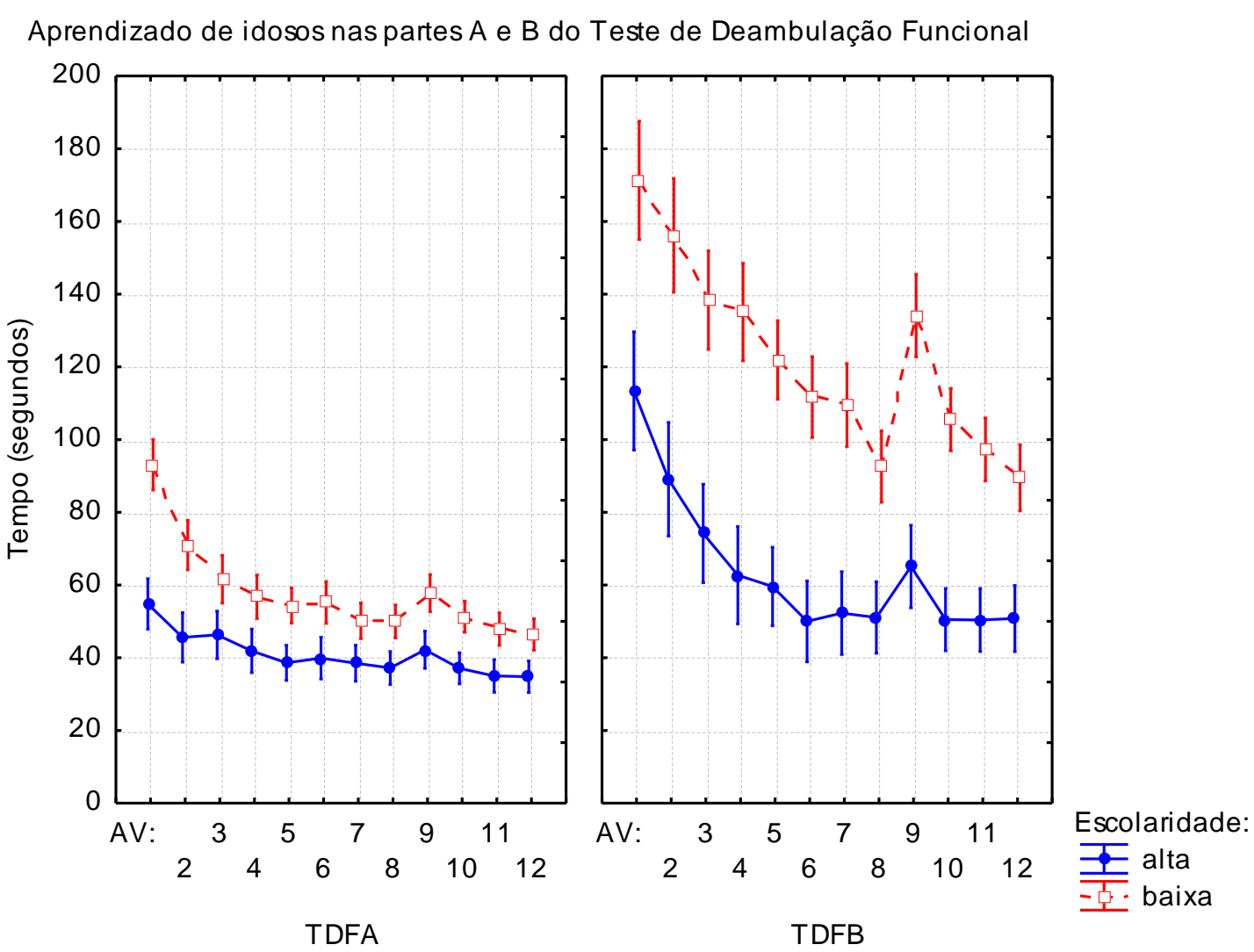

Figura 6: Tempo, em segundos (média \pm desvio-padrão) para realização do Teste de Deambulação Funcional em função da escolaridade e da parte do teste no aprendizado ao longo das 12 avaliações realizadas nos voluntários idosos. Houve interação idade $X$ escolaridade $X$ avaliação $X$ parte do teste $\left[F_{22,704}=1,64 ; p=0,033\right]$. Os idosos com escolaridade baixa foram mais lentos que os com escolaridade alta na avaliação 1 da parte A do TDF e em todas as avaliações da parte B do TDF. Legenda: TDFA: parte A do Teste de Deambulação Funcional; TDFB: parte B do Teste de Deambulação Funcional. 


\subsection{DISCUSSÃo}

O presente estudo visou investigar o impacto da idade e da escolaridade na execução e no aprendizado de uma tarefa cognitivo-motora. Para isso, a resposta motora do TMT foi modificada de modo a demandar a deambulação sobre um tatame, ao invés de movimentos manuais ao riscar uma folha de papel. Foram realizadas comparações entre a resposta deste novo teste (TDF) e a resposta do teste tradicional (TMT).

Esperávamos que a idade e a escolaridade influenciassem de modo diferente a resposta tradicional (TMT) e essa nova resposta (TDF), o que, conseqüentemente poderia influenciar, de formas distintas, o delta cognitivo e o delta motor. Além disso, foi investigada a influência da idade e da escolaridade sobre o aprendizado e a retenção da nova resposta motora (TDF).

\subsection{Desempenho nas partes A e B do TMT e do TDF}

Primeiramente, analisamos a influência da idade e da escolaridade no desempenho nas partes A e B do TMT e do TDF. Encontramos uma interação idade $\mathrm{X}$ escolaridade $\mathrm{X}$ teste, a qual evidenciou que os indivíduos apresentaram respostas diferentes aos testes, de acordo com sua idade e sua escolaridade. 


\subsubsection{A influência da idade}

Supúnhamos que, quanto mais idoso, mais lento o indivíduo seria para riscar o papel e para deambular de um círculo a outro. Esta hipótese se confirmou. De modo geral, os idosos foram mais lentos que os adultos maduros, que, por sua vez, foram mais lentos que os adultos jovens, o que pode ser explicado por uma menor habilidade sensorial (CHAPMAN e HOLLANDS, 2006; LORD, 2006; KOVACS, 2005), motora (VAN IERSEL et al., 2007; MELZER et al., 2007; COPPIN et al., 2006; MELZER e ODDSSON, 2004; TURANO et al., 2004; BROMAN et al., 2004; BRAUER, WOOLLACCOT e SHUMWAY-COOK, 2001) e cognitiva (KENNEDY e RAZ, 2009; HANNAPLADDY, 2007; OXLEY et al., 2005; BALL e OWSLEY, 1993) dos idosos.

Ble et al. (2005) avaliaram idosos em duas tarefas de locomoção: uma mais simples, na qual o idoso deveria andar por $4 \mathrm{~m}$ na velocidade usual e outra mais complexa, na qual o idoso deveria andar por $7 \mathrm{~m}$ o mais rápido possível e saltar dois obstáculos, de 6 e $30 \mathrm{~cm}$ de altura. Os autores discutem que na segunda tarefa houve maior demanda da função executiva, logo, esta esteve correlacionada com o desempenho no TMT, o que não ocorreu com a primeira tarefa. Concluem que a função executiva teria um papel importante na execução de atividades motoras complexas em idosos. Esses resultados estão de acordo com os nossos.

Os idosos apresentaram menor velocidade para emissão de respostas motoras, em relação a indivíduos mais jovens, assim como em diversos outros estudos (KENNEDY e RAZ, 2009; TEIXEIRA et al., 2008; MELZER, 2007; OXLEY et al., 2005). A diminuição da velocidade com o aumento da idade foi mais expressiva para indivíduos com escolaridade baixa. Enquanto idosos com 
escolaridade alta foram mais lentos do que adultos jovens apenas na parte $B$ do TMT e do TDF, idosos com escolaridade baixa foram mais lentos tanto na parte $A$, quanto na parte $B$ dos testes. Além disso, enquanto idosos com escolaridade alta foram mais lentos que adultos maduros apenas na parte $B$ do TDF, idosos com escolaridade baixa foram mais lentos nas partes $A$ e $B$ do TDF e na parte B do TMT.

Com base na informação de que, sobretudo para idosos, a parte B do TMT é mais difícil que a parte A (PERIÀÑEZ et al., 2007; ZALONIS et al., 2007; HASHIMOTO et al., 2006; SEO et al., 2006; HESTER et al., 2005; TOMBAUGH, 2004), podemos supor que, para indivíduos com escolaridade alta, tenha sido necessária uma tarefa mais complexa, como a parte $\mathrm{B}$, para evidenciar a perda de desempenho decorrente do envelhecimento, porém, para indivíduos com escolaridade baixa, essa diferença já apareceu em tarefas mais simples, como a parte A. O mesmo efeito de interação idade $X$ parte do teste, já descrito para o TMT (PERIÀÑEZ et al., 2007; ZALONIS et al., 2007; HASHIMOTO et al., 2006; SEO et al., 2006; HESTER et al., 2005; TOMBAUGH, 2004), ocorreu com o TDF.

Também esperávamos que indivíduos idosos demorassem mais tempo para concluir o TDF do que o TMT. Essa hipótese não foi verdadeira para todos os grupos, pois a escolaridade interagiu com a idade. Indivíduos com escolaridade alta foram mais lentos no TDF do que no TMT, conforme esperado. Indivíduos com escolaridade baixa apresentaram este comportamento na parte $A$, mas não na parte $B$ dos testes. Na parte $B$ a grande dificuldade cognitiva, tanto do TMT quanto do TDF, parece ter minimizado o impacto do aumento de complexidade motora do TDF com 
relação ao TMT. Essa discussão será aprofundada nos itens 6.1.2 e 6.1.3, a seguir.

\subsubsection{A influência da escolaridade}

Esperávamos que, quanto menor a escolaridade, maior a dificuldade no TMT e no TDF. Essa diferença de desempenho decorrente da escolaridade não foi observada para adultos jovens e maduros, mas foi constatada nos idosos. Verificamos que idosos com escolaridade baixa foram mais lentos que idosos com escolaridade alta no TDFA, TDFB e TMTB. Na parte A do TMT essa diferença também foi observada, mas não chegou a nível significativo.

O primeiro aspecto a ser ressaltado com relação a esses resultados é o fato de a diferença de escolaridade ter aparecido nos idosos, mas não nos adultos jovens e maduros. De acordo com a teoria da reserva cognitiva, a educação fornece uma reserva, por meio de mudanças neuronais ou aumento da eficiência de redes de processamento, que faz com que o declínio fisiológico do envelhecimento e de possíveis processos patológicos associados a ele surjam mais tardiamente (VAN DER ELST et al., 2006; KULAIF, 2005; FRITSCH et al., 2001).

Tun e Lachman (2008) e Van der Elst et al. (2006) defenderam a idéia de que níveis mais altos de escolaridade estariam associados a um melhor desempenho da função executiva. Tun e Lachman (2008) relataram que, em uma tarefa que exigia função executiva, indivíduos com escolaridade alta apresentaram desempenho equivalente a indivíduos com escolaridade baixa que eram dez anos mais jovens. Van der Elst et al. (2006) demonstraram que o 
desempenho no teste de Stroop piora com o envelhecimento e que este declínio é mais acentuado em indivíduos menos escolarizados. Os autores alegam que a educação tem um efeito protetor contra as perdas de funções cerebrais causadas pelo envelhecimento.

O presente estudo, assim como o de Tun e Lachman (2008) e o de Van der Elst et al. (2006), também envolve uma tarefa de função executiva. Em todos eles, a escolaridade alta diminuiu a influência do envelhecimento, já que idosos com escolaridade alta apresentaram menos diferenças com relação aos indivíduos mais jovens que os idosos com escolaridade baixa.

O segundo aspecto a ser ressaltado é o fato de não ter sido constatada uma diferença significativa na parte A do TMT, mas sim nos demais testes.

Nas partes A do TDF e do TMT era necessário apenas seguir a seqüência $1,2,3,4,5$, etc., que é uma seqüência automática, tanto para pessoas de alta, quanto de baixa escolaridade, principalmente na amostra estudada, na qual indivíduos com escolaridade baixa tinham, no mínimo, seis anos de estudo formal. Já na parte $B$, a demanda cognitiva era maior, pois números deveriam ser alternados com letras. Nessa situação, as pessoas com escolaridade alta poderiam ter tido melhor desempenho por terem conseguido alternar a seqüência de números com a de letras com maior facilidade e por terem conseguido inibir uma seqüência e evocar a outra com maior eficiência.

A habilidade de alternar seqüências, também conhecida como flexibilidade mental, é parte da função executiva que, por sua vez, é mais desenvolvida em indivíduos com escolaridade alta (YASSUDA et al., 2009; TUN e LACHMAN, 2008; VAN DER ELST et al., 2006; LEE et al., 2003). Tun e 
Lachman (2008) estudaram uma tarefa de função executiva, que envolvia controle inibitório e alternância de padrão de resposta a estímulos auditivos e verificaram que indivíduos com nível superior apresentaram melhor desempenho em do que indivíduos que cursaram a escola até o ginásio ou colegial. Hanna-Pladdy (2007) destacou a importância da habilidade inibitória na realização do TMT, sobretudo da parte $B$.

Embora a influência da escolaridade seja muito forte e consistente na literatura a respeito da parte B do TMT (ZALONIS et al., 2007; SEO et al., 2006; TOMBAUGH, 2004; HESTER et al., 2005), há estudos que, assim como o presente, não evidenciaram diferenças de escolaridade na parte A (IVNIK et al., 1996; TOMBAUGH, 2004; HESTER et al., 2005). Nesses estudos têm-se argumentado que, como a parte $A$ exige apenas velocidade na resposta motora, essa diferença não havia sido constatada porque tal velocidade é menos dependente da escolaridade.

Foi sugerida na literatura a existência de maior complexidade motora e perceptual na parte B do TMT com relação à parte A (ROSSINI e KARL, 1994; GAUDINO et al., 1997; CROWE, 1998). A maior complexidade motora deverse-ia às maiores mudanças de direção e maiores distâncias entre os círculos a serem conectados na parte B. A maior complexidade perceptual ocorreria porque os números estariam mais embaralhados. Esses fatos poderiam contribuir para explicar as diferenças de escolaridade do presente estudo: pior desempenho de indivíduos com escolaridade baixa para a parte B do TMT, mas não para a parte A do TMT. 
Por fim, é importante discutirmos a relação da escolaridade com a natureza das tarefas cognitivo-motoras propostas. Os achados do presente estudo, serão relacionados aos de Andrade-Machado et al. (2009) e os de Neves (2008) de modo a se abordar essa questão de forma mais detalhada, pois nos três estudos, foram evidenciadas diferenças de escolaridade em atividades motoras.

No estudo de Andrade-Machado et al. (2009), uma tarefa cognitiva, de comparação de figuras, foi associada a uma tarefa motora de alternância de passos do chão a uma plataforma. Os indivíduos com escolaridade baixa apresentaram maior dificuldade em cada uma das tarefas isoladamente e, o que ainda foi mais interessante, um aumento mais acentuado dos erros na tarefa visual quando esta foi realizada simultaneamente à tarefa motora, ou seja, uma piora do desempenho cognitivo nessa situação. A complexidade do componente motor estava em monitorar continuamente o grau de flexão do tornozelo, joelho e quadril, em uma sala de iluminação reduzida, para não tropeçar na plataforma. É importante ressaltar que ambas as tarefas eram independentes, a realização de uma não dependia de informações da outra. Por outro lado, havia competição entre os recursos atencionais disponíveis para a realização das tarefas.

No estudo de Neves (2008), a complexidade motora estava em selecionar continuamente o dedo correto para cada parte de uma seqüência motora que consistia em cinco movimentos de oposição de dedos. A tarefa deveria ser repetida diversas vezes, o mais rápido possível. A autora testou a generalização do aprendizado desta seqüência para outra seqüência de oposição de dedos, que não havia sido treinada. A generalização ocorreu para 
os indivíduos com escolaridade alta, mas não para aqueles com escolaridade baixa.

No presente estudo, assim como no estudo de Neves (2008), houve a exigência de realização de uma atividade motora complexa, não apenas associada, mas na dependência de informações obtidas pela tarefa cognitiva, pois era preciso saber a seqüência correta para saber para onde andar no tatame ou em que direção riscar o papel.

Diante desses três estudos, acreditamos que a influência da escolaridade em tarefas cognitivo-motoras possa ser explicada não apenas pela dificuldade cognitiva de indivíduos com escolaridade baixa, amplamente discutida na literatura (YASSUDA et al., 2009; BRUCKI e NITRINI, 2008; BARNES et al., 2004; NITRINI et al., 2004; LE CARRET et al., 2003; ARDILA et al., 2000), mas também pela competição entre o componente cognitivo e o motor. Essa competição parece não ocorrer só em tarefas-duplas, nas quais claramente uma tarefa não contribui e sim compete com a outra, como no estudo de Andrade-Machado et al. (2009), mas também em tarefas nas quais a resposta motora depende de um processamento eficiente dos componentes da tarefa cognitiva, como a utilizada por Neves (2008) e a do presente estudo. Indivíduos com escolaridade mais alta conseguiriam lidar com essa competição de forma mais efetiva do que indivíduos com escolaridade baixa.

Quando uma tarefa cognitiva é associada a uma tarefa motora, quanto mais complexo for um dos componentes (cognitivo ou motor), mais ele irá prejudicar o outro componente (ANDRADE-MACHADO et al., 2009; TEIXEIRA et al., 2008; MELZER, 2007; COPPIN et al., 2006; OXLEY et al., 2005). Isso 
também foi constatado no presente estudo, tanto na execução do TMT, quanto do TDF. Mesmo os idosos com escolaridade alta tiveram maior dificuldade em associar tarefas, quando comparados aos jovens com mesma escolaridade.

DiFabio et al. (2005) estudaram dois grupos de indivíduos idosos, um com pontuações abaixo de 160s na parte B do TMT, considerado o grupo com boa função executiva e outro com pontuações acima deste valor, considerado com pouca habilidade de função executiva. Verificaram que o grupo com boa função executiva apresentou melhor habilidade ao saltar obstáculos e melhor controle visual sobre a tarefa. Essa é mais uma evidência de que o componente cognitivo do TDF está intimamente relacionado com 0 componente motor, pois ambos (e não apenas o cognitivo) sofrem grande influência da função executiva.

\subsubsection{A influência da resposta motora do teste}

Tínhamos interesse em investigar possíveis interações escolaridade $X$ idade nos dois tipos de resposta motora (riscar o papel e andar sobre 0 tatame), já que os efeitos da idade e da escolaridade poderiam variar de acordo com o tipo de resposta.

Os idosos com escolaridade alta foram mais lentos na parte B do TDF do que na parte B do TMT. Se, por um lado, a parte B de ambos os testes foi muito difícil para idosos com escolaridade baixa, o que pode ter minimizado a complexidade da resposta motora diante da complexidade cognitiva, isso não ocorreu para idosos com escolaridade alta, que tiveram mais dificuldade em andar pela trilha sobre o tatame do que em riscar a trilha de números e letras 
alternados no papel. A dificuldade não parece ter ocorrido para entender a regra de seguir uma seqüência, mas para mudar de direção, transferir o peso de uma perna à outra, manter o equilíbrio.

Esse resultado está de acordo com os achados de Melzer (2007) e Melzer e Oddsson (2004), que estudaram uma tarefa de dar um passo para frente ou para o lado o mais rápido possível, após um estímulo tátil no tornozelo, em duas condições: tarefa isolada (tarefa motora) e tarefa-dupla (tarefa motora associada a uma tarefa cognitiva, que consistiu em realizar o teste de Stroop). Os idosos foram mais lentos que os jovens na tarefa isolada e, principalmente, na tarefa-dupla. Embora esses estudos tenham excluído indivíduos com demência por meio do Mini Exame do Estado Mental, a escolaridade dos voluntários não é informada em nenhum deles, o que dificulta a análise mais aprofundada.

\subsection{O delta cognitivo do TMT e do TDF}

Na segunda análise estatística, que testou a influência da idade e da escolaridade no delta cognitivo do TMT e do TDF (TMTB - TMTA e TDFB TDFA), foi evidenciada uma interação idade $X$ escolaridade $X$ delta.

\subsubsection{A influência da idade}

Entre os indivíduos com escolaridade alta, não houve diferenças de idade para o delta cognitivo do TMT. O delta cognitivo do TDF dos idosos com escolaridade alta foi maior que o de adultos jovens com mesma escolaridade. Entre os indivíduos com escolaridade baixa, os deltas cognitivos do TMT e do TDF de idosos foram maiores que os de adultos jovens e de adultos maduros. 
$\mathrm{Na}$ literatura, são descritos os efeitos antagônicos da idade e da escolaridade sobre o delta cognitivo do TMT: há aumento do delta com o aumento da idade e há diminuição do delta com o aumento da escolaridade (HESTER et al., 2005; HASHIMOTO et al., 2007). Portanto, indivíduos mais idosos e menos escolarizados apresentam maiores deltas.

A escolaridade alta eliminou a influência da idade sobre o delta cognitivo do TMT. Entre indivíduos com escolaridade alta, foi observada apenas uma diferença no delta cognitivo do TDF entre idosos e adultos jovens e não foram observadas diferenças entre adultos maduros e idosos. A ausência de diferenças de idade para o delta cognitivo do TMT e a diminuição dessas diferenças para o delta cognitivo do TDF entre indivíduos com escolaridade alta podem ser explicadas pelo fato de a influência da escolaridade tender a prevalecer sobre a da idade em diversos testes neuropsicológicos (ARDILA et al., 2000).

É possível que a educação tenha atuado como uma proteção e que tenha minimizado o processo de envelhecimento cognitivo nos indivíduos com escolaridade alta, o que resultou em diferenças de idade menos evidentes nesses indivíduos. Esse efeito protetor da escolaridade não neutralizou a influência da idade sobre o delta cognitivo do TDF. Como já explicado anteriormente, a resposta motora do TDF parece ter gerado uma competição com o processamento cognitivo em idosos com escolaridade alta, o que impediu que a influência da escolaridade neutralizasse a influência da idade.

Para indivíduos com escolaridade baixa, foram evidenciadas diferenças expressivas de idade tanto para o delta cognitivo do TDF, quanto para o delta cognitivo do TMT. O pior desempenho de função executiva em indivíduos 
idosos com escolaridade baixa, em relação aos de mesma idade e com maior número de anos de estudo, foi descrito na literatura tanto para o delta cognitivo do TMT (HASHIMOTO et al., 2007; ZALONIS et al., 2007; SEO et al., 2006; HESTER et al., 2005), o que reforça os achados do presente estudo, quanto para o teste de Stroop (VAN DER ELST et al., 2006).

Segundo Van der elst (2006), o desempenho no teste de Stroop, que é um teste também muito usado para avaliação da função executiva, piora com o envelhecimento e esse declínio é mais acentuado em indivíduos com menos anos de estudo formal.

\subsubsection{A influência da escolaridade}

O delta cognitivo do TMT de idosos com escolaridade baixa foi maior que o delta cognitivo do TMT de idosos com escolaridade alta. Esses dados estão de acordo com a literatura, já que estudos prévios descreveram efeitos mais expressivos do envelhecimento sobre o delta cognitivo do TMT para indivíduos com escolaridade baixa (HASHIMOTO et al., 2007; ZALONIS et al., 2007; SEO et al., 2006; HESTER et al., 2005).

Não houve diferença entre idosos com escolaridade alta e idosos com escolaridade baixa para o delta cognitivo do TDF. Os idosos com escolaridade baixa podem ter tido menor prejuízo em resolver o componente cognitivo envolvido na parte B do TDF do que em resolver esse componente na parte B do TMT. Inicialmente, ao modificarmos o componente motor do TMT e criarmos o TDF, acreditávamos que não tínhamos alterado o componente cognitivo do TMT, mas pode não ter sido isso o que de fato aconteceu. 
Em tarefas de representação tridimensional, como o TDF, as diferenças de escolaridade são minimizadas (REIS et al., 2001; PETERSSON et al., 2001). Porém, os estudos que mencionam menor prejuízo em indivíduos com escolaridade baixa incluíram em sua amostra pessoas com menos anos de estudo formal que o presente estudo. Por isso, mesmo diante dos achados de Petersson et al. (2001) e de Reis et al. (2001), esse resultado ainda é surpreendente no presente estudo.

Outra explicação seria a de que a escolaridade mais alta favoreceria a capacidade de utilizar uma regra pré-estabelecida e informações verbais para selecionar a resposta motora de forma mais eficiente, ou seja, para utilizar, de forma mais adequada, a informação cognitiva, fosse ela verbal, visual ou mnêmica, para nortear a resposta motora (NITRINI et al., 2004; CAVALCANTE, 2004; NEVES, 2008). Como, no TDF, o corpo todo seguiu o trajeto a ser realizado, talvez tenha havido um número maior de informações para nortear a resposta motora e essas informações tenham captado maior atenção e facilitado a seleção da próxima resposta que seria executada. Isso pode ter tornado o teste mais fácil para indivíduos menos escolarizados.

\subsubsection{A influência do teste}

O delta cognitivo do TMT foi maior que o delta cognitivo do TDF para os idosos com escolaridade baixa. Ou seja, para idosos com escolaridade baixa, mas não para idosos com escolaridade alta, o componente cognitivo do TMT foi mais difícil que o do TDF. Uma possível explicação para este fato seria que 
riscar um papel, por ser menos familiar para idosos com escolaridade baixa, teria sido uma resposta motora mais difícil do que andar sobre um tatame, o que teria influenciado negativamente no desempenho, competindo com 0 controle cognitivo da tarefa.

Outra explicação seria que, de fato, a mudança do TMT para o TDF, que aparentemente consistia apenas em proporcionar demandas motoras distintas, acabou por modificar aspectos cognitivos da tarefa. Em atividades escolares, o reconhecimento de símbolos e de imagens bidimensionais é extensivamente treinado, o que faz com que indivíduos com maior escolaridade tenham maior familiaridade em decodificar e interpretar informações em duas dimensões (REIS et al., 2001). Quanto mais anos de estudo formal, maior a familiaridade com conhecimentos abstratos e maior a capacidade de gerar regras a partir deles e não de objetos concretos. Portanto, é possível que, para indivíduos com escolaridade alta, seja indiferente compreender a regra de alternância entre tarefas riscando uma folha de papel ou andando sobre um tatame, mas que, para indivíduos com escolaridade baixa, essa compreensão seja mais fácil andando sobre um tatame.

\subsection{O delta motor do TMT e do TDF}

Na terceira análise estatística, que visou testar a influência da idade e da escolaridade nos deltas motores (TDFA - TMTA e TDFB - TMTB) do TMT e do TDF, foi encontrada uma interação idade $\mathrm{X}$ escolaridade $\mathrm{X}$ delta. 
Deltas motores acima de zero indicam maior facilidade em gerenciar o componente motor do TMT com relação ao componente motor do TDF (tempo mais baixo para concluir o TMT do que para concluir o TDF). Deltas motores abaixo de zero indicam maior facilidade em gerenciar o componente motor do TDF com relação ao do TMT (tempo mais baixo para finalizar o TDF do que para finalizar o TMT).

\subsubsection{A influência da idade}

Não houve diferenças significativas referentes à idade no delta motor. Esperávamos que, quanto maior fosse a idade, maior seria o delta motor. Essa tendência, de fato, pôde ser observada entre os indivíduos com escolaridade alta, na figura 3, mas não chegou a nível significativo.

Como a análise de variância levou em consideração a idade e a escolaridade conjuntamente, as diferenças de idade parecem ter sido minimizadas pelo desempenho de indivíduos com escolaridade baixa, que não apresentaram esse aumento do delta com o aumento da idade, principalmente na parte B do teste. Isso sugere que a escolaridade exerça maior influência sobre o delta motor do que a idade.

\subsubsection{A influência da escolaridade}

Na parte B, o delta motor de idosos com escolaridade baixa foi menor que o delta motor de idosos com escolaridade alta. Isso significa que alternar números e letras foi mais fácil ao deambular sobre um tatame do que ao riscar uma folha de papel para idosos com escolaridade baixa. 
Embora não tenham sido registradas sistematicamente, foram muito freqüentes as hesitações, com pausas prolongadas, de idosos com escolaridade baixa ao riscar a parte B do TMT. Essas pausas também existiram, mas foram menos freqüentes no TDF. Indivíduos com escolaridade baixa costumam apresentar maior medo de errar, o que faz com que, freqüentemente, reduzam a velocidade de tarefas motoras em momentos de avaliação (ANDRADE-MACHADO et al., 2009; ARDILA et al., 2000).

O erro ao riscar no papel no TMT ficou mais evidente, pois o risco não foi apagado, o que reforça a hipótese de que indivíduos com escolaridade baixa tenham tido maior medo de errar no TMT do que no TDF. Tanto no TDF, quanto no TMT, a cada erro cometido, o examinador solicitou o retorno ao círculo anterior e continuidade do teste, mas o erro não foi visível no tatame, uma vez que a trajetória não ficou marcada sobre o tapete de teste.

\subsubsection{A influência da parte do teste}

O delta motor A foi maior que o delta motor $\mathrm{B}$ para idosos com escolaridade baixa. Portanto, a maior facilidade de idosos com escolaridade baixa no TDF, com relação ao TMT, só ficou evidente na parte B. Acreditamos

que a formulação de uma regra para $1,2,3,4,5,6$, etc. tenha sido algo muito mais simples do que para $1, \mathrm{~A}, 2, \mathrm{~B}, 3, \mathrm{C}$, etc. Isso explicaria porque na parte mais simples do teste não surgiram diferenças de desempenho decorrentes da escolaridade, mas na parte mais complexa do teste, o componente cognitivo exerceu uma competição com o componente motor, prejudicando-o. 
Para idosos com escolaridade alta, a realização de um teste de lápis e papel e a realização de um teste de deambulação poderiam ser consideradas tarefas igualmente familiares. Já para idosos com escolaridade baixa, a deambulação seria mais familiar do que riscar o caminho no papel. Portanto, é possível a suposição de que, diante da competição cognitivo-motora, os grupos de idosos apresentaram dificuldades diferentes.

Para os idosos com escolaridade alta, foi mais fácil conciliar a tarefa cognitiva com a tarefa motora de riscar o papel, porque esta requisitava menor equilíbrio, que é uma habilidade que diminui com o envelhecimento (MELZER, 2007; MELZER e ODDSSON, 2004). Estudos prévios demonstraram a dificuldade de idosos ao associarem uma tarefa cognitiva à deambulação (VERGHESE et al., 2007; VAN IERSEL et al., 2007; COPPIN et al.; 2006; BLE et al., 2005; OXLEY et al., 2005). Verghese et al. (2007) demonstraram que idosos diminuíram a velocidade da marcha quando esta foi associada a uma tarefa cognitiva complexa (dizer as letras do alfabeto de forma alternada). $\mathrm{O}$ decréscimo na velocidade não foi observado quando os idosos realizaram a deambulação associada a uma tarefa simples (dizer as letras do alfabeto).

Para os idosos com escolaridade baixa o comportamento motor mais treinado ao longo da vida era o de andar. A experiência prévia em tarefas motoras similares à tarefa testada pode facilitar o desempenho no teste, enquanto a falta de familiaridade com determinados componentes da tarefa testada podem prejudicá-lo (BEILOCK et al., 2004). Acreditamos que, para idosos com escolaridade baixa, no TDF o componente motor era familiar e, por isso foi mais fácil, enquanto no TMT, o componente motor, por ser menos familiar, exigiu mais atenção e mais tempo para ser realizado. 


\subsection{A influência da idade e da escolaridade no aprendizado de cada uma das partes do TDF}

Por fim, o TDF foi usado para estudo da influência da idade e da escolaridade no aprendizado de uma tarefa cognitivo-motora. Houve interação idade $\mathrm{X}$ escolaridade $\mathrm{X}$ avaliação $\mathrm{X}$ parte do teste.

\subsubsection{A influência da idade}

Os adultos maduros e os idosos, mas não os jovens, apresentaram melhora de desempenho na parte A do TDF. Isso ocorreu porque a parte A do TDF consistiu numa tarefa pouco desafiadora para os adultos jovens, portanto, houve um efeito-piso no desempenho dos mesmos, não havendo mais como melhorar (diminuir o tempo) a cada repetição. Melzer e Oddsson (2004) também encontraram esse efeito-piso no desempenho de jovens, ao comparálos aos idosos em uma tarefa cognitivo-motora de dar passos para frente, para o lado ou para trás e realizar simultaneamente o teste de Stroop.

Tanto adultos jovens, quanto adultos maduros, quanto idosos demonstraram aprendizado na parte B do TDF. Porém, para adultos maduros e idosos, o desempenho estabilizou mais lentamente do que para adultos jovens e para idosos estabilizou mais lentamente do que para adultos maduros. Adultos jovens já partiram de pontuações mais baixas, o que facilitou a estabilização do desempenho. Para todos os grupos, o desempenho tendeu a se estabilizar mais lentamente para indivíduos com escolaridade baixa do que para indivíduos com escolaridade alta. Esse mesmo resultado de estabilização 
tardia em indivíduos menos escolarizados foi observado no trabalho de Neves (2008).

Não houve diferença entre o desempenho de adultos jovens, adultos maduros e idosos com escolaridade alta na parte A do TDF. Portanto, a escolaridade alta eliminou diferenças de idade na parte A do TDF, que é uma tarefa de menor complexidade que a parte B.

Ainda dentre os indivíduos com escolaridade alta, os idosos foram mais lentos do que os adultos jovens nas avaliações 1, 2, 3 e 9 da parte B do TDF. Os idosos foram mais lentos que os adultos maduros na avaliação 1 da parte B do TDF. Na parte $\mathrm{B}$, devido à maior complexidade, a escolaridade alta não eliminou as diferenças de idade, mas tornou-as restritas às três primeiras avaliações do primeiro dia e à primeira avaliação do segundo dia (nona avaliação).

Dentre os indivíduos com escolaridade baixa, não houve diferença entre o desempenho de adultos jovens e maduros. Os idosos foram mais lentos que os adultos maduros nas avaliações 1 e 2 na parte A do TDF. Ou seja, apareceram diferenças de idade já na parte $A$ do TDF, o que não havia ocorrido para o grupo com escolaridade alta.

Os idosos foram mais lentos que os adultos jovens e maduros em todas as avaliações na parte B. Ou seja, para indivíduos com escolaridade baixa, as diferenças de idade ficaram mais evidentes do que para indivíduos com escolaridade alta na parte B. Enquanto houve diferenças de idade apenas para as avaliações iniciais do primeiro e segundo dias de avaliação para o grupo 
com escolaridade alta, essas diferenças estiveram presentes em todas as avaliações para o grupo com escolaridade baixa.

\subsubsection{A influência da escolaridade}

Quando o desempenho dos grupos com escolaridade alta e baixa foi comparado a cada avaliação, constatou-se que os adultos jovens e os adultos maduros com escolaridade alta não diferiram dos com escolaridade baixa nas partes $A$ e B do TDF. Já os idosos com escolaridade baixa foram mais lentos que os com escolaridade alta na avaliação 1 da parte A do TDF e em todas as avaliações da parte B do TDF.

Esses resultados estão de acordo com a teoria de que a escolaridade alta atuaria como um agente protetor, minimizando perdas decorrentes do envelhecimento. Há evidências de que um maior nível de escolaridade ocasionaria maior ativação sináptica, com melhora na percepção, memória e raciocínio (LEE et al., 2003; CHIU et al., 2004; STERN et al. 2005). Assim, podemos considerar que o grupo de idosos com escolaridade baixa teve seu desempenho prejudicado.

Paralelamente, podemos supor que os idosos com escolaridade alta (maior ou igual a onze anos) tiveram seu desempenho favorecido. De acordo com Paradise, Cooper e Livingston (2009), níveis mais altos de educação

compensam a progressão de quadros demenciais e atrasam suas manifestações clínicas. A educação proporciona uma reserva cognitiva e neurológica, por meio de mudanças neuronais ou aumento da eficiência de 
redes de processamento (FRITSCH et al., 2001; ALLEY, SUTHERS e CRIMMINS, 2007; TUN e LACHMAN, 2008).

Nossos resultados nos indicam que, ao atendermos indivíduos idosos em situações de prevenção de perdas funcionais, otimização da capacidade física e/ou reabilitação após enfermidades, a escolaridade deva ser levada em consideração para a seleção mais adequada do tratamento, com base na interação cognitivo-motora, que parece ser distinta entre estes subgrupos. Essa conclusão está de acordo com estudos de Gitlin et al. (2008) e de Voos, Custódio e Malaquias (2009).

Gitlin et al. (2008), ao verificarem os resultados de um programa de orientações sobre resolução de problemas, uso de ferramentas, conservação de energia, segurança, prevenção de quedas, treino de equilíbrio e fortalecimento muscular, chegaram a conclusão de que indivíduos com escolaridade baixa apresentaram maiores benefícios do que indivíduos com escolaridade alta. Voos, Custódio e Malaquias (2009) constataram que indivíduos com maior escolaridade apresentaram melhor desempenho na Escala de Equilíbrio de Berg e no Timed Up and Go Test.

\subsection{Limitações do estudo}

O presente estudo tem algumas limitações. Primeiro, a amostra foi dividida em escolaridade abaixo de onze anos (classificada como escolaridade baixa) e maior ou igual a onze anos (classificada como escolaridade alta). Essa divisão não reflete a realidade do Brasil e demais países em desenvolvimento. No Brasil, a escolaridade média da população é de sete anos de estudo formal (Anexo E). Essa taxa diminui conforme aumenta a idade da população, 
chegando a cerca de três anos de estudo para indivíduos acima de 60 anos (IBGE, 2009). Por outro lado, nossa amostra permite a comparação com estudos que aplicaram o TMT em grupos com escolaridade dividida da mesma forma que o presente estudo, realizados em diversos países (Anexo F).

Segundo, as diferenças encontradas podem ter sofrido influência do fator sócio-econômico, comumente associado às diferenças de escolaridade (ANDRADE-MACHADO et al., 2009; LEE et al., 2003; ARDILA et al., 2000). Para minimizar este efeito, foram recrutados participantes da comunidade USP, porém, mesmo dentro desta população, podem ter havido diferenças sócioeconômicas que contribuíram com as diferenças encontradas.

Em terceiro lugar, como foram avaliados três grupos de idade que apresentam uma série de características distintas, algumas diferenças de escolaridade entre os adultos jovens e maduros podem ter sido mascaradas por um efeito mais significativo no caso dos idosos com escolaridade baixa, o que não significa que não possam existir.

Em quarto lugar, seria interessante estudar um número maior de indivíduos e classificá-los de acordo com sua profissão, ou levando em consideração o fato de os idosos ainda exercerem ou não atividades ocupacionais. Acreditamos que essas variáveis interajam com a escolaridade e também possam atenuar ou exacerbar o efeito fisiológico do envelhecimento. 


\subsection{CONCLUSÃO}

O TDF mostrou-se uma ferramenta complementar eficaz para avaliar indivíduos com diferentes idades e escolaridades. Ele seria menos influenciado pela experiência prévia do indivíduo do que o TMT, devido à atividade motora requerida. Indivíduos mais idosos e com escolaridade mais baixa apresentaram tempos mais altos tanto no TMT quanto no TDF.

O delta cognitivo do TDF não parece ter sido equivalente ao do TMT em indivíduos com escolaridade baixa, já que eles apresentaram menor dificuldade em resolver cognitivamente o TDF. Os idosos com alta e baixa escolaridade apresentaram resultados antagônicos no delta motor. Enquanto idosos com escolaridade baixa apresentaram menor dificuldade no TDF, com relação ao TMT, o contrário ocorreu para idosos com escolaridade alta.

Idosos apresentaram estabilização mais lenta no desempenho do que adultos maduros, que por sua vez apresentaram estabilização mais lenta que jovens. A escolaridade baixa prejudicou o aprendizado e a retenção da tarefa, principalmente em idosos. 


\subsection{REFERÊNCIAS BIBLIOGRÁFICAS}

1. ALLEY, D.; SUTHERS, K.; CRIMMINS, E. Education and cognitive decline in older Americans. Research on Aging, v. 29, n. 1, p. 73-94, 2007.

2. ANDRADE-MACHADO, M.S.; VOOS, M. C.; TEIXEIRA, P. P. S.; PIEMONTE, M. E. P.; RIBEIRO DO VALLE, L. E. The impact of educational status on dual-task performance. Neuroscience Letters. 2009. Submetido.

3. ARDILA, A.; OSTROSKY-SOLIS, F.; ROSSELINI, M.; GÓMEZ, C. Agerelated cognitive decline during normal aging: the complex effect of education. Archives of Clinical Neuropsychology, v. 15, n. 6, p. 495-513, 2000.

4. ARBUTHNOTT, K.; FRANK, J. Trail Making Test, Part B as a measure of executive control: validation using a set switching paradigm. Journal of Clinical and Experimental Neuropsychology, v. 22, n. 4, p. 518-528, 2000.

5. ASHENDORF, L.; JEFFERSON, A. L.; O'CONNOR, M. K.; CHAISSON C.; GREEN, R. C.; STERN, R. A. Trail Making Test errors in normal aging, mild cognitive impairment, and dementia. Archives of Clinical Neuropsychology, v. 23, n. 2, p. 129-137, 2008.

6. BALL, K.; OWSLEY, C.J. The useful field of view test: a new technique for evaluating age related declines in visual function. Journal of the American Optometric Association, v. 64, n. 1, p. 71-79, 1993. 
7. BARNES, D. E.; TAGER, I. B.; SATARIANO, W. A.; YAFFE, K. The relationship between literacy and cognition in well-educated elders. Journal of Gerontology, v. 59A, n. 4, p. 390-395, 2004.

8. BASSO, M. R.; BORNSTEIN, R. A.; LANG, J. L. Practice effects on commonly used measures of executive function across twelve months. Clinical Neuropsychology, v. 13, n. 3, p. 283-292, 1999.

9. BEILOCK, S. L.; BERTHENTAL, B. I.; MCCOY, A. M.; CARR, T. H. Haste does not always make waste: Expertise, direction of attention, and speed versus accuracy in performing sensorimotor skills. Psychonomic Bulletin \& Review, v. 11, n. 2, p. 373-379, 2004.

10. BELL-MCGINTY, S.; PODELL, K.; FRANZEN, M.; BAIRD, A.D.; WILLIAMS, M. J. Standard measures of executive function in predicting instrumental activities of daily living in older adults. International Journal of Geriatric Psychiatry, v. 17, n. 9, p. 828-834, 2002.

11. BENNETT, D. A.; WILSON, R. S.; SCHNEIDER, J. A.; EVANS, D. A.; MENDES DE LEON, C. F.; ARNOLD, S. E. et al. Education modifies the relation of $A D$ pathology to level of cognitive function in older persons. Neurology, v. 60, n. 12, p. 1909-1915, 2003. 
12. BERTOLUCCI, P. H. F.; OKAMOTO, I. H.; BRUCKI, S. M. D.; SIVIERO, M. O.; NETO, J. T.; RAMOS, L. R. Applicability of the CERAD neuropsychological battery to Brazilian elderly. Arquivos de Neuropsiquiatria, v. 59, n. 3A, p. 532-536, 2001.

13. BHERER, L.; KRAMER, A. F.; PETERSON, M. S.; COLCOMBE, S.; ERICKSON, K.; BECIC, E. Testing the limits of cognitive plasticity in older adults: Application to attentional control. Acta Psychologica, v. 123, n. 3, p. 261-278, 2006.

14. BLE, A.; VOLPATO, S.; ZULIANI, G.; GURALVINIK, J. M.; BANDINELLI, S.; LAURETANI, F. et al. Executive function correlates with walking speed in older persons: the InCHIANTI study. Journal of the American Geriatric Society, v. 53 , n. 3 , p. $410-415,2006$.

15. BOWIE, C. R.; HARVEY, P. D. Administration and interpretation of the Trail Making Test. Nature Protocols, v. 5, n. 1, p. 2277-2281, 2006.

16. BRAUER, S. G.; WOOLLACOTT, M.; SHUMWAY-COOK, A. The interacting effects of cognitive demand and recovery of postural stability in balance-impaired elderly persons. The Journals of Gerontology Series A: Biological Sciences and Medical Sciences, v. 56, n. 8, p. M489-96, 2001.

17. BROMAN, A. T.; WEST, S.; MUÑOZ, B.; BANDEEN-ROCHE, K.; RUBIN, G.; TURANO, K. A. Divided attention as a predictor of bumping while 
walking: The Salisbury eye evaluation. Investigative Ophtalmology and Visual Science, v. 45, n. 9, p. 2955-2960, 2004.

18. BRUCKI, S. M. D.; NITRINI, R.; CARAMELLI, P.; BERTOLUCCI, P. H. F.; OKAMOTO, I. H. Sugestões para uso do Mini Exame do Estado Mental no Brasil. Arquivos de Neuropsiquiatria, v. 61, n.3B, p. 777-781, 2003.

19. BRUCKI, S. M. D.; ROCHA, M. S. G. Category fluency test: effects of age, gender and education on total scores, clustering and switching in Brazilian Portuguese-speaking subjects. Brazilian Journal of Medical and Biological Research, v. 37, n. 12, p. 1771-1777, 2004.

20. BRUCKI, S. M. D.; NITRINI, R. Cancellation task in very low educated people. Archives of Clinical Neuropsychology, v. 23, n. 2, p. 139-147, 2008.

21. CASTRO-CALDAS, A.; PETERSSON, K. M.; REIS, A.; STONEELANDER, S.; INGVAR, M. The illiterate brain: learning to read and write during childhood influences the functional organization of the adult brain. Brain, v. 21, n. 6, p. 1053-1063, 1998.

22. CAVALCANTE, K.R. Avaliação do desempenho de idosos normais em um protocolo de produção e reconhecimento de gestos: influência do sexo, da idade e da escolaridade no perfil de normalidade. Dissertação (Mestrado). Departamento de Neurologia da Faculdade de Medicina da Universidade de São Paulo, São Paulo, 88 p., 2004. 
23. CHAPMAN, G. J.; HOLLANDS, M. A. Age-related differences in stepping performance during step cycle-related removal of vision. Experimental Brain Research, v. 174, n. 4, p. 613-621, 2006.

24. CHIU, N. T.; LEE, B. F.; HSIAO, S.; PAI M. C. Educational level influences regional cerebral blood flow in patients with Alzheimer's disease. Journal of Nuclear Medicine, v. 45, n. 11, p.1860-1863, 2004.

25. COPPIN, A. K.; SHUMWAY-COOK, A.; SACZYNSKI, J.; PATEL, K. V.; BLE, A.; FERRUCCI, L. et al. Association of executive function and performance of dual-task physical tests among older adults: analyses from the InChianti study. Age and Ageing, v. 35, n. 6, p. 619-624, 2006.

26. CROWE, S. F. The differential contribution of mental tracking, cognitive flexibility, visual search, and motor speed to performance on parts $A$ and $B$ of the Trail Making Test. Journal of Clinical Psychology, v. 54, n. 5, p. 585-591, 1998.

27. DANSILIO, S.; CHARAMELO, A. Constructional functions and figure copying in illiterates or low-schooled Hispanics. Archives of Clinical Neuropsychology, v. 20, n. 8, p. 1105-1112, 2005.

28. DELOCHE, G.; SOUZA, L.; BRAGA, L. W.; DELLATOLAS, G. A calculation and number processing battery for clinical application illiterates and semi-literates. Cortex, v. 35, n. 4, p. 503-521, 1999. 
29. DEMAKIS, G. Frontal lobe damage and tests of executive processing: a meta-analysis of the category test, Stroop Test, and Trail Making Test. Journal of Clinical and Experimental Neuropsychology, v. 26, n.3, p. 441-450, 2004.

30. DI FABIO, R.P.; ZAMPIERI, C.; HENKE, J.; OLSON, K.; RICKHEIM, D.; RUSSELL, M. Influence of elderly executive cognitive function on attention in the lower visual field during step initiation. Gerontology, v. 51, p. 94-107, 2005.

31. DIKMEN, S. S.; HEATON, R. K.; GRANT, I.; TEMKIN, N. R. Test-retest reliability and practice effects of expanded Halstead-Reitan Neuropsychological Battery. Journal of the International Neuropsychological Society, v. 5, n. 4, p. 346-356, 1999.

32. DUARTE, W. R.; BARROS, A. J. D.; COSTA, J. S. D.; CATTAN, J. M. Prevalência de deficiência visual de perto e fatores associados: um estudo de base populacional. Caderno de Saúde Pública, v. 19, n. 2, p. 551-559, 2003.

33. FRITSCH, T.; MCCLENDON, M. J.; SMYTH, K. A.; LERNER, A. J.; CHEN, C. H.; PETOT, G. J. et al. Effects of educational attainment on the clinical expression of Alzheimer's disease: results from a research registry. American Journal of Alzheimer's Disease and Other Dementias, v. 16, n. 6, p. 369-376, 2001. 
34. GAUDINO, E. A.; GEISLER, M. W.; SQUIRES, N. K. Construct validity of the Trail Making Test: what makes part B harder? Journal of Clinical and Experimental Neuropsychology, v. 17, n. 4, p. 529-535, 1995.

35. GIOVAGNOLI, A. R.; DEL PESCE, M.; MASCHERONI, S.; SIMONCELLI M.; LAIACONA M.; CAPITANI, E. Trail making test: normative values from 287 normal adult controls. Italian Journal of Neurological Sciences, v. 17, n. 4, p. 305-309, 1996.

36. GITLIN, L. N.; WINTER, L.; DENNIS, M. P.; HAUCK, W. W. Variation in response to a home intervention to support daily function by age, race, sex, and education. The Journals of Gerontology Series A: Biological Sciences and Medical Sciences, v. 63, n. 7, p. 745-750, 2008.

37. HANNA - PLADDY, B. Dysexecutive Syndromes in Neurologic Disease. Journal of Neurological Physical Therapy, v. 31, n. 3, p. 119-127, 2007.

38. HASHIMOTO, R.; MEGURO, K.; LEE, E.; KASAI, M.; ISHII, H.; YAMAGUCHI, S. Effect of age and education on the Trail Making Test and determination of normative data for Japanese elderly people: The Tajiri Project. Psychiatry and Clinical Neurosciences, v. 60, n. 4, p. 422-428, 2006.

39. HAUSDORFF, J. M.; YOGEV, G.; SPRINGER, S.; SIMON, E. S.; GILADI, N. Walking is more like catching than tapping: gait in the elderly as a complex cognitive task. Experimental Brain Research, v. 164, n. 4, p. 541-548, 2005. 
40. HESTER, R. L.; KINSELLA, G. J.; ONG, B.; MCGREGOR, J. Demographic influences on baseline and derived scores from the trail making test in healthy older Australian adults. The Clinical Neuropsychologist, v. 19, n. 1, p. 45-54, 2005.

41. IBGE. Perfil dos idosos responsáveis por domicílios. Disponível em <http://www.ibge.gov.br/home/presidencia/noticias/25072002pidoso.shtm>. Acesso em 15 de ago. 2009.

42. IVNIK, R. J.; MALEC, J. F.; SMITH, G. E. et al. Neuropsychological tests' norms above age 55: COWAT, BNT, MAE Token, WRAT-R Reading, AMNART, Stroop, TMT and JLO. Clinical Neuropsychology, v. 10, p. 262-278, 1996.

43. JAGGER, C.; MATTHEWS, R.; MELZER, D.; MATTHEWS, F.; BRAYNE, C. Educational differences in the dynamics of disability incidence, recovery and mortality: findings from the MRC Cognitive Function and Ageing Study (MRCCFAS). International Journal of Epidemiology, v. 36, n. 2, p. 358-365, 2007.

44. KENNEDY, K. M.; RAZ, N. Aging white matter and cognition: differential effects of regional variations in diffusion properties on memory, executive functions, and speed. Neuropsychologia, v. 47, n. 3, p. 916-927, 2009. 
45. KORTTE, K. B.; HORNER, M. D.; WINDHAM, W. K. The Trail Making Test, part B: cognitive flexibility or ability to maintain set? Applied Neuropsychology, v. 9, n. 2, p. 106-109, 2002.

46. KOVACS, C. R. Age-related changes in gait and obstacle avoidance capabilities in older adults: a review. Journal of Applied Gerontology, v. 24, n. 1, p. 21-34, 2005.

47. KULAIF, T. O teste de cores e palavras de Stroop modificado para analfabetos. Dissertação (Mestrado). Instituto de Psicologia, Neurociências e Comportamento, Universidade de São Paulo, São Paulo, 101 f., 2005.

48. Le CARRET, N.; RAINVILLE, C.; LeCHEVALLIER, N.; LAFONT, S.; LETENNEUR, L.; FABRIGOULE, C. Influence of education on the Benton visual retention test performance as mediated by a strategic search component. Brain and Cognition, v. 53, n. 2, p. 408-411, 2003.

49. LEE, S.; KAWACHI, I.; BERKMAN, L. F.; GRODSTEIN, F. Education, other socioeconomic indicators, and cognitive function. American Journal of Epidemiology, v. 157, n. 8, p. 712-720, 2003.

50. LEZÀK, M. D. Neuropsychological Assessment In: Lezàk M. D., Howieson D. B., Loring D. W. 4th ed. New York: Oxford University Press, 2004. 
51. LIU - AMBROSE, T. Y.; ASHE, M. C.; GRAF, P.; BEATTIE, B. L.; KHAN, K. M. Increased risk of falling in older community-dwelling women with mild cognitive impairment. Physical Therapy, v. 88, n. 12, p. 1482-1491, 2008.

52. LORD, S. R. Visual risk factors for falls in older people. Age and Ageing, v. 35, n. S2, p. ii42-ii45, 2006.

53. MANCKOUNDIA, P.; PFITZENMEYER, P.; D'ATHIS, P.; DUBOST, V.; MOUREY, F. Impact of cognitive task on the posture of elderly subjects with Alzheimer's disease compared to healthy elderly subjects. Movement Disorders, v. 21, n. 2 , p. 236-241, 2006.

54. MCCAFFREY, R. J.; ORTEGA, A.; HAASE, R. F. Effects of repeated neuropsychological assessments. Archives of Clinical Neuropsychology, v. 8, n. 6, p. 519-524, 1993.

55. MELZER, I.; SHTILMAN, I.; ROSENBLATT, N.; ODDSSON, L. I. E. Reliability of voluntary step execution behavior under single and dual task conditions. Journal of NeuroEngineering and Rehabilitation, v. 4, n. 16, p. 1622, 2007.

56. MELZER, I.; ODDSSON, L. I. E. The effect of a cognitive task on voluntary step execution in healthy elderly and young individuals. Journal of the American Geriatric Society, v. 52, n. 8, p. 1255-1262, 2004. 
57. MINER, T.; FERRARO, R. The role of speed of processing, inhibitory mechanisms and presentation order in Trail Making Test Performance. Brain and Cognition, v. 38, n. 2, p. 246-253, 1998.

58. MIYAMOTO, S. T.; LOMBARDI-JR I.; BERG, K. O.; RAMOS, L. R.; NATOUR, J. Brazilian version of the Berg balance scale. Brazilian Journal of Medical and Biological Research, v. 37, n. 9, p. 1411-1421, 2004.

59. NEVES, E. T. Aprendizagem de movimentos seqüenciais de dedos em idosos saudáveis: efeito da escolaridade. Dissertação (Mestrado). Instituto de Psicologia, Neurociências e Comportamento, Universidade de São Paulo, São Paulo, 92 f., 2008.

60. NITRINI, R.; CARAMELLI, P.; HERRERA-JR, E.; PORTO, C. S.; CHARCHAT - FICHMAN, H.; CARTHERT, M.T. et al. Performance of illiterate and literate non-demented elderly subjects in two tests of long-term memory. Journal of the International Neuropsychological Society, v. 10, n. 4, p. 634-638, 2004.

61. NITRINI, R.; CARAMELLI, P.; HERRERA-JR, E.; CHARCHATFICHMAN, H. ; PORTO, H. S. Performance in Luria's fist-edge-palm test according to educational level. Cognitive and Behavioral Neurology, v. 18, n. 4, p. 211-214, 2005. 
62. NOVACK, T. A.; BAÑOS, J. H.; ALDERSON, A. L.; SCHNEIDER, J. J.; WEED, W.; BLANKENSHIP, J.; SALISBURY, D. UFOV performance and driving ability following traumatic brain injury. Brain Injury, v. 20, n. 5, p. 455$461,2006$.

63. OLIVEIRA-SOUZA, R.; MOLL, J.; PASSMAN, L. J.; CUNHA, F. C.; PAES, F.; ADRIANO, M. V. et al. Trail making and cognitive set-shifting. Arquivos de Neuropsiquiatria, v. 58, n. 3-B, p. 826-829, 2000.

64. OSTWALD, S. K.; SNOWDON, D. A.; RYSAVY, D. M.; KEENAN, N. L.; KANE, R. L. Manual dexterity as a correlate of dependency in the elderly. Journal of the American Geriatrics Society, v. 37, n. 10, p. 963-969, 1989.

65. OXLEY, J. A.; IHSEN, E.; FILDES, B. N.; CHARLTON, J. L.; DAY, R. H. Crossing roads safely: an experimental study of age differences in gap selection by pedestrians. Accident Analysis and Prevention, v. 37, n. 5, p. 962-971, 2005.

66. PARADISE, M.; COOPER, C.; LIVINGSTON, G. Systematic review of the effect of education on survival in Alzheimer's disease. International Psychogeriatrics, v. 21, n.1, p. 25-32, 2009.

67. PERIÀÑEZ, J. A.; RÌOS-LAGO, M.; RODRIGUEZ-SANCHEZ, J. M.; ADROVER-ROIG, D.; SANCHEZ-CUBILLO, I.; CRESPO-FACORRO, B. et al. Trail Making Test in traumatic brain injury, schizophrenia, and normal ageing: 
sample comparisons and normative data. Archives of Clinical Neuropsychology, v. 22 , n. 4 , p. 433-447, 2007.

68. PETERSSON, K. M; REIS, A.; INGVAR, M. Cognitive processing in the literate and illiterate subjects: A review of some recent behavioral and functional neuroimaging data. Scandinavian Journal of Psychology, v. 42, n. 3, p. 251 267, 2001.

69. REBOK, G. W.; CARLSON, M. C.; LANGBAUM, J. C. Training and maintaining memory abilities in healthy older adults: traditional and novel approaches. The Journals of Gerontology Series B: Psychological Sciences and Social Sciences Advance Access, v. 62, n. 1, p. 53-61, 2007.

70. REIS, A.; PETERSSON, K. M.; CASTRO-CALDAS, A.; INGVAR, M. Formal schooling influences two- but not three-dimensional naming skills. Brain and Cognition, v. 47, n. 3; p. 397-411, 2001.

71. REIS, A.; FAÍSCA, L.; INGVAR, M.; PETERSSON, K. M. Color makes a difference: two-dimensional object naming in literate and illiterate subjects. Brain and Cognition, v. 60, n. 1, p. 49-54, 2006.

72. REITAN, R. Validity of the Trail Making Test as an indicator of organic brain damage. Perceptual and Motor Skills, v. 8, n. 1, p. 271-276, 1958. 
73. ROE, C. M.; XIONG, C.; MILLER, J. P.; MORRIS, J. C. Education and Alzheimer disease without dementia: support for the cognitive reserve hypothesis. Neurology, v. 68, n. 3, p. 223-228, 2007.

74. ROSSINI, E. D.; KARL, M. A. The Trail Making test A and B: a technical note on structural nonequivalence. Perceptual and Motor Skills, v. 78, n. 2, p. 625-626, 1994.

75. SAHADEVAN, S.; TAN, NJL; TAN, T.; TAN, S. Cognitive testing of elderly Chinese people in Singapore: influence of education and age on normative scores. Age and Ageing, v. 26, n. 6, p. 481-486, 1997.

76. SEO, E. H.; LEE, D. Y.; KIM, K. W.; LEE, J. H.; JHOO, J. H.; YOUN, J. C. et al. A normative study of the Trail Making Test in Korean elders. International Journal of Geriatric Psychiatry, v. 21, n. 9, p. 844-852, 2006.

77. SHIBUYA-TAYOSHI, S.; SUMITANI, S.; KIKUCHI, K.; TANAKA, T.; TAYOSHI, S.; UENO, S. et al. Activation of the prefrontal cortex during the Trail-Making Test detected with multichannel near-infrared spectroscopy. Psychiatry and Clinical Neurosciences, v. 61, n. 6, p. 616-621, 2007.

78. SNOWDON, D. A.; OSTWALD, S. K.; KANE, R. L. Education, survival, and independence in elderly Catholic sisters, 1936-1988. American Journal of Epidemiology, v. 130, n. 5, p. 999-1012, 1989. 
79. SNOWDON, D. A.; KEMPER, S. J.; MORTIMER, J. A.; GREINER, L. H.; WEKSTEIN, D. R.; MARKESBERY, W. R. Linguistic ability in early life and cognitive function and Alzheimer's disease in late life. Findings from the Nun Study. The Journal of the American Medical Association ${ }_{2}$ v. 275, n. 7, p. 528532, 1996.

80. SPARROW, W. A.; BRADSHAW, E. J.; LAMOUREUX, E.; TIROSH, O. Aging effects on the attention demands of walking. Human Movement Science, v. 21, n. 5-6, p. 961-972, 2002.

81. STERN, Y.; ALEXANDER, G. E.; PROHOVNIK, I.; MAYEUX, R. Inverse relationship between education and parietotemporal perfusion deficit in Alzheimer's disease. Annals of Neurology, v. 32, n. 3, p. 371-375, 1992.

82. STERN, Y.; HABECK, C.; MOELLER, J.; SCARMEAS, N.; ANDERSON, K. E.; HILTON, H. J. et al. Brain networks associated with cognitive reserve in healthy young and old adults. Cerebral Cortex, v. 15, n. 4, p. 394-402, 2005.

83. STUSS, D. T.; BISSCHOP, S. M.; ALEXANDER, M. P.; LEVINE, B.; KATZ, D.; IZUKAWA, D. The Trail Making Test: A study in focal lesion patients. Psychological Assessment, v. 13, n. 2, p. 230-239, 2001.

84. TEIXEIRA, P. P. S.; VOOS, M. C.; ANDRADE-MACHADO, M. S.; CAStelli, L. Z.; RIBEIRO-DO-VAlle, L. E.; PIEMONTE, M. E. P. 
Interferência mútua entre atividade visual e atividade motora em jovens e idosos. Fisioterapia \& Pesquisa, v. 15, n. 2, p. 142-148, 2008.

85. TISSERAND, D. J.; VAN BOXTEL, M. P. J.; PRUESSNER, J. C.; HOFMAN, P.; EVANS, A. C.; JOLES, J. A voxel-based morphometric study to determine individual differences in gray matter density associated with age and cognitive change over time. Cerebral Cortex, v. 14, n. 9, p. 966-973, 2004.

86. TOMBAUGH, T. N. Trail Making Test A and B: Normative data stratified by age and education. Archives of Clinical Neuropsychology, v. 19, n. 2, p. 203214, 2004.

87. TUN, P. A.; LACHMAN, M. E. Age Differences in Reaction time and Attention in a National Telephone Sample of Adults: Education, Sex, and Task Complexity Matter. Developmental Psychology, v. 44, n. 5, p. 1421-1429, 2008.

88. TURANO, K. A.; BROMAN, A. T.; BANDEEN-ROCHE, K.; MUÑOZ, B.; RUBIN, G. S.; WEST, S. Association of visual field loss and mobility performance in older adults: Salisbury eye evaluation study. Optometry and Vision Science, v. 81, n. 5, p. 298-307, 2004.

89. UC, E. Y.; RIZZO, M.; ANDERSON, S. W.; SPARKS, J.; RODNITSKY, R. L.; DAWSON, J. D. Impaired visual search in drivers with Parkinson's Disease. Annals of Neurology, v. 60, n. 4, p. 407-413, 2006. 
90. VAN DER ELST, W.; VAN BOXTEL, M. P.; VAN BREUKELEN, G. J.; JOLLES, J. The Stroop color-word test: influence of age, sex, and education, and normative data for a large sample across the adult age range. Assessment, v. 13 , n. 1, p. 62-79, 2006.

91. VAN IERSEL, M. B.; RIBBERS, H.; MUNNEKE, M.; BORM, G. F.; OLDE RIKKERT, M. G. The effect of cognitive dual tasks on balance during walking in physically fit elderly people. Archives of Physical Medicine and Rehabilitation, v. 88, n. 2, p. 187-191, 2007.

92. VERGHESE, J.; KUSLANSKY, G.; HOLTZER, R.; KATZ, M.; XUE, X.; BUSCHKE, H.; PAHOR, M. Walking while talking: effect of task prioritization in the elderly. Archives of Physical Medicine and Rehabilitation, v. 88, n. 1, p. 5053, 2007.

93. VON HOFSTEN. Action in development. Developmental Science, v. 10, n. 1, p. 54-60, 2007.

94. VOOS, M. C.; CUSTÓDIO, E.; MALAQUIAS, J. Relationship of executive function and educational status with functional balance in older adults. Journal of Geriatric Physical Therapy. 2009. Submetido.

95. YAMAZAKI, G. N. Comparação da capacidade atentiva de idosos saudáveis e com Doença de Parkinson: implicações para a reabilitação. Monografia (Graduação). Departamento de Fisioterapia, Fonoaudiologia e 
Terapia Ocupacional, Faculdade de Medicina, Universidade de São Paulo, São Paulo, 2009.

96. YAO, S.; ZENG, H.; SUN, S. Investigation on status and influential factors of cognitive function of the community: dwelling elderly in Changsha City. Archives of Gerontology and Geriatry, v.49, n.3, p. 329-334, 2009.

97. YASSUDA, M.; DINIZ, B. S. O.; FLAKS, M. K.; VIOLA, L. F.; PEREIRA, F. S. et al. Neuropsychological profile of Brazilian older adults with heterogeneous educational backgrounds. Archives of Clinical Neuropsychology, v. 24, n.1, p. 71-79, 2009.

98. ZALONIS, I.; KARARIZOU, E.; TRIANTAFYLLOU, N. I.; KAPAKI, E.; PAPAGEORGIOU, S.; SGOUROPOULOS, P. et al. A normative study of the trail making test A and B in Greek adults. The Clinical Neuropsychologist, v. 22, n. 5, p. 842-850, 2007.

99. ZIMMERMAN, M.E.; BRICKMAN, A.M.; PAUL, R.H.; GRIEVE, S.M.; TATE, D.F.; GUNSTAD, J. et al. The relationship between frontal gray matter volume and cognition varies across the healthy adult lifespan. American Journal of Geriatric Psychiatry, v. 14, n. 10, p. 823-833, 2006. 


\section{ANEXO A}

Trail Making Test - Partes A e B

Instruções dadas segundo Bowie \& Harvey (2006).

Figura 7 - Exemplo do TMT, realizado pelo examinador - Parte A

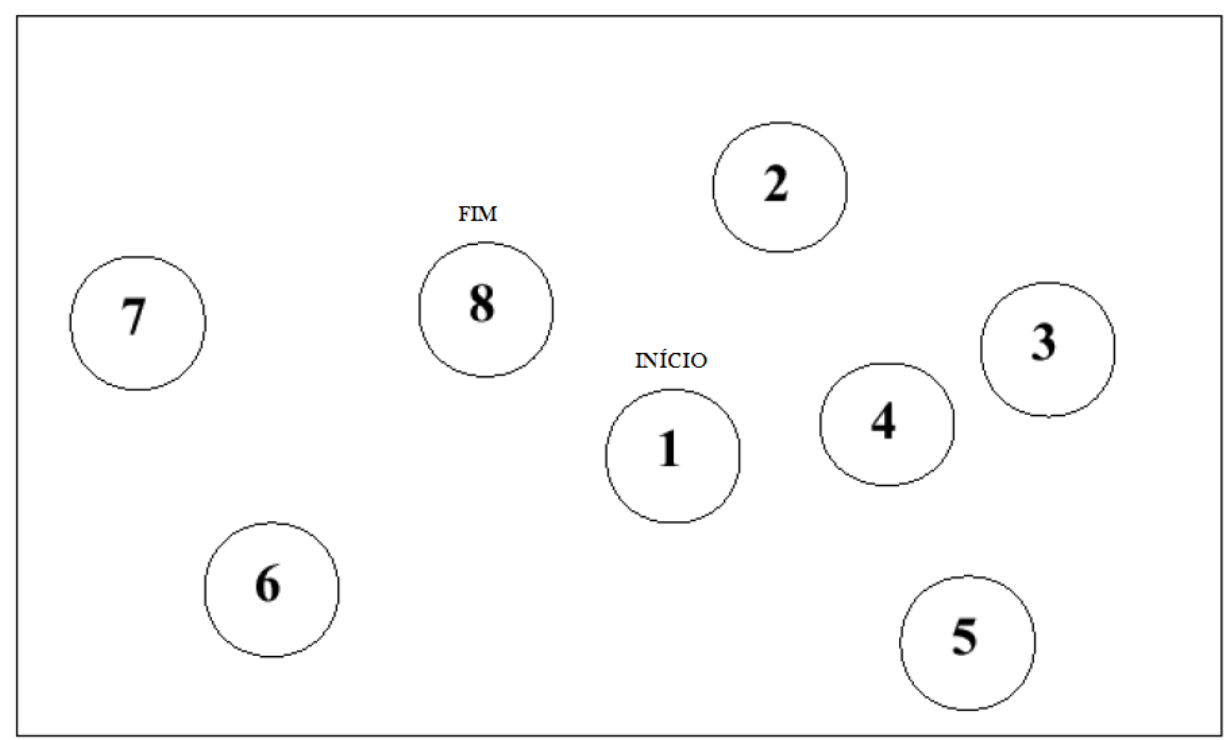


Figura 8 - Versão do Trail Making Test realizada pelo paciente (Parte A)

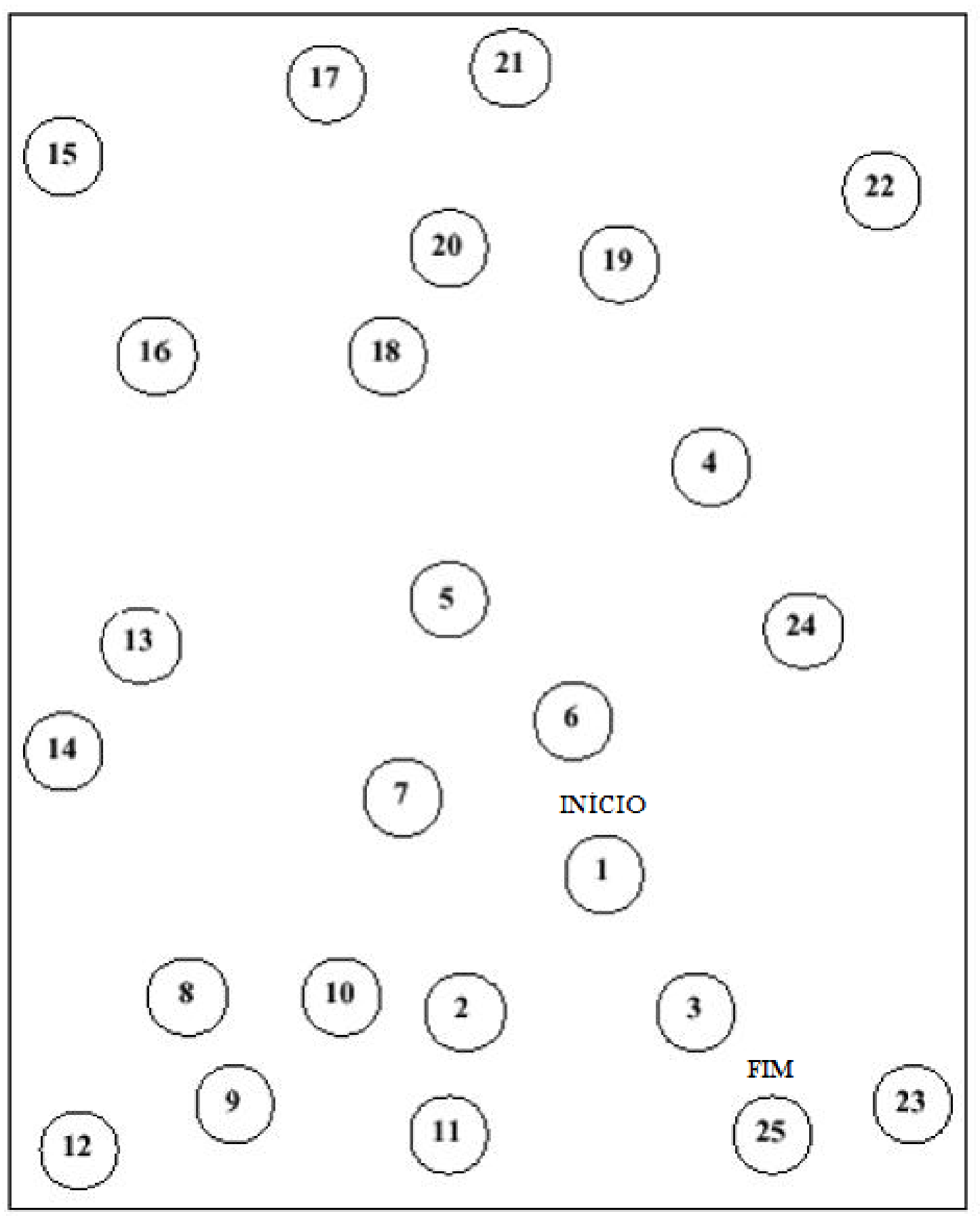


Figura 9 - Exemplo do TMT, realizado pelo examinador - Parte B

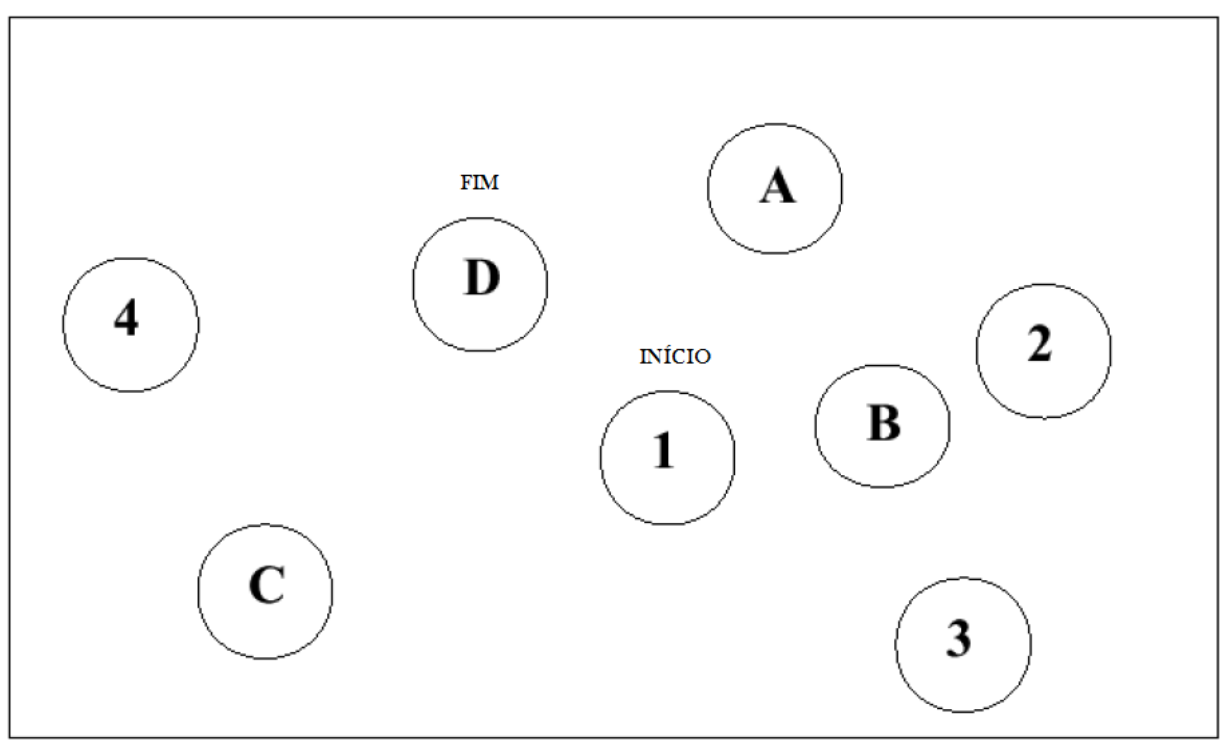


Figura 10 - Versão do Trail Making Test realizada pelo paciente (Parte B)

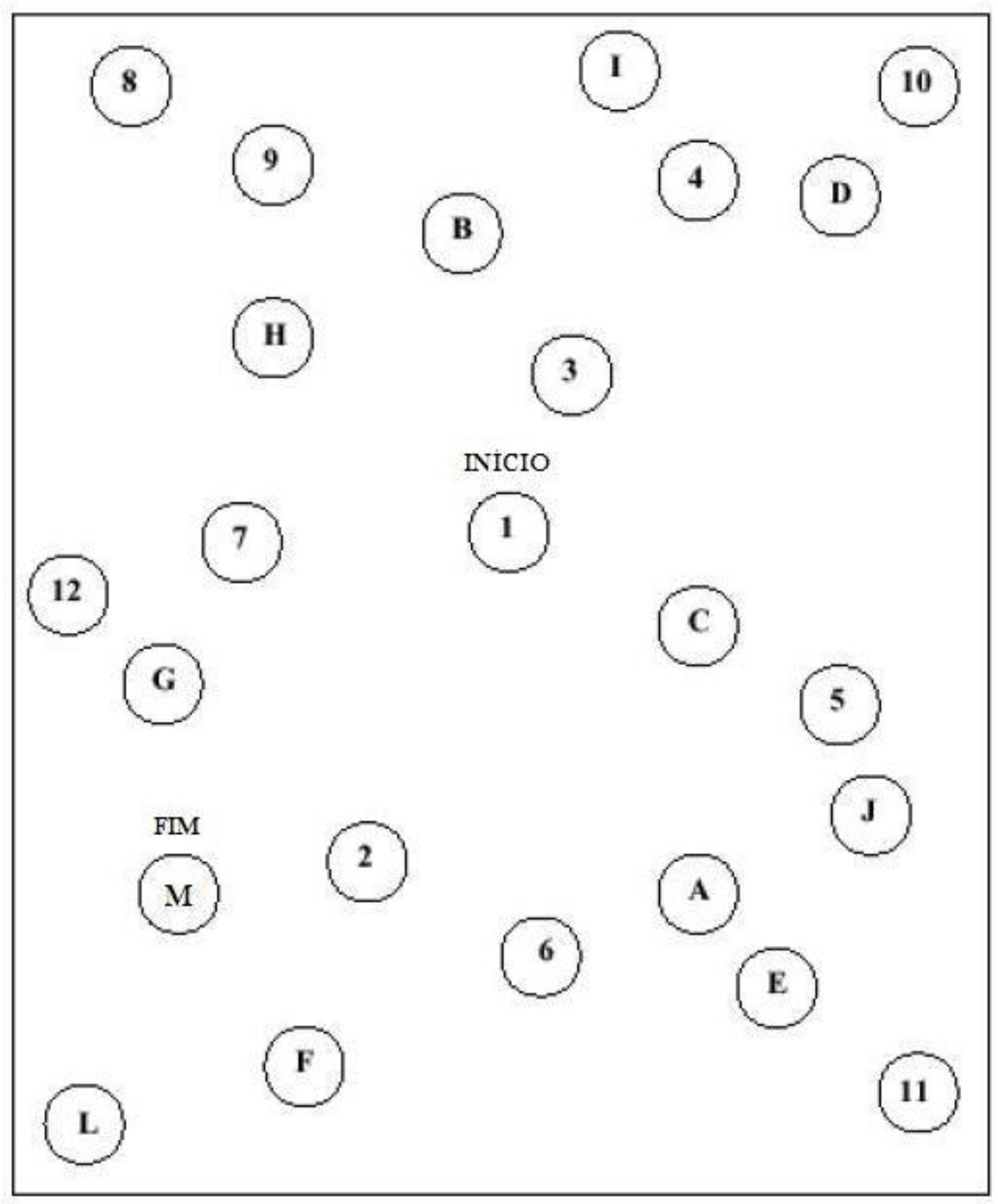




\section{ANEXO B: Teste de Deambulação Funcional}

Figura 11 - Exemplo realizado pelo examinador (Parte A)

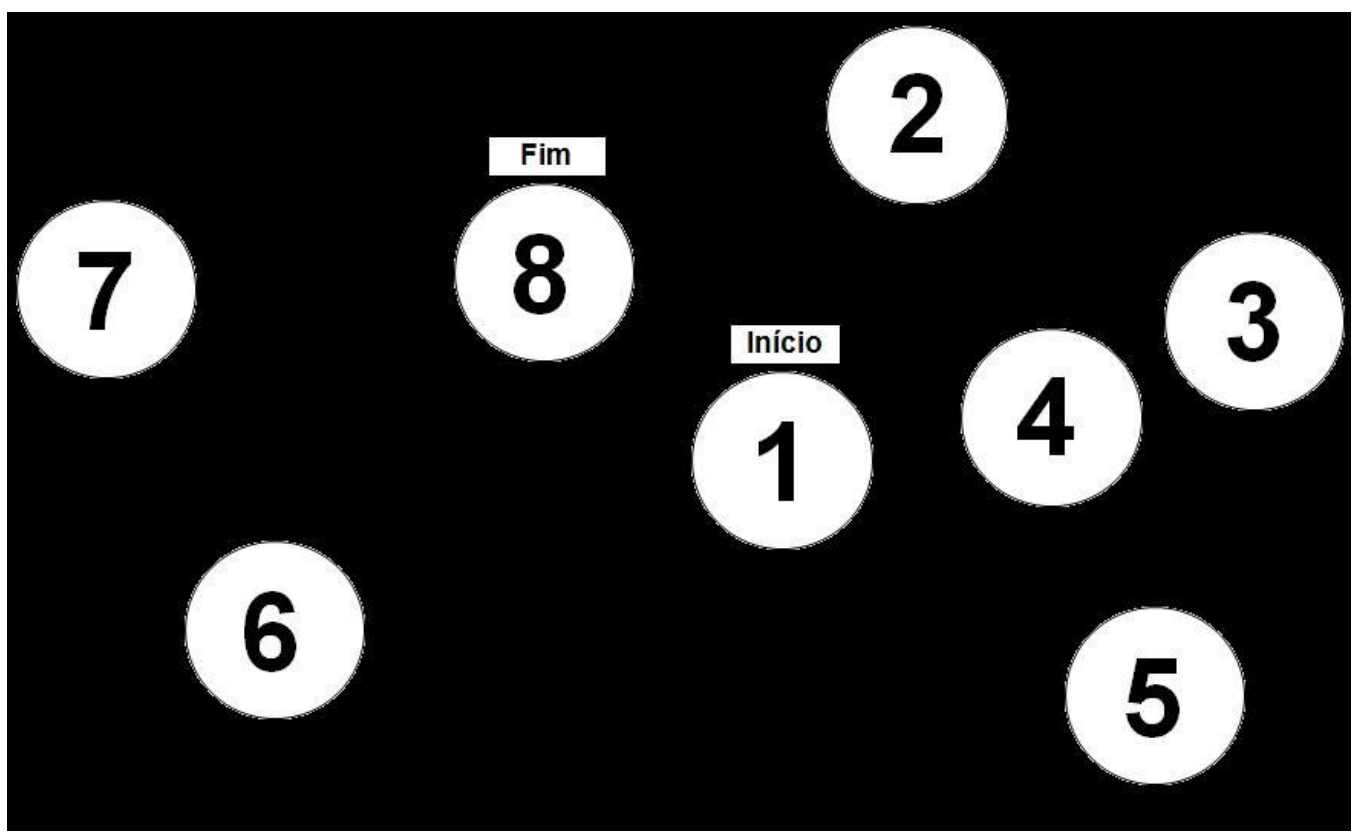

\section{Instrução:}

"O senhor (a senhora) deverá andar dentro deste retângulo, pisando nos números de 1 a 8 , na ordem certa. Precisa fazer isso o mais rápido possível, mas não pode errar a seqüência. Eu vou fazer uma vez para o senhor (a senhora) ver como é, depois o senhor (a senhora) vai fazer também uma vez também."

O examinador realiza o trajeto do modelo e, em seguida, o voluntário faz o mesmo. Se houver qualquer tipo de erro, o examinador diz: "Espere um momento. O senhor (a senhora) errou este número. Volte para o número e continue". 
Figura 12 - Versão do Teste de Deambulação Funcional realizada pelo paciente (Parte A)

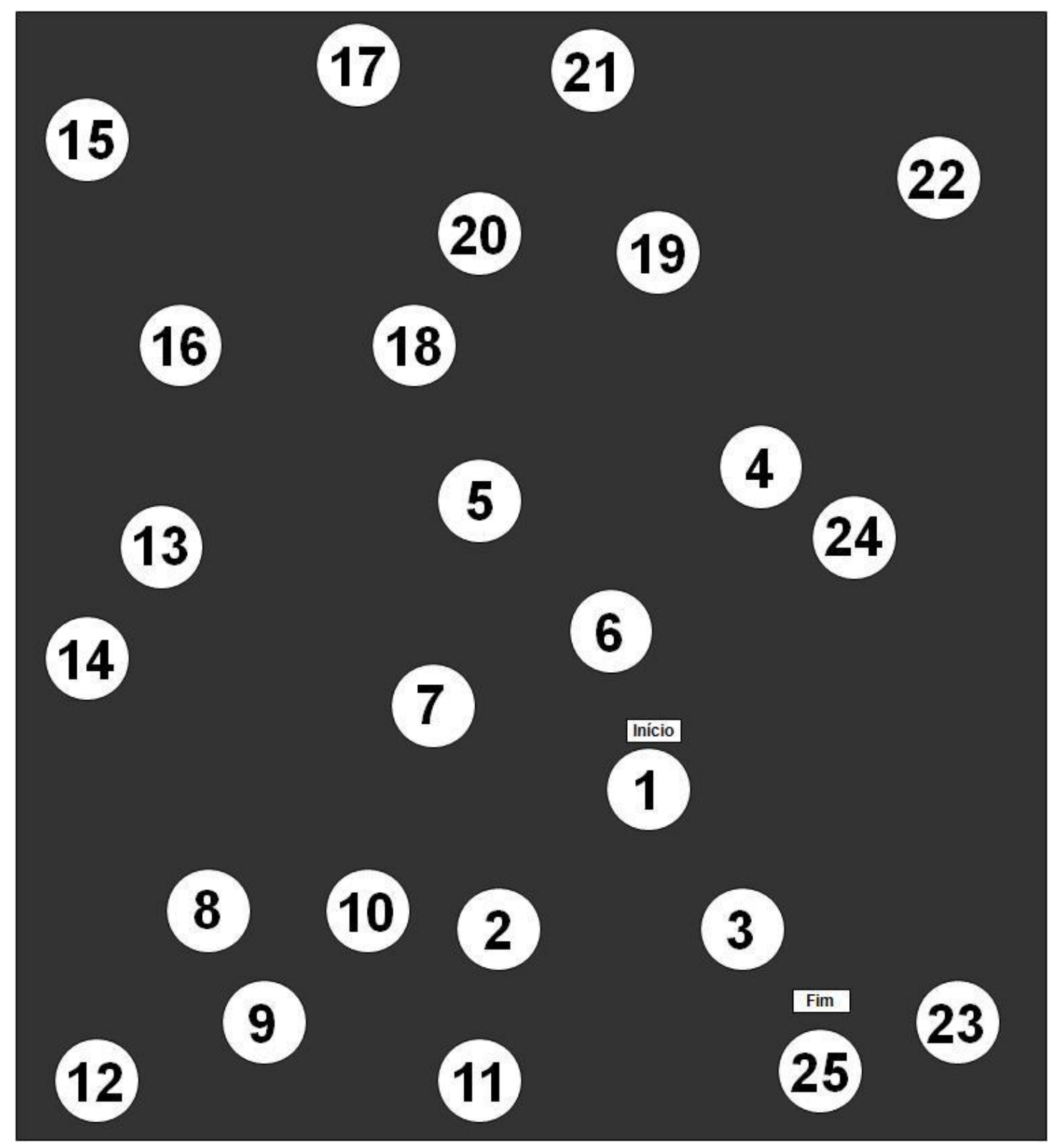

Instrução:

"Agora o senhor (a senhora) vai fazer a mesma coisa, mas os números vão de 1 a 25. Não precisa pisar só nas bolinhas brancas, pode andar pisando na parte preta também. Mas precisa ser o mais rápido possível e sem errar." Se houver erro, repetir o procedimento do modelo.

Figura 13 - Exemplo realizado pelo examinador (Parte B) 


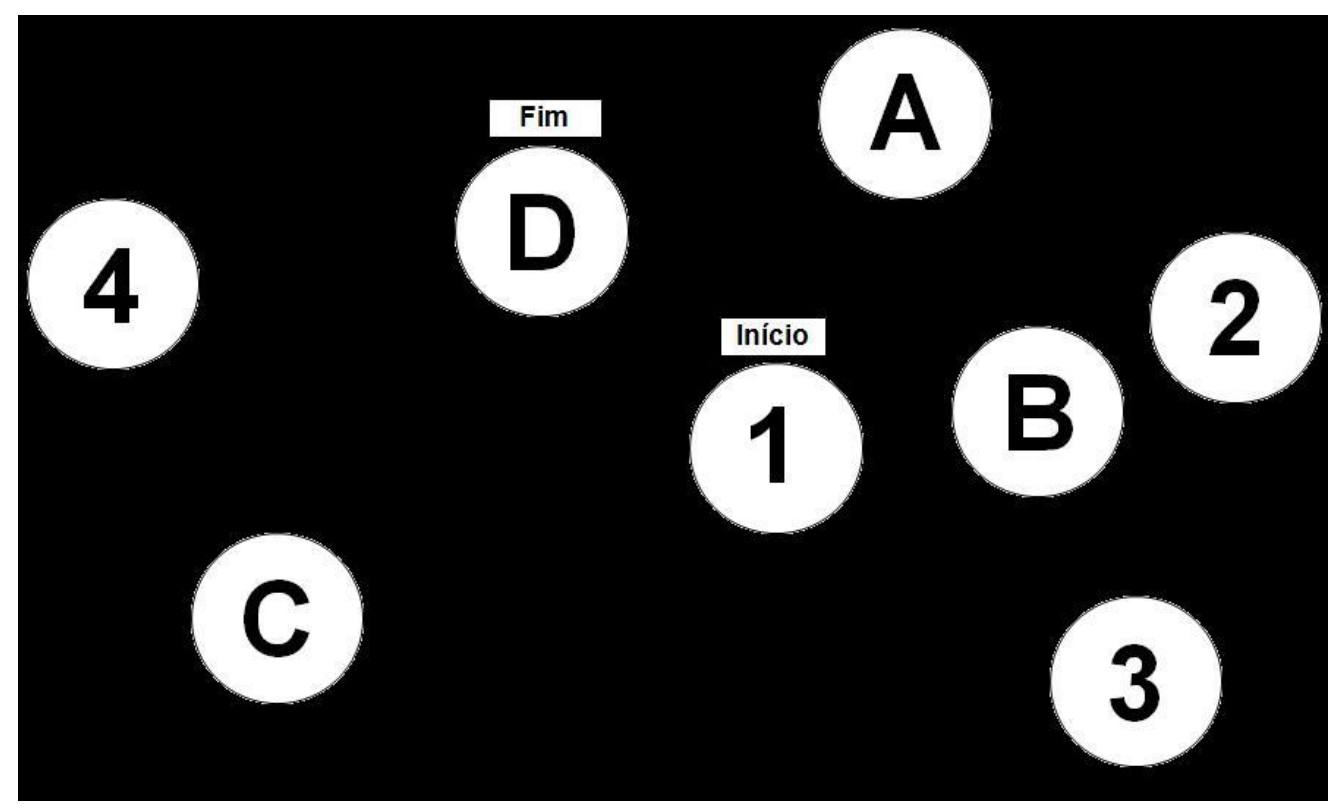

\section{Instrução:}

"Agora o senhor (a senhora) deverá andar dentro deste retângulo, pisando nos números e nas letras na ordem certa. Vai pisar primeiro num número, depois numa letra, depois num número de novo e assim por diante. A ordem vai ser: 1A, 2B, 3C, qual vem depois?" O voluntário deve responder 4D. Se a resposta estiver errada, corrigir e explicar esse trecho novamente.

"Precisa fazer isso o mais rápido possível, mas não pode errar a seqüência. Eu vou fazer uma vez para o senhor (a senhora) ver como é, depois o senhor (a senhora) vai fazer também uma vez também."

O examinador realiza o trajeto do modelo e, em seguida, o voluntário faz o mesmo. Se houver qualquer tipo de erro, o examinador diz: "Espere um momento. O senhor (a senhora) errou este número/ esta letra. Volte para o número/ a letra e continue". 
Figura 14 - Versão do Teste de Deambulação Funcional realizada pelo paciente (Parte B)

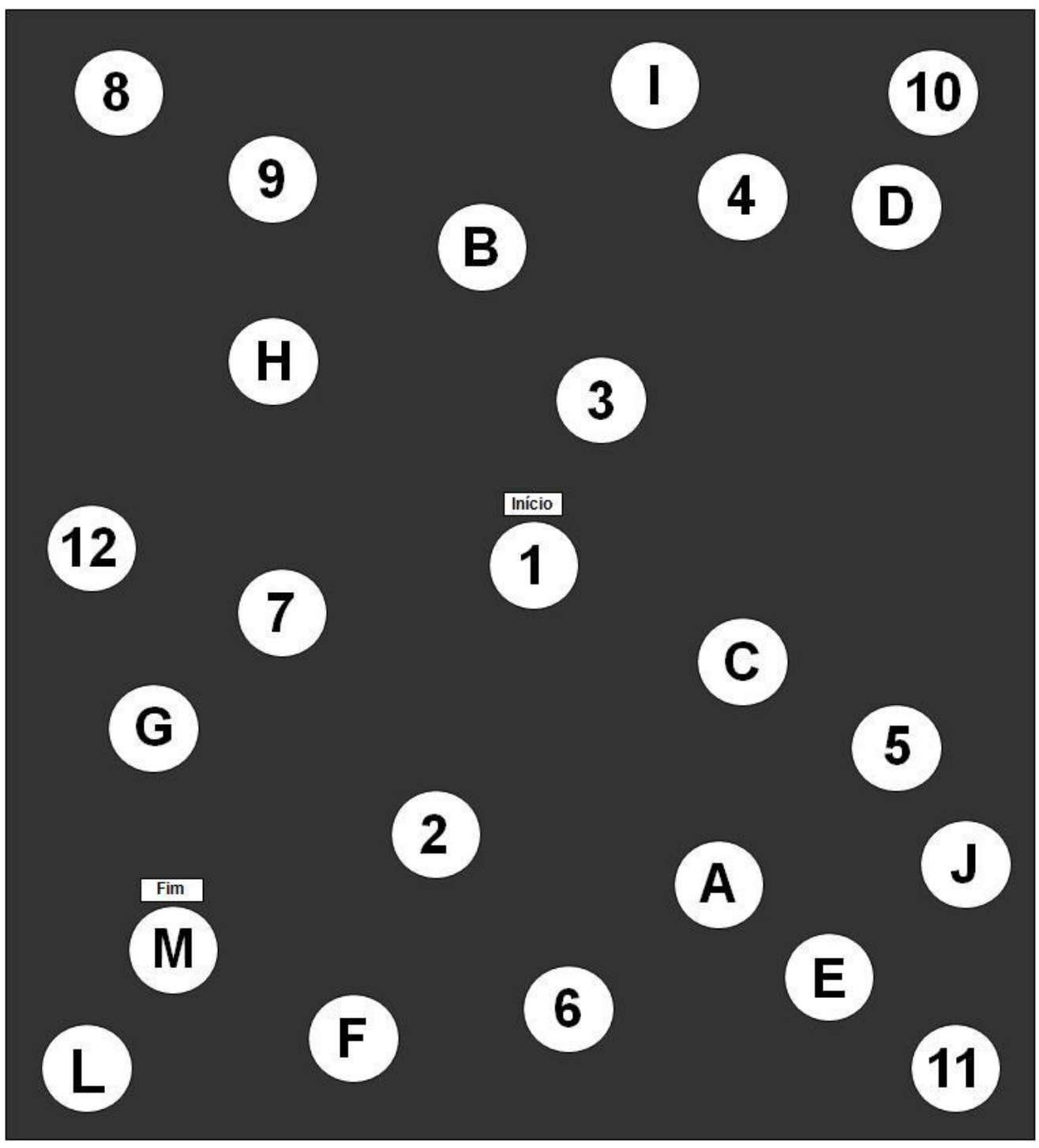

\section{Instrução}

"Agora o senhor (a senhora) vai fazer a mesma coisa, mas os números vão de 1 até 12 e as letras vão de A até M. Não precisa pisar só nas bolinhas brancas, pode andar pisando na parte preta também. Mas precisa ser o mais rápido possível e sem errar. Não se esqueça de que é sempre um número e depois uma letra, um número e uma letra de novo, até aparecer a palavra FIM." Se houver erro, repetir o procedimento do modelo. 


\section{ANEXO C}

HOSPITAL DAS CLÍNICAS DA FACULDADE DE MEDICINA DA

UNIVERSIDADE DE SÃO PAULO-HCFMUSP

TERMO DE CONSENTIMENTO LIVRE E ESCLARECIDO

\section{DADOS DE IDENTIFICAÇÃO DO SUJEITO DA PESQUISA OU RESPONSÁVEL LEGAL}

1. NOME:

DOCUMENTO DE IDENTIDADE № :

SEXO : $M \square F_{\square}$

DATA NASCIMENTO

ENDEREÇO

№

APTO:

BAIRRO: CIDADE

CEP:

TELEFONE: DDD

2.RESPONSÁVEL LEGAL

NATUREZA (grau de parentesco, tutor, curador etc.)

DOCUMENTO DE IDENTIDADE : SEXO: $M \square F \square$ DATA NASCIMENTO.:

ENDEREÇO:

№ APTO

BAIRRO:

CIDADE:

CEP:

TELEFONE: DDD (

DADOS SOBRE A PESQUISA

1. TÍTULO DO PROTOCOLO DE PESQUISA: VALIDAÇÃO DE UM NOVO TESTE DE MARCHA PARA IDOSOS: O TESTE DE DEAMBULAÇÃO FUNCIONAL (TDF)

2. PESQUISADOR: Mariana Callil Voos

CARGO/FUNÇÃO: Fisioterapeuta INSCRIÇÃO CONSELHO REGIONAL № 3/31192-F UNIDADE DO HCFMUSP: Departamento de Fisioterapia, Fonoaudiologia e Terapia Ocupacional

3. AVALIAÇÃO DO RISCO DA PESQUISA: RISCO MÍNIMO X RISCO MÉDIO

RISCO BAIXO $\square \quad$ RISCO MAIOR

4.DURAÇÃO DA PESQUISA : 24 meses 
1 - O objetivo deste trabalho é estudar a capacidade de andar rápido e de mudar de direção. Isso é importante para (1) conhecermos o desempenho de pessoas saudáveis para futuras comparações com pacientes e com outros testes; (2) termos certeza de que esse teste serve para avaliar as pessoas e (3) verificarmos se, com as repetições, as pessoas se tornam mais rápidas e erram menos.

2 - O Senhor/A Senhora deverá andar sobre uma superfície antiderrapante de 2,0 X 2,5 metros seguindo uma seqüência. Na parte $A$, haverá números pretos de 1 a 25, dentro de círculos brancos. O tempo será cronometrado e os erros (pisar no número errado) serão registrados. Na parte $B$, haverá números de $1 \mathrm{a}$ 12 alternados com letras de A a M (exemplo: 1, A, 2, B, 3, C, etc.). No primeiro dia, o teste será realizado oito vezes seguidas para a parte $A$ e oito para a parte $B$. Uma semana depois, haverá uma reavaliação. Tanto na primeira quanto na segunda sessão, outros testes serão realizados: ligar números e letras em uma folha de papel, responder a algumas perguntas.

3 - Um examinador permanecerá o tempo todo do experimento ao seu lado, para minimizar o risco de desequilíbrio ou queda em todos os procedimentos propostos. A pressão arterial será medida diversas vezes durante o estudo. Se a pressão arterial estiver acima do normal, o experimento será interrompido. Será feito um teste de leitura para verificar sua capacidade visual.

4 - O Senhor/ A Senhora poderá sentir cansaço ou desequilíbrio. Se houver algum desconforto, o experimento será interrompido. Todas as pessoas que apresentarem risco de quedas ou dificuldades de locomoção serão orientadas e encaminhadas ao ambulatório de fisioterapia.

5 - Somente no final do estudo poderemos concluir a presença de algum benefício, mas é possível que haja melhora da atenção e do equilíbrio com o procedimento realizado. Nesse caso, o ganho poderá ser mantido com a realização dos exercícios parecidos com os realizados durante o experimento, que serão orientados pelo examinador no final da segunda sessão.

6 - O procedimento que poderá ser vantajoso é a execução repetida do Teste de Deambulação Funcional.

7 - Garantia de acesso: em qualquer etapa do estudo, o Senhor/ a Senhora terá acesso aos profissionais responsáveis pela pesquisa para esclarecimento de eventuais dúvidas. O principal investigador é a Ft. Ms. Mariana Callil Voos, que pode ser encontrada na R Cipotânea, 51, Telefone 30917464. Se tiver alguma consideração ou dúvida sobre a ética da pesquisa, entre em contato com o Comitê de Ética em Pesquisa (CEP) - Rua Ovídio Pires de Campos, 225 - 5o andar - tel: 3069-6442 ramais 16, 17, 18 ou 20, FAX: 3069-6442 ramal 26, email: cappesq@hcnet.usp.br.

8 - É garantida a liberdade da retirada de consentimento a qualquer momento e deixar de participar do estudo, sem qualquer prejuízo;

9 - Direito de confidencialidade - As informações obtidas serão analisadas em conjunto com outros pacientes, não sendo divulgada a identificação de nenhum paciente;

10 - O Senhor / a Senhora poderá ser mantido(a) atualizado(a) sobre os resultados parciais das pesquisas, quando em estudos abertos, ou de resultados que sejam do conhecimento dos pesquisadores;

11 - Despesas e compensações: não há despesas pessoais em qualquer fase do estudo, incluindo exames e consultas. Também não há compensação financeira relacionada à sua participação. Se existir qualquer despesa adicional, ela será absorvida pelo orçamento da pesquisa.

12 - Em caso de dano pessoal, diretamente causado pelos procedimentos ou tratamentos propostos neste estudo (nexo causal comprovado), o participante terá direito a tratamento médico na Instituição. 
13 - Existe o compromisso do pesquisador de usar os dados e o material coletado somente para esta pesquisa.

Acredito ter sido suficientemente informado a respeito das informações que li ou que foram lidas para mim, descrevendo o estudo: "Validação de um novo teste de marcha para idosos: o Teste de Deambulação Funcional (TDF)".

Eu discuti com a Ft. Ms. Mariana Callil Voos sobre a minha decisão em participar nesse estudo. Ficaram claros para mim quais são os objetivos do estudo, os procedimentos, seus desconfortos e riscos, as garantias de confidencialidade e de esclarecimentos permanentes. Ficou claro também que minha participação é gratuita e que tenho garantia do acesso a tratamento hospitalar quando necessário. Concordo voluntariamente em participar deste estudo e poderei retirar o meu consentimento a qualquer momento, antes ou durante o mesmo, sem penalidades ou prejuízo ou perda de qualquer benefício que eu possa ter recebido, ou no meu atendimento neste Serviço.

Assinatura do paciente/representante legal

Data

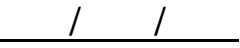

Assinatura da testemunha

Data

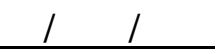

Para casos de pacientes menores de 18 anos, analfabetos, semi-analfabetos ou portadores de deficiência auditiva ou visual.

(Somente para o responsável do projeto)

Declaro que obtive de forma apropriada e voluntária o Consentimento Livre e Esclarecido deste paciente ou representante legal para a participação neste estudo.

Data

11

\section{ANEXO D}


Tabela 12: Resultados do teste post hoc de Tukey, realizado após ter sido constatada a interação idade $X$ escolaridade $X$ avaliação $X$ parte do teste $\left[F_{22,704}=1,64 ; p=0,033\right]$. Legenda: $A$ : avaliação, TDF: Teste de Deambulação Funcional.

\begin{tabular}{|c|c|c|c|c|c|}
\hline Comparações & $p$ & Comparações & $\mathrm{p}$ & Comparações & $p$ \\
\hline $\mathrm{A} 1 \times \mathrm{A} 2$ & 0,999 & A3 X A5 & 0,999 & A5 X A12 & 0,999 \\
\hline$\overline{A 1 \times A 3}$ & 0,999 & $\mathrm{~A} 3 \times \mathrm{A} 6$ & 0,999 & $\mathrm{~A} 6 \times \mathrm{A} 7$ & 0,999 \\
\hline $\mathrm{A} 1 \times \mathrm{A} 4$ & 0,992 & A3 X A7 & 0,999 & $\mathrm{~A} 6 \times \mathrm{A} 8$ & 0,999 \\
\hline $\mathrm{A} 1 \times \mathrm{A} 5$ & 0,955 & $A 3 \times A 8$ & 0,999 & $A 6 \times A 9$ & 0,999 \\
\hline $\mathrm{A} 1 \times \mathrm{A} 6$ & 0,671 & A3 X A9 & 0,999 & A6 X A10 & 0,999 \\
\hline $\mathrm{A} 1 \times \mathrm{A} 7$ & 0,371 & A3 $\times$ A10 & 0,999 & $\mathrm{~A} 6 \times \mathrm{A} 11$ & 0,999 \\
\hline $\mathrm{A} 1 \times \mathrm{A} 8$ & 0,224 & A3 X A11 & 0,999 & $\mathrm{~A} 6 \times \mathrm{A} 12$ & 0,999 \\
\hline A1 X A9 & 0,982 & A3 X A12 & 0,999 & A7 X A8 & 0,999 \\
\hline $\mathrm{A} 1 \mathrm{X} \mathrm{A} 10$ & 0,578 & A4 X A5 & 0,999 & A7 X A9 & 0,999 \\
\hline $\mathrm{A} 1 \mathrm{X} \mathrm{A} 11$ & 0,371 & $\mathrm{~A} 4 \times \mathrm{A} 6$ & 0,999 & A7 X A10 & 0,999 \\
\hline $\mathrm{A} 1 \mathrm{X} \mathrm{A} 12$ & 0,168 & A4 X A7 & 0,999 & A7 X A11 & 0,999 \\
\hline $\mathrm{A} 2 \times \mathrm{A} 3$ & 0,999 & $\mathrm{~A} 4 \times \mathrm{A} 8$ & 0,999 & A7 X A12 & 0,999 \\
\hline $\mathrm{A} 2 \times \mathrm{A} 4$ & 0,999 & A4 X A9 & 0,999 & A8 X A9 & 0,999 \\
\hline $\mathrm{A} 2 \times \mathrm{A} 5$ & 0,999 & $\mathrm{~A} 4 \times \mathrm{A} 10$ & 0,999 & $\mathrm{~A} 8 \times \mathrm{A} 10$ & 0,999 \\
\hline $\mathrm{A} 2 \times \mathrm{A} 6$ & 0,999 & A4 X A11 & 0,999 & A8 X A11 & 0,999 \\
\hline $\mathrm{A} 2 \times \mathrm{A} 7$ & 0,999 & $\mathrm{~A} 4 \times \mathrm{A} 12$ & 0,999 & $\mathrm{~A} 8 \times \mathrm{A} 12$ & 0,999 \\
\hline $\mathrm{A} 2 \times \mathrm{A} 8$ & 0,999 & A5 X A6 & 0,999 & A9 X A10 & 0,999 \\
\hline A2 $\times$ A9 & 0,999 & A5 X A7 & 0,999 & A9 $\times A 11$ & 0,999 \\
\hline $\mathrm{A} 2 \times \mathrm{A} 10$ & 0,999 & A5 X A8 & 0,999 & A9 X A12 & 0,999 \\
\hline $\mathrm{A} 2 \times \mathrm{A} 11$ & 0,999 & A5 $\times$ A9 & 0,999 & $\mathrm{~A} 10 \times \mathrm{A} 11$ & 0,999 \\
\hline A2 X A12 & 0,999 & A5 X A10 & 0,999 & $\mathrm{~A} 10 \times \mathrm{A} 12$ & 0,999 \\
\hline $\mathrm{A} 3 \times \mathrm{A} 4$ & 0,999 & $\mathrm{~A} 5 \times \mathrm{A} 11$ & 0,999 & $\mathrm{~A} 11 \times \mathrm{A} 12$ & 0,999 \\
\hline \multicolumn{6}{|c|}{ Adultos jovens - Escolaridade alta - Parte B do Teste de Deambulação Funcional } \\
\hline Comparações & $p$ & Comparações & $p$ & Comparações & $\mathrm{p}$ \\
\hline $\mathrm{A} 1 \times \mathrm{A} 2$ & 0,181 & A3 X A5 & 0,999 & A5 X A12 & 0,999 \\
\hline $\mathrm{A} 1 \times \mathrm{A} 3$ & $0,002^{*}$ & $\mathrm{~A} 3 \times \mathrm{A} 6$ & 0,973 & A6 X A7 & 0,999 \\
\hline $\mathrm{A} 1 \times \mathrm{A} 4$ & $0,001^{*}$ & A3 X A7 & 0,851 & $\mathrm{~A} 6 \times \mathrm{A} 8$ & 0,999 \\
\hline $\mathrm{A} 1 \times \mathrm{A} 5$ & $0,001^{*}$ & A3 X A8 & 0,578 & $\mathrm{A6} \times \mathrm{A9}$ & 0,999 \\
\hline $\mathrm{A} 1 \times \mathrm{A} 6$ & $0,001^{*}$ & A3 $\times$ A9 & 0,999 & $\mathrm{~A} 6 \mathrm{X} \mathrm{A} 10$ & 0,999 \\
\hline $\mathrm{A} 1 \times \mathrm{A} 7$ & $0,001^{*}$ & A3 X A10 & 0,738 & $\mathrm{~A} 6 \times \mathrm{A} 11$ & 0,999 \\
\hline $\mathrm{A} 1 \times \mathrm{A} 8$ & $0,001^{*}$ & A3 X A11 & 0,168 & $\mathrm{~A} 6 \times \mathrm{A} 12$ & 0,999 \\
\hline A1 X A9 & $0,001^{*}$ & A3 X A12 & 0,168 & A7 X A8 & 0,999 \\
\hline $\mathrm{A} 1 \times \mathrm{A} 10$ & $0,001^{*}$ & A4 X A5 & 0,999 & A7 X A9 & 0,999 \\
\hline $\mathrm{A} 1 \times \mathrm{A} 11$ & $0,001^{*}$ & $\mathrm{~A} 4 \times \mathrm{A} 6$ & 0,999 & A7 X A10 & 0,999 \\
\hline $\mathrm{A} 1 \mathrm{X} \mathrm{A} 12$ & $0,001^{*}$ & A4 X A7 & 0,999 & A7 X A11 & 0,999 \\
\hline A2 X A3 & 0,999 & $\mathrm{~A} 4 \times \mathrm{A} 8$ & 0,996 & A7 X A12 & 0,999 \\
\hline $\mathrm{A} 2 \times \mathrm{A} 4$ & 0,999 & A4 X A9 & 0,999 & A8 X A9 & 0,999 \\
\hline $\mathrm{A} 2 \times \mathrm{A} 5$ & 0,998 & $\mathrm{~A} 4 \times \mathrm{A} 10$ & 0,999 & $\mathrm{~A} 8 \times \mathrm{A} 10$ & 0,999 \\
\hline $\mathrm{A} 2 \times \mathrm{A} 6$ & 0,168 & A4 X A11 & 0,851 & A8 X A11 & 0,999 \\
\hline $\mathrm{A} 2 \times \mathrm{A} 7$ & 0,997 & A4 X A12 & 0,851 & A8 X A12 & 0,999 \\
\hline $\mathrm{A} 2 \times \mathrm{A} 8$ & 0,062 & A5 X A6 & 0,999 & $\mathrm{~A} 9 \times \mathrm{A} 10$ & 0,999 \\
\hline A2 $\times$ A9 & $0,018^{*}$ & A5 X A7 & 0,999 & A9 $\times \mathrm{A} 11$ & 0,998 \\
\hline $\mathrm{A} 2 \times \mathrm{A} 10$ & 0,999 & A5 X A8 & 0,999 & A9 X A12 & 0,998 \\
\hline $\mathrm{A} 2 \times \mathrm{A} 11$ & $0,036^{*}$ & A5 $\times$ A9 & 0,999 & $\mathrm{~A} 10 \times \mathrm{A} 11$ & 0,999 \\
\hline
\end{tabular}




\begin{tabular}{|c|c|c|c|c|c|}
\hline $\mathrm{A} 2 \times \mathrm{A} 12$ & $0,002^{*}$ & A5 X A10 & 0,999 & $\mathrm{~A} 10 \times \mathrm{A} 12$ & 0,999 \\
\hline A3 $\times$ A4 & 0,999 & A5 $\times$ A11 & 0,999 & $\mathrm{~A} 11 \times \mathrm{A} 12$ & 0,999 \\
\hline \multicolumn{6}{|c|}{ Adultos Maduros - Escolaridade alta - Parte A do Teste de Deambulação Funcional } \\
\hline Comparações & $\mathrm{p}$ & Comparações & $\mathrm{p}$ & Comparações & $\mathrm{p}$ \\
\hline $\mathrm{A} 1 \times \mathrm{A} 2$ & 0,759 & A3 X A5 & 0,999 & A5 X A12 & 0,999 \\
\hline $\mathrm{A} 1 \times \mathrm{A} 3$ & $0,032^{*}$ & A3 $\times$ A6 & 0,999 & A6 X A7 & 0,999 \\
\hline A1 X A4 & $0,016^{*}$ & A3 X A7 & 0,999 & $\mathrm{~A} 6 \times \mathrm{A} 8$ & 0,999 \\
\hline A1 X A5 & $0,001^{*}$ & A3 X A8 & 0,999 & $\mathrm{~A} 6 \times \mathrm{A} 9$ & 0,999 \\
\hline $\mathrm{A} 1 \mathrm{X} \mathrm{A} 6$ & $0,001^{*}$ & A3 $\times$ A9 & 0,999 & $A 6 \times A 10$ & 0,999 \\
\hline A1 X A7 & $0,001^{*}$ & A3 X A10 & 0,999 & $\mathrm{~A} 6 \times \mathrm{A} 11$ & 0,999 \\
\hline $\mathrm{A} 1 \times \mathrm{A} 8$ & $0,001^{*}$ & A3 X A11 & 0,999 & A6 X A12 & 0,999 \\
\hline A1 X A9 & $0,050^{*}$ & A3 X A12 & 0,999 & A7 X A8 & 0,999 \\
\hline $\mathrm{A} 1 \mathrm{X} \mathrm{A} 10$ & $0,001^{*}$ & A4 X A5 & 0,999 & A7 X A9 & 0,999 \\
\hline $\mathrm{A} 1 \mathrm{X} \mathrm{A} 11$ & $0,001^{*}$ & A4 X A6 & 0,999 & A7 X A10 & 0,999 \\
\hline $\mathrm{A} 1 \mathrm{X} \mathrm{A} 12$ & $0,001^{*}$ & A4 X A7 & 0,999 & A7 X A11 & 0,999 \\
\hline $\mathrm{A} 2 \times \mathrm{A} 3$ & 0,999 & $\mathrm{~A} 4 \times \mathrm{A} 8$ & 0,999 & A7 X A12 & 0,999 \\
\hline $\mathrm{A} 2 \times \mathrm{A} 4$ & 0,999 & A4 X A9 & 0,999 & A8 X A9 & 0,999 \\
\hline $\mathrm{A} 2 \times \mathrm{A} 5$ & 0,999 & $\mathrm{~A} 4 \times \mathrm{A} 10$ & 0,999 & $A 8 \times A 10$ & 0,999 \\
\hline $\mathrm{A} 2 \times \mathrm{A} 6$ & 0,999 & $\mathrm{~A} 4 \times \mathrm{A} 11$ & 0,999 & $\mathrm{~A} 8 \times \mathrm{A} 11$ & 0,999 \\
\hline $\mathrm{A} 2 \times \mathrm{A} 7$ & 0,999 & A4 X A12 & 0,999 & $\mathrm{~A} 8 \times \mathrm{A} 12$ & 0,999 \\
\hline $\mathrm{A} 2 \times \mathrm{A} 8$ & 0,999 & A5 X A6 & 0,999 & A9 $\times A 10$ & 0,999 \\
\hline A2 $\times$ A9 & 0,999 & A5 X A7 & 0,999 & A9 $\times A 11$ & 0,999 \\
\hline $\mathrm{A} 2 \times \mathrm{A} 10$ & 0,999 & A5 X A8 & 0,999 & A9 X A12 & 0,999 \\
\hline $\mathrm{A} 2 \times \mathrm{A} 11$ & 0,999 & $A 5 \times A 9$ & 0,999 & $\mathrm{~A} 10 \times \mathrm{A} 11$ & 0,999 \\
\hline $\mathrm{A} 2 \times \mathrm{A} 12$ & 0,999 & A5 X A10 & 0,999 & $\mathrm{~A} 10 \times \mathrm{A} 12$ & 0,999 \\
\hline A3 $\times$ A4 & 0,999 & $\mathrm{~A} 5 \times \mathrm{A} 11$ & 0,999 & $\mathrm{~A} 11 \times \mathrm{A} 12$ & 0,999 \\
\hline \multicolumn{6}{|c|}{ Adultos Maduros - Escolaridade alta - Parte B do Teste de Deambulação Funcional } \\
\hline Comparações & $p$ & Comparações & $\mathrm{p}$ & Comparações & $\mathrm{p}$ \\
\hline $\mathrm{A} 1 \times \mathrm{A} 2$ & 0,274 & A3 X A5 & 0,999 & $\mathrm{~A} 5 \times \mathrm{A} 12$ & 0,999 \\
\hline $\mathrm{A} 1 \times \mathrm{A3}$ & $0,001^{*}$ & A3 X A6 & 0,988 & $\mathrm{~A} 6 \times \mathrm{X} 7$ & 0,999 \\
\hline $\mathrm{A} 1 \times \mathrm{A} 4$ & $0,001^{*}$ & A3 X A7 & 0,985 & $\mathrm{~A} 6 \times \mathrm{A} 8$ & 0,999 \\
\hline $\mathrm{A} 1 \times \mathrm{A} 5$ & $0,001^{*}$ & $\mathrm{~A} 3 \times \mathrm{A} 8$ & 0,506 & $\mathrm{~A} 6 \times \mathrm{A} 9$ & 0,999 \\
\hline $\mathrm{A} 1 \times \mathrm{A} 6$ & $0,001^{*}$ & A3 X A9 & 0,999 & A6 X A10 & 0,999 \\
\hline A1 X A7 & $0,001^{*}$ & A3 $\times$ A10 & 0,224 & $\mathrm{~A} 6 \times \mathrm{A} 11$ & 0,999 \\
\hline $\mathrm{A} 1 \times \mathrm{A} 8$ & $0,001^{*}$ & A3 X A11 & $0,036^{\star}$ & $\mathrm{A} 6 \times \mathrm{A} 12$ & 0,999 \\
\hline A1 X A9 & $0,001^{*}$ & A3 X A12 & $0,007^{*}$ & A7 X A8 & 0,999 \\
\hline $\mathrm{A} 1 \mathrm{X} \mathrm{A} 10$ & $0,001^{*}$ & A4 X A5 & 0,999 & A7 X A9 & 0,999 \\
\hline $\mathrm{A} 1 \mathrm{X} \mathrm{A} 11$ & $0,001^{*}$ & $\mathrm{~A} 4 \times \mathrm{A} 6$ & 0,999 & A7 X A10 & 0,999 \\
\hline $\mathrm{A} 1 \mathrm{X} \mathrm{A} 12$ & $0,001^{*}$ & A4 X A7 & 0,999 & A7 X A11 & 0,999 \\
\hline $\mathrm{A} 2 \times \mathrm{A} 3$ & 0,955 & A4 X A8 & 0,999 & A7 $\times A 12$ & 0,999 \\
\hline A2 X A4 & 0,133 & A4 X A9 & 0,999 & A8 X A9 & 0,999 \\
\hline $\mathrm{A} 2 \times \mathrm{A} 5$ & $0,001^{*}$ & $\mathrm{~A} 4 \times \mathrm{A} 10$ & 0,988 & $\mathrm{~A} 8 \times \mathrm{A} 10$ & 0,999 \\
\hline $\mathrm{A} 2 \times \mathrm{A} 6$ & $0,001^{*}$ & $\mathrm{~A} 4 \times \mathrm{A} 11$ & 0,738 & A8 X A11 & 0,999 \\
\hline A2 X A7 & $0,001^{*}$ & $\mathrm{~A} 4 \times \mathrm{A} 12$ & 0,371 & $\mathrm{~A} 8 \times \mathrm{A} 12$ & 0,999 \\
\hline $\mathrm{A} 2 \times \mathrm{A} 8$ & $0,001^{*}$ & A5 X A6 & 0,999 & A9 X A10 & 0,999 \\
\hline A2 $\times$ A9 & $0,018^{*}$ & A5 X A7 & 0,999 & A9 $\times$ A11 & 0,988 \\
\hline $\mathrm{A} 2 \times \mathrm{A} 10$ & $0,001^{*}$ & $\mathrm{~A} 5 \times \mathrm{A} 8$ & 0,999 & $\mathrm{~A} 9 \times \mathrm{A} 12$ & 0,851 \\
\hline $\mathrm{A} 2 \times \mathrm{A} 11$ & $0,001^{*}$ & A5 X A9 & 0,999 & $\mathrm{~A} 10 \times \mathrm{A} 11$ & 0,999 \\
\hline $\mathrm{A} 2 \times \mathrm{A} 12$ & $0,001^{*}$ & A5 X A10 & 0,999 & $\mathrm{~A} 10 \times \mathrm{A} 12$ & 0,999 \\
\hline A3 X A4 & 0,999 & A5 X A11 & 0,999 & $\mathrm{~A} 11 \times \mathrm{A} 12$ & 0,999 \\
\hline \multicolumn{6}{|c|}{ Idosos - Escolaridade alta - Parte A do Teste de Deambulação Funcional } \\
\hline Comparações & $p$ & Comparações & $\mathrm{p}$ & Comparações & $p$ \\
\hline $\mathrm{A} 1 \times \mathrm{A} 2$ & 0,999 & A3 X A5 & 0,999 & A5 X A12 & 0,999 \\
\hline $\mathrm{A} 1 \times \mathrm{A3}$ & 0,999 & $\mathrm{~A} 3 \times \mathrm{A} 6$ & 0,999 & A6 X A7 & 0,999 \\
\hline
\end{tabular}




\begin{tabular}{|c|c|c|c|c|c|}
\hline $\mathrm{A} 1 \mathrm{XA4}$ & 0,562 & A3 X A7 & 0,999 & $A 6 \times A 8$ & 0,999 \\
\hline A1 X A5 & $0,033^{*}$ & A3 $\times$ A8 & 0,999 & $\mathrm{~A} 6 \times \mathrm{A9}$ & 0,999 \\
\hline $\mathrm{A} 1 \times \mathrm{A} 6$ & 0,130 & A3 $\times$ A9 & 0,999 & $\mathrm{~A} 6 \times \mathrm{A} 10$ & 0,999 \\
\hline $\mathrm{A} 1 \times \mathrm{A} 7$ & $0,030^{*}$ & A3 $\times A 10$ & 0,999 & $\mathrm{~A} 6 \times \mathrm{A} 11$ & 0,999 \\
\hline $\mathrm{A} 1 \times \mathrm{A} 8$ & $0,006^{*}$ & A3 X A11 & 0,922 & $\mathrm{~A} 6 \times \mathrm{A} 12$ & 0,999 \\
\hline A1 X A9 & 0,646 & A3 X A12 & 0,894 & A7 X A8 & 0,999 \\
\hline $\mathrm{A} 1 \mathrm{X} \mathrm{A} 10$ & $0,005^{\star}$ & A4 X A5 & 0,999 & A7 X A9 & 0,999 \\
\hline $\mathrm{A} 1 \mathrm{X} \mathrm{A} 11$ & $0,001^{*}$ & $\mathrm{~A} 4 \times \mathrm{A} 6$ & 0,999 & A7 X A10 & 0,999 \\
\hline $\mathrm{A} 1 \mathrm{X} \mathrm{A} 12$ & $0,001^{*}$ & A4 X A7 & 0,999 & A7 X A11 & 0,999 \\
\hline $\mathrm{A} 2 \times \mathrm{A} 3$ & 0,999 & $\mathrm{~A} 4 \times \mathrm{A} 8$ & 0,999 & A7 X A12 & 0,999 \\
\hline $\mathrm{A} 2 \times \mathrm{A} 4$ & 0,999 & A4 X A9 & 0,999 & A8 X A9 & 0,999 \\
\hline $\mathrm{A} 2 \times \mathrm{A} 5$ & 0,999 & $\mathrm{~A} 4 \times \mathrm{A} 10$ & 0,999 & $\mathrm{~A} 8 \times \mathrm{A} 10$ & 0,999 \\
\hline $\mathrm{A} 2 \times \mathrm{A} 6$ & 0,999 & A4 X A11 & 0,999 & $\mathrm{~A} 8 \times \mathrm{A} 11$ & 0,999 \\
\hline $\mathrm{A} 2 \times \mathrm{A} 7$ & 0,999 & $\mathrm{~A} 4 \times \mathrm{A} 12$ & 0,999 & $\mathrm{~A} 8 \times \mathrm{A} 12$ & 0,999 \\
\hline $\mathrm{A} 2 \times \mathrm{A} 8$ & 0,999 & A5 X A6 & 0,999 & A9 X A10 & 0,999 \\
\hline $\mathrm{A} 2 \times \mathrm{A} 9$ & 0,999 & A5 X A7 & 0,999 & $\mathrm{~A} 9 \times \mathrm{A} 11$ & 0,999 \\
\hline $\mathrm{A} 2 \times \mathrm{A} 10$ & 0,999 & A5 X A8 & 0,999 & A9 X A12 & 0,999 \\
\hline $\mathrm{A} 2 \mathrm{XA11}$ & 0,980 & A5 $\times$ A9 & 0,999 & $\mathrm{~A} 10 \times \mathrm{A} 11$ & 0,999 \\
\hline $\mathrm{A} 2 \times \mathrm{A} 12$ & 0,969 & A5 X A10 & 0,999 & $\mathrm{~A} 10 \times \mathrm{A} 12$ & 0,999 \\
\hline A3 X A4 & 0,999 & A5 X A11 & 0,999 & $\mathrm{~A} 11 \times \mathrm{A} 12$ & 0,999 \\
\hline \multicolumn{6}{|c|}{ Idosos - Escolaridade alta - Parte B do Teste de Deambulação Funcional } \\
\hline Comparações & $p$ & Comparações & $p$ & Comparações & $p$ \\
\hline $\mathrm{A} 1 \mathrm{X}$ A2 & $0,001^{\star}$ & A3 X A5 & 0,171 & A5 X A12 & 0,999 \\
\hline $\mathrm{A} 1 \mathrm{X} \mathrm{A} 3$ & $0,001^{*}$ & $\mathrm{~A} 3 \times \mathrm{A} 6$ & $0,001^{*}$ & A6 X A7 & 0,999 \\
\hline $\mathrm{A} 1 \mathrm{X}$ A4 & $0,001^{*}$ & A3 X A7 & $0,001^{*}$ & $\mathrm{~A} 6 \times \mathrm{A} 8$ & 0,999 \\
\hline $\mathrm{A} 1 \times \mathrm{A} 5$ & $0,001^{*}$ & A3 X A8 & $0,001^{*}$ & $\mathrm{~A} 6 \times \mathrm{A} 9$ & 0,108 \\
\hline $\mathrm{A} 1 \mathrm{XA6}$ & $0,001^{*}$ & A3 X A9 & 0,999 & $\mathrm{~A} 6 \mathrm{X} \mathrm{A} 10$ & 0,999 \\
\hline A1 X A7 & $0,001^{*}$ & A3 X A10 & $0,001^{*}$ & A6 X A11 & 0,999 \\
\hline $\mathrm{A} 1 \mathrm{XA8}$ & $0,001^{*}$ & A3 X A11 & $0,001^{*}$ & $\mathrm{~A} 6 \times \mathrm{A} 12$ & 0,999 \\
\hline $\mathrm{A} 1 \times \mathrm{A} 9$ & $0,001^{*}$ & $\mathrm{~A} 3 \times \mathrm{A} 12$ & $0,001^{*}$ & A7 X A8 & 0,999 \\
\hline $\mathrm{A} 1 \mathrm{X} \mathrm{A} 10$ & $0,001^{*}$ & A4 X A5 & 0,999 & A7 X A9 & 0,591 \\
\hline $\mathrm{A} 1 \times \mathrm{A} 11$ & $0,001^{*}$ & $\mathrm{~A} 4 \times \mathrm{A} 6$ & 0,619 & A7 X A10 & 0,999 \\
\hline $\mathrm{A} 1 \mathrm{X} A 12$ & $0,001^{*}$ & A4 X A7 & 0,988 & A7 X A11 & 0,999 \\
\hline $\mathrm{A} 2 \times \mathrm{A} 3$ & 0,130 & A4 X A8 & 0,878 & A7 X A12 & 0,999 \\
\hline A2 X A4 & $0,001^{*}$ & A4 X A9 & 0,999 & A8 X A9 & 0,280 \\
\hline A2 X A5 & $0,001^{*}$ & $\mathrm{~A} 4 \times \mathrm{A} 10$ & 0,752 & $\mathrm{~A} 8 \times \mathrm{A} 10$ & 0,999 \\
\hline A2 X A6 & $0,001^{*}$ & A4 X A11 & 0,726 & $\mathrm{~A} 8 \times \mathrm{A} 11$ & 0,999 \\
\hline A2 X A7 & $0,001^{*}$ & $\mathrm{~A} 4 \times \mathrm{A} 12$ & 0,821 & $\mathrm{~A} 8 \times \mathrm{A} 12$ & 0,999 \\
\hline A2 X A8 & $0,001^{*}$ & A5 X A6 & 0,999 & A9 X A10 & 0,171 \\
\hline A2 $\times$ A9 & $0,001^{*}$ & A5 X A7 & 0,999 & A9 $\times A 11$ & 0,157 \\
\hline $\mathrm{A} 2 \times \mathrm{A} 10$ & $0,001^{*}$ & A5 X A8 & 0,999 & A9 X A12 & 0,221 \\
\hline $\mathrm{A} 2 \times \mathrm{A} 11$ & $0,001^{*}$ & A5 X A9 & 0,999 & $\mathrm{~A} 10 \times \mathrm{A} 11$ & 0,999 \\
\hline A2 X A12 & $0,001^{*}$ & $\mathrm{~A} 5 \times \mathrm{A} 10$ & 0,999 & $\mathrm{~A} 10 \times \mathrm{A} 12$ & 0,999 \\
\hline A3 X A4 & 0,849 & A5 X A11 & 0,999 & $\mathrm{~A} 11 \times \mathrm{A} 12$ & 0,999 \\
\hline \multicolumn{6}{|c|}{ Adultos Jovens - Escolaridade baixa - Parte A do Teste de Deambulação Funcional } \\
\hline Comparações & $p$ & Comparações & $p$ & Comparações & $p$ \\
\hline $\mathrm{A} 1 \mathrm{X}$ A2 & 0,999 & A3 X A5 & 0,999 & A5 X A12 & 0,999 \\
\hline $\mathrm{A} 1 \times \mathrm{A} 3$ & 0,988 & $\mathrm{~A} 3 \times \mathrm{A} 6$ & 0,999 & A6 X A7 & 0,999 \\
\hline $\mathrm{A} 1 \mathrm{XA4}$ & 0,562 & A3 X A7 & 0,999 & $\mathrm{~A} 6 \times \mathrm{A} 8$ & 0,999 \\
\hline A1 X A5 & 0,302 & A3 X A8 & 0,999 & A6 X A9 & 0,999 \\
\hline $\mathrm{A} 1 \mathrm{X}$ A6 & $0,050^{*}$ & A3 $\times$ A9 & 0,999 & $\mathrm{~A} 6 \times \mathrm{A} 10$ & 0,999 \\
\hline A1 X A7 & $0,021^{*}$ & $\mathrm{~A} 3 \times \mathrm{A} 10$ & 0,999 & $\mathrm{~A} 6 \times \mathrm{A} 11$ & 0,999 \\
\hline A1 X A8 & $0,008^{\star}$ & A3 X A11 & 0,999 & A6 X A12 & 0,999 \\
\hline $\mathrm{A} 1 \times \mathrm{A} 9$ & 0,058 & A3 X A12 & 0,999 & A7 X A8 & 0,999 \\
\hline $\mathrm{A} 1 \mathrm{X} \mathrm{A} 10$ & $0,003^{*}$ & A4 X A5 & 0,999 & A7 X A9 & 0,999 \\
\hline A1 X A11 & $0,001^{*}$ & $\mathrm{~A} 4 \times \mathrm{A} 6$ & 0,999 & A7 X A10 & 0,999 \\
\hline
\end{tabular}




\begin{tabular}{|c|c|c|c|c|c|}
\hline $\mathrm{A} 1 \mathrm{X} \mathrm{A} 12$ & $0,001^{*}$ & A4 X A7 & 0,999 & A7 X A11 & 0,999 \\
\hline $\mathrm{A} 2 \times \mathrm{A} 3$ & 0,999 & A4 X A8 & 0,999 & A7 X A12 & 0,999 \\
\hline $\mathrm{A} 2 \times \mathrm{A} 4$ & 0,999 & A4 X A9 & 0,999 & A8 X A9 & 0,999 \\
\hline $\mathrm{A} 2 \times \mathrm{A} 5$ & 0,999 & A4 X A10 & 0,999 & A8 $\times$ A10 & 0,999 \\
\hline A2 X A6 & 0,999 & A4 X A11 & 0,999 & A8 X A11 & 0,999 \\
\hline A2 X A7 & 0,980 & $\mathrm{~A} 4 \times \mathrm{A} 12$ & 0,999 & $\mathrm{~A} 8 \times \mathrm{A} 12$ & 0,999 \\
\hline A2 X A8 & 0,909 & A5 X A6 & 0,999 & A9 $\times A 10$ & 0,999 \\
\hline A2 $\times$ A9 & 0,999 & A5 X A7 & 0,999 & A9 $\times A 11$ & 0,999 \\
\hline $\mathrm{A} 2 \times \mathrm{A} 10$ & 0,776 & A5 X A8 & 0,999 & A9 $\times A 12$ & 0,999 \\
\hline A2 X A11 & 0,591 & A5 $\times$ A9 & 0,999 & $\mathrm{~A} 10 \times \mathrm{A} 11$ & 0,999 \\
\hline $\mathrm{A} 2 \times \mathrm{A} 12$ & 0,591 & A5 X A10 & 0,999 & $\mathrm{~A} 10 \times \mathrm{A} 12$ & 0,999 \\
\hline A3 X A4 & 0,999 & A5 X A11 & 0,999 & $\mathrm{~A} 11 \times \mathrm{A} 12$ & 0,999 \\
\hline \multicolumn{6}{|c|}{ Adultos jovens - Escolaridade baixa - Parte B do Teste de Deambulação Funcional } \\
\hline Comparações & $\mathrm{p}$ & Comparações & $\mathrm{p}$ & Comparações & $\mathrm{p}$ \\
\hline $\mathrm{A} 1 \mathrm{XA2}$ & 0,999 & A3 X A5 & 0,878 & A5 $\times$ A12 & 0,451 \\
\hline A1 $X$ A3 & 0,187 & A3 X A6 & $0,037^{*}$ & A6 X A7 & 0,999 \\
\hline A1 X A4 & $0,001^{*}$ & A3 X A7 & $0,001^{*}$ & $\mathrm{~A} 6 \mathrm{X} \mathrm{A} 8$ & 0,999 \\
\hline A1 X A5 & $0,001^{*}$ & A3 X A8 & $0,001^{*}$ & A6 X A9 & 0,999 \\
\hline A1 X A6 & $0,001^{*}$ & A3 X A9 & $0,023^{*}$ & $\mathrm{~A} 6 \times \mathrm{A} 10$ & 0,999 \\
\hline A1 X A7 & $0,001^{*}$ & A3 $\times$ A10 & $0,001^{*}$ & $\mathrm{~A} 6 \times \mathrm{A} 11$ & 0,999 \\
\hline A1 X A8 & $0,001^{*}$ & A3 X A11 & $0,001^{*}$ & $\mathrm{~A} 6 \times \mathrm{A} 12$ & 0,999 \\
\hline A1 X A9 & $0,001^{*}$ & A3 X A12 & $0,001^{*}$ & A7 X A8 & 0,999 \\
\hline $\mathrm{A} 1 \mathrm{X} \mathrm{A} 10$ & $0,001^{*}$ & A4 X A5 & 0,999 & A7 X A9 & 0,999 \\
\hline $\mathrm{A} 1 \mathrm{X} \mathrm{A} 11$ & $0,001^{*}$ & A4 X A6 & 0,997 & A7 X A10 & 0,999 \\
\hline $\mathrm{A} 1 \mathrm{X} \mathrm{A} 12$ & $0,001^{*}$ & A4 X A7 & 0,619 & A7 X A11 & 0,999 \\
\hline A2 $\times$ A3 & 0,999 & A4 X A8 & 0,591 & A7 X A12 & 0,999 \\
\hline A2 X A4 & 0,187 & A4 X A9 & 0,991 & A8 X A9 & 0,999 \\
\hline A2 X A5 & $0,001^{*}$ & $\mathrm{~A} 4 \mathrm{X} \mathrm{A} 10$ & $0,030^{*}$ & $\mathrm{~A} 8 \times \mathrm{A} 10$ & 0,999 \\
\hline A2 X A6 & $0,001^{*}$ & A4 X A11 & $0,005^{\star}$ & $\mathrm{A} 8 \times \mathrm{A} 11$ & 0,999 \\
\hline A2 X A7 & $0,001^{*}$ & $\mathrm{~A} 4 \mathrm{X} \mathrm{A} 12$ & $0,001^{*}$ & A8 X A12 & 0,999 \\
\hline A2 X A8 & $0,001^{*}$ & A5 X A6 & 0,999 & A9 X A10 & 0,999 \\
\hline A2 $\times$ A9 & $0,001^{*}$ & A5 X A7 & 0,999 & A9 $\times$ A11 & 0,999 \\
\hline $\mathrm{A} 2 \times \mathrm{A} 10$ & $0,001^{*}$ & A5 X A8 & 0,999 & A9 $\times A 12$ & 0,999 \\
\hline $\mathrm{A} 2 \times \mathrm{A} 11$ & $0,001^{*}$ & A5 X A9 & 0,999 & $\mathrm{~A} 10 \times \mathrm{A} 11$ & 0,999 \\
\hline A2 X A12 & $0,001^{*}$ & A5 X A10 & 0,962 & $\mathrm{~A} 10 \times \mathrm{A} 12$ & 0,999 \\
\hline A3 X A4 & 0,999 & A5 X A11 & 0,726 & $\mathrm{~A} 11 \times \mathrm{A} 12$ & 0,999 \\
\hline \multicolumn{6}{|c|}{ Adultos Maduros - Escolaridade baixa - Parte A do Teste de Deambulação Funcional } \\
\hline Comparações & $\mathrm{p}$ & Comparações & $\mathrm{p}$ & Comparações & $\mathrm{p}$ \\
\hline $\mathrm{A} 1 \mathrm{X} \mathrm{A} 2$ & 0,085 & A3 X A5 & 0,999 & A5 X A12 & 0,999 \\
\hline A1 X A3 & $0,001^{*}$ & A3 X A6 & 0,999 & $\mathrm{~A} 6 \times \mathrm{A} 7$ & 0,999 \\
\hline A1 X A4 & $0,001^{*}$ & A3 X A7 & 0,999 & A6 X A8 & 0,999 \\
\hline A1 X A5 & $0,001^{*}$ & A3 X A8 & 0,999 & A6 $\times$ A9 & 0,999 \\
\hline A1 X A6 & $0,001^{*}$ & A3 X A9 & 0,999 & $\mathrm{~A} 6 \times \mathrm{A} 10$ & 0,999 \\
\hline A1 X A7 & $0,001^{*}$ & A3 X A10 & 0,999 & $\mathrm{~A} 6 \times \mathrm{A} 11$ & 0,999 \\
\hline $\mathrm{A} 1 \mathrm{X}$ A8 & $0,001^{*}$ & A3 X A11 & 0,999 & $\mathrm{~A} 6 \times \mathrm{A} 12$ & 0,999 \\
\hline A1 X A9 & $0,001^{*}$ & A3 X A12 & 0,999 & A7 X A8 & 0,999 \\
\hline $\mathrm{A} 1 \mathrm{X} \mathrm{A} 10$ & $0,001^{*}$ & A4 X A5 & 0,999 & A7 X A9 & 0,999 \\
\hline $\mathrm{A} 1 \mathrm{X}$ A11 & $0,001^{*}$ & A4 X A6 & 0,999 & A7 X A10 & 0,999 \\
\hline $\mathrm{A} 1 \mathrm{X} \mathrm{A} 12$ & $0,001^{*}$ & A4 X A7 & 0,999 & A7 X A11 & 0,999 \\
\hline A2 X A3 & 0,999 & A4 X A8 & 0,999 & A7 X A12 & 0,999 \\
\hline A2 X A4 & 0,999 & A4 X A9 & 0,999 & A8 X A9 & 0,999 \\
\hline $\mathrm{A} 2 \times \mathrm{A} 5$ & 0,998 & A4 X A10 & 0,999 & A8 $\times$ A10 & 0,999 \\
\hline $\mathrm{A} 2 \times \mathrm{A} 6$ & 0,976 & A4 X A11 & 0,999 & A8 X A11 & 0,999 \\
\hline A2 X A7 & 0,494 & $\mathrm{~A} 4 \times \mathrm{A} 12$ & 0,999 & $\mathrm{~A} 8 \times \mathrm{A} 12$ & 0,999 \\
\hline A2 X A8 & 0,308 & A5 X A6 & 0,999 & $\mathrm{~A} 9 \times \mathrm{A} 10$ & 0,999 \\
\hline A2 X A9 & 0,894 & A5 X A7 & 0,999 & A9 $\times A 11$ & 0,999 \\
\hline $\mathrm{A} 2 \times \mathrm{A} 10$ & 0,571 & A5 X A8 & 0,999 & A9 X A12 & 0,999 \\
\hline
\end{tabular}




\begin{tabular}{|c|c|c|c|c|c|}
\hline $\mathrm{A} 2 \times \mathrm{A} 11$ & 0,268 & A5 X A9 & 0,999 & A10 X A11 & 0,999 \\
\hline $\mathrm{A} 2 \times \mathrm{A} 12$ & 0,308 & A5 X A10 & 0,999 & $\mathrm{~A} 10 \times \mathrm{A} 12$ & 0,999 \\
\hline A3 X A4 & 0,999 & A5 X A11 & 0,999 & $\mathrm{~A} 11 \times \mathrm{A} 12$ & 0,999 \\
\hline \multicolumn{6}{|c|}{ Adultos Maduros - Escolaridade baixa - Parte B do Teste de Deambulação Funcional } \\
\hline Comparações & $\mathrm{p}$ & Comparações & $p$ & Comparações & $p$ \\
\hline $\mathrm{A} 1 \times \mathrm{A} 2$ & 0,144 & A3 X A5 & 0,647 & A5 X A12 & $0,003^{*}$ \\
\hline $\mathrm{A} 1 \times \mathrm{A} 3$ & $0,001^{*}$ & $\mathrm{~A} 3 \times \mathrm{A} 6$ & $0,039^{\star}$ & $\mathrm{A} 6 \times \mathrm{A} 7$ & 0,999 \\
\hline $\mathrm{A} 1 \times \mathrm{A} 4$ & $0,001^{*}$ & A3 X A7 & $0,001^{*}$ & $\mathrm{~A} 6 \times \mathrm{A} 8$ & 0,999 \\
\hline $\mathrm{A} 1 \times \mathrm{A} 5$ & $0,001^{*}$ & A3 X A8 & $0,001^{*}$ & $\mathrm{~A} 6 \times \mathrm{A} 9$ & 0,999 \\
\hline $\mathrm{A} 1 \times \mathrm{A} 6$ & $0,001^{*}$ & A3 $\times$ A9 & 0,215 & $\mathrm{~A} 6 \times \mathrm{A} 10$ & 0,184 \\
\hline $\mathrm{A} 1 \times \mathrm{A} 7$ & $0,001^{*}$ & $\mathrm{~A} 3 \times \mathrm{A} 10$ & $0,001^{*}$ & $\mathrm{~A} 6 \mathrm{XA11}$ & 0,420 \\
\hline $\mathrm{A} 1 \times \mathrm{A} 8$ & $0,001^{*}$ & A3 X A11 & $0,001^{*}$ & $\mathrm{~A} 6 \times \mathrm{A} 12$ & 0,999 \\
\hline A1 X A9 & $0,001^{*}$ & $\mathrm{~A} 3 \times \mathrm{A} 12$ & $0,001^{*}$ & A7 X A8 & 0,999 \\
\hline $\mathrm{A} 1 \mathrm{X} \mathrm{A} 10$ & $0,001^{*}$ & A4 X A5 & 0,976 & A7 X A9 & 0,999 \\
\hline $\mathrm{A} 1 \mathrm{X} \mathrm{A} 11$ & $0,001^{*}$ & A4 X A6 & 0,250 & A7 X A10 & 0,999 \\
\hline $\mathrm{A} 1 \mathrm{X} \mathrm{A} 12$ & $0,001^{*}$ & A4 X A7 & $0,001^{*}$ & A7 X A11 & 0,999 \\
\hline $\mathrm{A} 2 \times \mathrm{A} 3$ & 0,808 & $\mathrm{~A} 4 \times \mathrm{A} 8$ & $0,001^{*}$ & A7 X A12 & 0,999 \\
\hline $\mathrm{A} 2 \times \mathrm{A} 4$ & 0,308 & A4 X A9 & 0,696 & A8 X A9 & 0,999 \\
\hline $\mathrm{A} 2 \times \mathrm{A} 5$ & $0,001^{*}$ & $\mathrm{~A} 4 \times \mathrm{A} 10$ & $0,001^{*}$ & $\mathrm{~A} 8 \times \mathrm{A} 10$ & 0,999 \\
\hline $\mathrm{A} 2 \times \mathrm{A} 6$ & $0,001^{*}$ & A4 X A11 & $0,001^{*}$ & A8 X A11 & 0,999 \\
\hline A2 X A7 & $0,001^{*}$ & $\mathrm{~A} 4 \times \mathrm{A} 12$ & $0,001^{*}$ & $A 8 \times A 12$ & 0,999 \\
\hline A2 X A8 & $0,001^{*}$ & A5 X A6 & 0,999 & A9 $\times A 10$ & 0,981 \\
\hline A2 $\times$ A9 & $0,001^{*}$ & A5 X A7 & 0,999 & A9 $\times$ A11 & $0,031^{*}$ \\
\hline $\mathrm{A} 2 \times \mathrm{A} 10$ & $0,001^{*}$ & A5 X A8 & 0,920 & A9 X A12 & 0,102 \\
\hline $\mathrm{A} 2 \times \mathrm{A} 11$ & $0,001^{*}$ & A5 $\times$ A9 & 0,999 & $\mathrm{~A} 10 \times \mathrm{A} 11$ & 0,999 \\
\hline $\mathrm{A} 2 \times \mathrm{A} 12$ & $0,001^{*}$ & A5 X A10 & 0,999 & $\mathrm{~A} 10 \times \mathrm{A} 12$ & 0,999 \\
\hline A3 X A4 & 0,999 & A5 X A11 & $0,015^{*}$ & $\mathrm{~A} 11 \times \mathrm{A} 12$ & 0,999 \\
\hline \multicolumn{6}{|c|}{ Idosos - Escolaridade baixa - Parte A do Teste de Deambulação Funcional } \\
\hline Comparações & $\mathrm{p}$ & Comparações & $\mathrm{p}$ & Comparações & $\mathrm{p}$ \\
\hline $\mathrm{A} 1 \mathrm{X}$ A2 & $0,001^{*}$ & A3 X A5 & 0,999 & A5 X A12 & 0,999 \\
\hline $\mathrm{A} 1 \times \mathrm{A} 3$ & $0,001^{*}$ & A3 X A6 & 0,999 & $\mathrm{~A} 6 \times \mathrm{A} 7$ & 0,999 \\
\hline $\mathrm{A} 1 \mathrm{X}$ A4 & $0,001^{*}$ & A3 X A7 & 0,909 & $\mathrm{~A} 6 \times \mathrm{A} 8$ & 0,999 \\
\hline $\mathrm{A} 1 \times \mathrm{A5}$ & $0,001^{*}$ & A3 X A8 & 0,878 & $\mathrm{~A} 6 \times \mathrm{A9}$ & 0,999 \\
\hline $\mathrm{A} 1 \times \mathrm{A} 6$ & $0,001^{*}$ & A3 X A9 & 0,999 & $\mathrm{~A} 6 \mathrm{X} \mathrm{A} 10$ & 0,999 \\
\hline A1 X A7 & $0,001^{*}$ & A3 X A10 & 0,991 & $\mathrm{~A} 6 \times \mathrm{A} 11$ & 0,999 \\
\hline $\mathrm{A} 1 \mathrm{X}$ A8 & $0,001^{*}$ & A3 X A11 & 0,349 & $\mathrm{~A} 6 \mathrm{X} \mathrm{A} 12$ & 0,999 \\
\hline A1 X A9 & $0,001^{*}$ & A3 $\times$ A12 & 0,097 & A7 X A8 & 0,999 \\
\hline $\mathrm{A} 1 \mathrm{X} \mathrm{A} 10$ & $0,001^{*}$ & A4 X A5 & 0,999 & A7 X A9 & 0,999 \\
\hline $\mathrm{A} 1 \mathrm{X}$ A11 & $0,001^{*}$ & $\mathrm{~A} 4 \times \mathrm{A} 6$ & 0,999 & A7 X A10 & 0,999 \\
\hline $\mathrm{A} 1 \mathrm{X}$ A12 & $0,001^{*}$ & A4 X A7 & 0,999 & A7 X A11 & 0,999 \\
\hline A2 X A3 & 0,999 & A4 X A8 & 0,999 & A7 X A12 & 0,999 \\
\hline $\mathrm{A} 2 \times \mathrm{A} 4$ & 0,240 & A4 X A9 & 0,999 & A8 X A9 & 0,999 \\
\hline A2 $\times$ A5 & $0,021^{*}$ & A4 X A10 & 0,999 & A8 $\times A 10$ & 0,999 \\
\hline $\mathrm{A} 2 \times \mathrm{A} 6$ & $0,050^{*}$ & A4 X A11 & 0,999 & $\mathrm{~A} 8 \times \mathrm{A} 11$ & 0,999 \\
\hline A2 X A7 & $0,001^{*}$ & $\mathrm{~A} 4 \times \mathrm{A} 12$ & 0,988 & $\mathrm{~A} 8 \times \mathrm{A} 12$ & 0,999 \\
\hline A2 X A8 & $0,001^{*}$ & A5 X A6 & 0,999 & A9 X A10 & 0,999 \\
\hline A2 $\times$ A9 & 0,479 & A5 X A7 & 0,999 & A9 $\times$ A11 & 0,997 \\
\hline A2 X A10 & $0,001^{*}$ & A5 X A8 & 0,999 & A9 X A12 & 0,909 \\
\hline $\mathrm{A} 2 \times \mathrm{A} 11$ & $0,001^{*}$ & A5 X A9 & 0,999 & $\mathrm{~A} 10 \times \mathrm{A} 11$ & 0,999 \\
\hline A2 X A12 & $0,001^{*}$ & A5 X A10 & 0,999 & $\mathrm{~A} 10 \times \mathrm{A} 12$ & 0,999 \\
\hline A3 X A4 & 0,999 & A5 $\times$ A11 & 0,999 & $\mathrm{~A} 11 \times \mathrm{A} 12$ & 0,999 \\
\hline \multicolumn{6}{|c|}{ Idosos - Escolaridade baixa - Parte B do Teste de Deambulação Funcional } \\
\hline Comparações & $\mathrm{p}$ & Comparações & $p$ & Comparações & $\mathrm{p}$ \\
\hline $\mathrm{A} 1 \mathrm{X}$ A2 & 0,108 & A3 X A5 & $0,023^{*}$ & A5 X A12 & $0,001^{\star}$ \\
\hline $\mathrm{A} 1 \times \mathrm{A3}$ & $0,001^{*}$ & $\mathrm{~A} 3 \times \mathrm{A} 6$ & $0,001^{*}$ & A6 X A7 & 0,999 \\
\hline
\end{tabular}




\begin{tabular}{|c|c|c|c|c|c|}
\hline $\mathrm{A} 1 \times \mathrm{A} 4$ & $0,001^{*}$ & $\mathrm{~A} 3 \times \mathrm{A} 7$ & $0,001^{*}$ & A6 X A8 & $0,001^{*}$ \\
\hline A1 X A5 & $0,001^{*}$ & A3 $\times$ A8 & $0,001^{*}$ & $\mathrm{~A} 6 \times \mathrm{A9}$ & $0,001^{*}$ \\
\hline $\mathrm{A} 1 \times \mathrm{A} 6$ & $0,001^{*}$ & A3 $\times$ A9 & 0,999 & $\mathrm{~A} 6 \mathrm{X} \mathrm{A} 10$ & 0,999 \\
\hline A1 X A7 & $0,001^{*}$ & A3 X A10 & $0,001^{*}$ & $\mathrm{~A} 6 \times \mathrm{A} 11$ & 0,203 \\
\hline A1 X A8 & $0,001^{*}$ & A3 X A11 & $0,001^{*}$ & A6 X A12 & $0,001^{*}$ \\
\hline $\mathrm{A} 1 \times \mathrm{A} 9$ & $0,001^{*}$ & A3 X A12 & $0,001^{*}$ & A7 X A8 & $0,014^{*}$ \\
\hline $\mathrm{A} 1 \mathrm{X} \mathrm{A} 10$ & $0,001^{*}$ & A4 X A5 & 0,479 & A7 X A9 & $0,001^{*}$ \\
\hline $\mathrm{A} 1 \mathrm{X} \mathrm{A} 11$ & $0,001^{*}$ & $\mathrm{~A} 4 \times \mathrm{A} 6$ & $0,001^{*}$ & A7 X A10 & 0,999 \\
\hline $\mathrm{A} 1 \mathrm{X} \mathrm{A} 12$ & $0,001^{*}$ & A4 X A7 & $0,001^{*}$ & A7 X A11 & 0,752 \\
\hline A2 X A3 & $0,004^{*}$ & $\mathrm{~A} 4 \times \mathrm{A} 8$ & $0,001^{*}$ & A7 X A12 & $0,001^{*}$ \\
\hline $\mathrm{A} 2 \times \mathrm{A} 4$ & $0,001^{*}$ & A4 X A9 & 0,999 & A8 X A9 & $0,001^{*}$ \\
\hline A2 X A5 & $0,001^{*}$ & $\mathrm{~A} 4 \mathrm{X} \mathrm{A} 10$ & $0,001^{*}$ & A8 X A10 & 0,562 \\
\hline $\mathrm{A} 2 \times \mathrm{A} 6$ & $0,001^{*}$ & $\mathrm{~A} 4 \mathrm{X}$ A11 & $0,001^{*}$ & $\mathrm{~A} 8 \times \mathrm{A} 11$ & 0,999 \\
\hline A2 X A7 & $0,001^{*}$ & $\mathrm{~A} 4 \mathrm{X} \mathrm{A} 12$ & $0,001^{*}$ & A8 X A12 & 0,999 \\
\hline A2 X A8 & $0,001^{*}$ & A5 X A6 & 0,993 & A9 X A10 & $0,001^{*}$ \\
\hline A2 X A9 & $0,001^{*}$ & A5 X A7 & 0,700 & A9 X A11 & $0,001^{*}$ \\
\hline $\mathrm{A} 2 \times \mathrm{A} 10$ & $0,001^{*}$ & A5 X A8 & $0,001^{*}$ & A9 X A12 & $0,001^{*}$ \\
\hline $\mathrm{A} 2 \times \mathrm{A} 11$ & $0,001^{*}$ & A5 X A9 & 0,752 & $\mathrm{~A} 10 \times \mathrm{A} 11$ & 0,999 \\
\hline $\mathrm{A} 2 \times \mathrm{A} 12$ & $0,001^{*}$ & A5 X A10 & $0,026^{*}$ & $\mathrm{~A} 10 \times \mathrm{A} 12$ & $0,042^{\star}$ \\
\hline A3 X A4 & 0,999 & A5 X A11 & $0,001^{*}$ & $\mathrm{~A} 11 \times \mathrm{A} 12$ & 0,999 \\
\hline \multicolumn{6}{|c|}{ Adultos Jovens X Adultos Maduros - Escolaridade alta - Parte A do TDF } \\
\hline Comparações & $\mathrm{p}$ & Comparações & $\mathrm{p}$ & Comparações & $\mathrm{p}$ \\
\hline A1 & 0,999 & A5 & 0,999 & A9 & 0,999 \\
\hline A2 & 0,999 & A6 & 0,999 & A10 & 0,999 \\
\hline A3 & 0,999 & A7 & 0,999 & A11 & 0,999 \\
\hline A4 & 0,999 & A8 & 0,999 & $\mathrm{~A} 12$ & 0,999 \\
\hline \multicolumn{6}{|c|}{ Adultos jovens X Adultos Maduros - Escolaridade alta - Parte B do TDF } \\
\hline Comparações & $\mathrm{p}$ & Comparações & $\mathrm{p}$ & Comparações & $\mathrm{p}$ \\
\hline A1 & 0,090 & A5 & 0,873 & A9 & 0,777 \\
\hline $\mathrm{A} 2$ & 0,073 & A6 & 0,637 & A10 & 0,873 \\
\hline A3 & 0,676 & A7 & 0,527 & A11 & 0,832 \\
\hline A4 & 0,785 & A8 & 0,705 & $\mathrm{~A} 12$ & 0,926 \\
\hline \multicolumn{6}{|c|}{ Adultos Jovens X Idosos - Escolaridade alta - Parte A do TDF } \\
\hline Comparações & $p$ & Comparações & $p$ & Comparações & $p$ \\
\hline $\mathrm{A} 1$ & 0,782 & A5 & 0,999 & A9 & 0,989 \\
\hline A2 & 0,997 & A6 & 0,995 & A10 & 0,999 \\
\hline A3 & 0,911 & A7 & 0,998 & A11 & 0,999 \\
\hline A4 & 0,995 & A8 & 0,999 & A12 & 0,999 \\
\hline \multicolumn{6}{|c|}{ Adultos Jovens X Idosos - Escolaridade alta - Parte B do TDF } \\
\hline Comparações & $\mathrm{p}$ & Comparações & $\mathrm{p}$ & Comparações & $\mathrm{p}$ \\
\hline A1 & $0,001^{*}$ & A5 & 0,106 & A9 & $0,010^{*}$ \\
\hline $\mathrm{A} 2$ & $0,001^{*}$ & A6 & 0,640 & A10 & 0,414 \\
\hline A3 & $0,001^{*}$ & A7 & 0,266 & A11 & 0,220 \\
\hline A4 & 0,081 & A8 & 0,293 & A12 & 0,188 \\
\hline \multicolumn{6}{|c|}{ Adultos maduros X Idosos - Escolaridade alta - Parte A do TDF } \\
\hline Comparações & $\mathrm{p}$ & Comparações & $\mathrm{p}$ & Comparações & $\mathrm{p}$ \\
\hline A1 & 0,999 & A5 & 0,999 & A9 & 0,999 \\
\hline A2 & 0,999 & A6 & 0,999 & A10 & 0,999 \\
\hline A3 & 0,999 & A7 & 0,999 & A11 & 0,999 \\
\hline A4 & 0,999 & A8 & 0,999 & $\mathrm{~A} 12$ & 0,999 \\
\hline \multicolumn{6}{|c|}{ Adultos maduros X Idosos - Escolaridade alta - Parte B do TDF } \\
\hline Comparações & $p$ & Comparações & $p$ & Comparações & $p$ \\
\hline
\end{tabular}




\begin{tabular}{|c|c|c|c|c|c|}
\hline $\mathrm{A} 1$ & $0,003^{*}$ & A5 & 0,999 & A9 & 0,999 \\
\hline A2 & 0,663 & A6 & 0,999 & A10 & 0,999 \\
\hline A3 & 0,997 & A7 & 0,999 & $\mathrm{~A} 11$ & 0,999 \\
\hline A4 & 0,999 & A8 & 0,999 & $\mathrm{~A} 12$ & 0,108 \\
\hline \multicolumn{6}{|c|}{ Adultos Jovens X Adultos Maduros - Escolaridade baixa - Parte A do TDF } \\
\hline Comparações & $p$ & Comparações & $p$ & Comparações & $\mathrm{p}$ \\
\hline A1 & 0,999 & A5 & 0,999 & A9 & 0,999 \\
\hline $\mathrm{A} 2$ & 0,999 & A6 & 0,999 & $\mathrm{~A} 10$ & 0,999 \\
\hline A3 & 0,999 & A7 & 0,999 & A11 & 0,999 \\
\hline A4 & 0,999 & A8 & 0,999 & A12 & 0,999 \\
\hline \multicolumn{6}{|c|}{ Adultos jovens X Adultos Maduros - Escolaridade baixa - Parte B do TDF } \\
\hline Comparações & $p$ & Comparações & $p$ & Comparações & $p$ \\
\hline A1 & 0,910 & A5 & 0,999 & A9 & 0,999 \\
\hline $\mathrm{A} 2$ & 0,999 & A6 & 0,999 & A10 & 0,999 \\
\hline A3 & 0,999 & A7 & 0,999 & A11 & 0,999 \\
\hline A4 & 0,999 & A8 & 0,999 & A12 & 0,999 \\
\hline \multicolumn{6}{|c|}{ Adultos Jovens X Idosos - Escolaridade baixa - Parte A do TDF } \\
\hline Comparações & p & Comparações & $p$ & Comparações & $p$ \\
\hline $\mathrm{A} 1$ & $0,001^{*}$ & A5 & 0,590 & A9 & 0,118 \\
\hline A2 & $0,024^{*}$ & A6 & 0,301 & A10 & 0,460 \\
\hline A3 & 0,209 & A7 & 0,760 & $\mathrm{~A} 11$ & 0,770 \\
\hline A4 & 0,426 & A8 & 0,695 & A12 & 0,896 \\
\hline \multicolumn{6}{|c|}{ Adultos Jovens X Idosos - Escolaridade baixa - Parte B do TDF } \\
\hline Comparações & $p$ & Comparações & $p$ & Comparações & $p$ \\
\hline $\mathrm{A} 1$ & $0,001^{*}$ & A5 & $0,001^{*}$ & A9 & $0,001^{*}$ \\
\hline A2 & $0,001^{*}$ & A6 & $0,001^{*}$ & A10 & $0,001^{*}$ \\
\hline A3 & $0,001^{*}$ & A7 & $0,001^{*}$ & A11 & $0,001^{*}$ \\
\hline A4 & $0,001^{*}$ & A8 & $0,001^{*}$ & A12 & $0,001^{*}$ \\
\hline \multicolumn{6}{|c|}{ Adultos maduros X Idosos - Escolaridade baixa - Parte A do TDF } \\
\hline Comparações & $\mathrm{p}$ & Comparações & $\mathrm{p}$ & Comparações & p \\
\hline $\mathrm{A} 1$ & $0,003^{\star}$ & A5 & 0,925 & A9 & 0,401 \\
\hline A2 & 0,159 & A6 & 0,797 & A10 & 0,939 \\
\hline A3 & 0,709 & A7 & 0,971 & $\mathrm{~A} 11$ & 0,994 \\
\hline A4 & 0,828 & A8 & 0,955 & A12 & 0,999 \\
\hline \multicolumn{6}{|c|}{ Adultos maduros X Idosos - Escolaridade baixa - Parte B do TDF } \\
\hline Comparações & $\mathrm{p}$ & Comparações & $\mathrm{p}$ & Comparações & $\mathrm{p}$ \\
\hline $\mathrm{A} 1$ & $0,001^{*}$ & A5 & $0,001^{*}$ & A9 & $0,001^{*}$ \\
\hline A2 & $0,001^{*}$ & A6 & $0,001^{*}$ & A10 & $0,001^{*}$ \\
\hline A3 & $0,001^{*}$ & A7 & $0,001^{*}$ & A11 & $0,001^{*}$ \\
\hline A4 & $0,001^{*}$ & A8 & $0,001^{*}$ & A12 & $0,001^{*}$ \\
\hline \multicolumn{6}{|c|}{ Adultos jovens - Escolaridade alta X escolaridade baixa - Parte A do TDF } \\
\hline Comparações & $\mathrm{p}$ & Comparações & $\mathrm{p}$ & Comparações & $\mathrm{p}$ \\
\hline A1 & 0,999 & A5 & 0,999 & A9 & 0,999 \\
\hline A2 & 0,999 & A6 & 0,999 & A10 & 0,999 \\
\hline A3 & 0,999 & A7 & 0,999 & $\mathrm{~A} 11$ & 0,999 \\
\hline A4 & 0,999 & A8 & 0,999 & A12 & 0,999 \\
\hline \multicolumn{6}{|c|}{ Adultos jovens - Escolaridade alta X escolaridade baixa - Parte B do TDF } \\
\hline Comparações & $p$ & Comparações & $p$ & Comparações & p \\
\hline A1 & 0,999 & A5 & 0,999 & A9 & 0,999 \\
\hline
\end{tabular}




\begin{tabular}{|c|c|c|c|c|c|}
\hline A2 & 0,697 & A6 & 0,999 & A10 & 0,999 \\
\hline A3 & 0,995 & A7 & 0,999 & A11 & 0,999 \\
\hline A4 & 0,999 & A8 & 0,999 & $\mathrm{~A} 12$ & 0,999 \\
\hline \multicolumn{6}{|c|}{ Adultos maduros - Escolaridade alta X escolaridade baixa - Parte A do TDF } \\
\hline Comparações & $p$ & Comparações & $p$ & Comparações & $p$ \\
\hline A1 & 0,999 & A5 & 0,999 & A9 & 0,999 \\
\hline A2 & 0,999 & A6 & 0,999 & A10 & 0,999 \\
\hline A3 & 0,999 & A7 & 0,999 & A11 & 0,999 \\
\hline A4 & 0,999 & A8 & 0,999 & $\mathrm{~A} 12$ & 0,999 \\
\hline \multicolumn{6}{|c|}{ Adultos maduros - Escolaridade alta X escolaridade baixa - Parte B do TDF } \\
\hline Comparações & $p$ & Comparações & $p$ & Comparações & $p$ \\
\hline A1 & 0,999 & A5 & 0,999 & A9 & 0,999 \\
\hline $\mathrm{A} 2$ & 0,999 & A6 & 0,999 & A10 & 0,999 \\
\hline A3 & 0,999 & A7 & 0,999 & A11 & 0,999 \\
\hline A4 & 0,999 & A8 & 0,999 & A12 & 0,999 \\
\hline \multicolumn{6}{|c|}{ Idosos - Escolaridade alta X escolaridade baixa - Parte A do TDF } \\
\hline Comparações & $p$ & Comparações & $p$ & Comparações & $p$ \\
\hline A1 & $0,003^{\star}$ & A5 & 0,999 & A9 & 0,999 \\
\hline $\mathrm{A} 2$ & 0,602 & A6 & 0,999 & A10 & 0,999 \\
\hline A3 & 0,999 & A7 & 0,999 & A11 & 0,999 \\
\hline A4 & 0,999 & A8 & 0,999 & A12 & 0,999 \\
\hline \multicolumn{6}{|c|}{ Idosos - Escolaridade alta X escolaridade baixa - Parte B do TDF } \\
\hline Comparações & $p$ & Comparações & $p$ & Comparações & $p$ \\
\hline A1 & $0,001^{\star}$ & A5 & $0,001^{*}$ & A9 & $0,001^{*}$ \\
\hline A2 & $0,001^{*}$ & A6 & $0,001^{\star}$ & A10 & $0,001^{*}$ \\
\hline A3 & $0,001^{*}$ & A7 & $0,001^{*}$ & A11 & $0,001^{*}$ \\
\hline A4 & $0,001^{*}$ & A8 & $0,001^{*}$ & A12 & $0,001^{*}$ \\
\hline
\end{tabular}




\section{ANEXO E}

Tabela 13: Escolaridade Média nos estados do Brasil nos Anos 2001 e 2005

\begin{tabular}{|c|c|c|c|c|c|c|}
\hline \multirow[t]{2}{*}{ ESTADO / REGIÃO } & \multicolumn{2}{|c|}{$\begin{array}{c}\text { Escolaridade Média } \\
\text { GERAL }\end{array}$} & \multicolumn{2}{|c|}{$\begin{array}{l}\text { Escolaridade Média } \\
\text { ÁREAS URBANAS }\end{array}$} & \multicolumn{2}{|c|}{$\begin{array}{c}\text { Escolaridade Média } \\
\text { ÁREAS RURAIS }\end{array}$} \\
\hline & 2001 & 2005 & 2001 & 2005 & 2001 & 2005 \\
\hline BRASIL & 6,13 & 7,09 & 6,60 & 7,61 & 3,47 & 4,46 \\
\hline NORTE & 6,05 & 6,44 & 6,05 & 7,08 & - & 4,47 \\
\hline Acre & 5,92 & 5,97 & 5,92 & 7,04 & - & 3,39 \\
\hline Amapá & 7,33 & 7,68 & 7,33 & 7,83 & - & 5,40 \\
\hline Amazonas & 6,45 & 7,12 & 6,45 & 7,77 & - & 4,81 \\
\hline Pará & 5,81 & 6,11 & 5,81 & 6,74 & - & 4,19 \\
\hline Rondônia & 5,81 & 6,19 & 5,81 & 6,81 & - & 4,89 \\
\hline Roraima & 5,82 & 7,02 & 5,82 & 7,34 & - & 5,75 \\
\hline Tocantins & 5,21 & 6,31 & 5,94 & 6,97 & 3,36 & 4,27 \\
\hline NORDESTE & 4,77 & 5,79 & 5,55 & 6,62 & 2,68 & 3,69 \\
\hline Maranhão & 4,47 & 5,36 & 5,27 & 6,30 & 2,87 & 3,47 \\
\hline Piauí & 4,31 & 5,26 & 5,50 & 6,48 & 2,19 & 3,24 \\
\hline Ceará & 4,88 & 5,96 & 5,54 & 6,61 & 2,87 & 3,88 \\
\hline R.G.Norte & 5,30 & 6,18 & 5,99 & 6,78 & 3,35 & 4,59 \\
\hline Paraíba & 4,52 & 5,63 & 5,15 & 6,20 & 2,61 & 3,58 \\
\hline Pernambuco & 5,17 & 6,14 & 5,89 & 6,85 & 2,92 & 3,74 \\
\hline Alagoas & 4,15 & 5,01 & 4,90 & 5,87 & 2,52 & 3,29 \\
\hline Sergipe & 5,15 & 6,06 & 5,77 & 6,64 & 2,66 & 3,50 \\
\hline Bahia & 4,73 & 5,84 & 6,12 & 6,87 & 2,47 & 3,74 \\
\hline SUDESTE & 6,83 & 7,82 & 7,05 & 8,05 & 4,03 & 5,18 \\
\hline E.Santo & 6,20 & 7,45 & 6,69 & 7,93 & 4,10 & 4,99 \\
\hline M.Gerais & 6,02 & 6,97 & 6,48 & 7,42 & 3,65 & 4,48 \\
\hline R.Janeiro & 7,15 & 8,07 & 7,26 & 8,17 & 4,11 & 4,97 \\
\hline S.Paulo & 7,14 & 8,15 & 7,27 & 8,27 & 5,00 & 6,17 \\
\hline SUL & 6,53 & 7,56 & 6,89 & 8,00 & 4,36 & 5,51 \\
\hline Paraná & 6,39 & 7,48 & 6,81 & 7,89 & 4,42 & 5,31 \\
\hline S. Catarina & 6,66 & 7,85 & 7,13 & 8,27 & 4,69 & 5,87 \\
\hline R.G. Sul & 6,58 & 7,49 & 7,04 & 7,95 & 4,67 & 5,50 \\
\hline C.OESTE & 6,26 & 7,28 & 6,43 & 7,61 & 3,60 & 5,20 \\
\hline D.Federal & 7,81 & 8,93 & 7,88 & 9,05 & 6,04 & 6,72 \\
\hline Goiás & 5,92 & 6,96 & 6,18 & 7,23 & 4,13 & 5,04 \\
\hline M.Grosso & 5,79 & 6,84 & 6,33 & 7,39 & 3,84 & 4,99 \\
\hline M.Grosso Sul & 6,13 & 6,93 & 6,43 & 7,20 & 4,27 & 5,39 \\
\hline
\end{tabular}

Fonte: http://www.seae.ma.gov.br/

\section{ANEXO F}


Tabela 14: Comparação das pontuações no TMT - A e TMT - B no presente estudo com resultados de outros estudos que também investigaram a relação da idade com a escolaridade

\begin{tabular}{|c|c|c|c|c|c|c|c|}
\hline $\begin{array}{l}\text { Estudo } \\
\text { (autores) }\end{array}$ & $\begin{array}{c}\text { Escolaridade } \\
\text { (anos) }\end{array}$ & $\begin{array}{l}\text { Adultos } \\
\text { maduros } \\
\text { (anos) }\end{array}$ & $\begin{array}{c}\text { TMTA } \\
\text { (segundos) }\end{array}$ & $\begin{array}{c}\text { TMTB } \\
\text { (segundos) }\end{array}$ & $\begin{array}{l}\text { Idosos } \\
\text { (anos) }\end{array}$ & $\begin{array}{c}\text { TMTA } \\
\text { (segundos) }\end{array}$ & $\begin{array}{c}\text { TMTB } \\
\text { (segundos) }\end{array}$ \\
\hline \multirow{2}{*}{$\begin{array}{c}\text { Toumbaugh } \\
(2004)\end{array}$} & $<11$ & \multirow[t]{2}{*}{$60-69$} & 39,1 & 91,3 & \multirow[t]{2}{*}{$70-74$} & 42,5 & 109,9 \\
\hline & $\geq 11$ & & 33,8 & 67,1 & & 40,1 & 86,2 \\
\hline \multirow{2}{*}{$\begin{array}{l}\text { Hester et al. } \\
\quad(2005)\end{array}$} & $<11$ & \multirow[t]{2}{*}{$60-69$} & 43,6 & 103,4 & \multirow[t]{2}{*}{$70-74$} & 44,6 & 106,3 \\
\hline & $\geq 11$ & & 36,7 & 81,5 & & 42,9 & 101,7 \\
\hline \multirow{2}{*}{$\begin{array}{l}\text { Seo et al. } \\
(2006)\end{array}$} & 8 & \multirow[t]{2}{*}{$60-69$} & 68,3 & 185,1 & \multirow[t]{2}{*}{$70-74$} & 67,9 & 190,5 \\
\hline & $\geq 10$ & & 56,2 & 159,8 & & 58,0 & 163,8 \\
\hline \multirow{2}{*}{$\begin{array}{l}\text { Hashimoto et } \\
\text { al. (2007) }\end{array}$} & $<11$ & \multirow{2}{*}{$\begin{array}{c}\text { não } \\
\text { avaliado }\end{array}$} & \multirow{2}{*}{$\begin{array}{c}\text { não } \\
\text { avaliado }\end{array}$} & \multirow{2}{*}{$\begin{array}{c}\text { não } \\
\text { avaliado }\end{array}$} & \multirow[t]{2}{*}{$70-74$} & 63,4 & 190,6 \\
\hline & $\geq 11$ & & & & & 57,3 & 154,4 \\
\hline \multirow{2}{*}{$\begin{array}{l}\text { Zalonis et al. } \\
\quad(2007)\end{array}$} & $<9$ & \multirow[t]{2}{*}{$45-65$} & 59,2 & 146,1 & \multirow[t]{2}{*}{$60-80$} & 72,3 & 165,3 \\
\hline & $>13$ & & 45,5 & 94,5 & & 59,8 & 140,3 \\
\hline \multirow{2}{*}{$\begin{array}{l}\text { Ashendorf et } \\
\text { al. (2008) }\end{array}$} & $<16$ & \multirow[t]{2}{*}{$55-74$} & 33,5 & 79,0 & \multirow[t]{2}{*}{$75-98$} & 42,5 & 103,0 \\
\hline & $\geq 16$ & & 29,0 & 61,0 & & 38,5 & 88,0 \\
\hline \multirow{2}{*}{$\begin{array}{l}\text { Presente } \\
\text { estudo }\end{array}$} & $<11$ & \multirow[t]{2}{*}{$50-64$} & 39,3 & 80,8 & \multirow[t]{2}{*}{$65-79$} & 71,9 & 173,0 \\
\hline & $\geq 11$ & & 33,4 & 65,1 & & 38,8 & 87,1 \\
\hline
\end{tabular}

